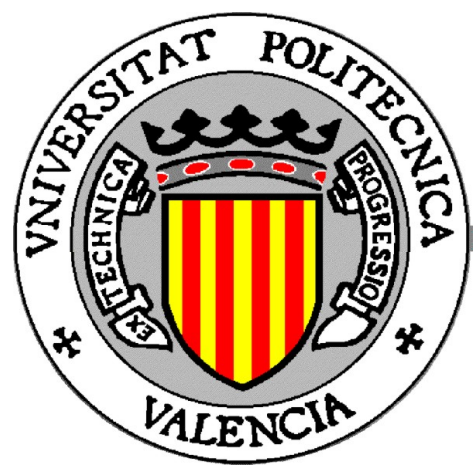

UNIVERSITAT POLITĖCNICA DE VALÈNCIA PROGRAMA DE DOCTORADO EN BIOTECNOLOGÍA DEPARTAMENTO DE BIOTECNOLOGÍA

\title{
PROTEIN KINASES AND PHOSPHATASES REGULATING THE YEAST PROTON PUMP
}

Tesis doctoral presentada por:

\section{Shima Mahmoud Ali Ibrahim}

Y dirigida por:

Prof. Dr. Ramón Serrano Salom

Julio 2015 

This doctoral thesis has been funded by an Erasmus Welcome travel grant of the European Union to Shima Mahmoud Ali Ibrahim and by grant BFU2011-22526 of the Spanish "Ministerio de Ciencia e Innovación” (Madrid) to Ramón Serrano 

"Allah loves that whenever any of you does something, he should excel in it." Prophet Muhammad 

TO MY MOM (NAHED HUSSEIN) 



\section{Acknowledgment}

I love reading, one of my biggest joys ever is when I spend time with a good book or novel, and I believe it was not a coincidence that the book I was carrying with me during my first flight from Egypt to Spain was Alchemist, by Paulo Coelho. Ironically, the main character of the novel was also travelling between Egypt and Spain but he was in the opposite direction of mine. One of the biggest inspirational phrases of this amazing writer was "When I have been truly searching for my treasure, I've discovered things along the way that I never would have seen had I not had the courage to try things that seemed impossible for a shepherd to achieve". The truth is what starts out as a journey to accomplish my aim turned into a discovery of the treasure found within the journey itself. It is all about the journey and what a journey it was! I am so grateful to many people and I hope I won't forget any of them.

First of all, I thank ALLAH who helped me to go through that very long journey, to rise up after each time I felt that I can't go any more and to have at the times I felt totally hopeless.

I am so grateful that I met and worked under supervision of Dr. Ramon Serrano. Thanks for your patience, endless teaching, the kind, big help and for never hesitating in helping me. Thanks for giving me so much of your time and mind and for helping me in everything. I was searching for an e. mail sent from you about the thesis and by chance I found those several e. mails of me saying "sorry can't come um sick" and always your reply was "sorry for you, take care and don't worry".....especially for this understanding and kind wishes I am really more than grateful and I also have learnt a big, important lesson of how to be a work manager. I've learnt here so much about science and also about scientist and I wish someday I could give science as even half what you did.

Having her around was a big relief, she was always so nice, so kind, modest and more than willing to help, thank you so much for all this Mariche.

All it took was just to dial her number and there she was for me...always and immediately....She is My Mom, no matter what her medical condition was, or the nonstop actions inside the family were, she was always there for me...very strong, very loving, very accepting and enormously supportive...just a great eternal unconditional love and support and non-stop prayers, all these were literally carrying me all the way through all the hard times, lots of obstacles, pain of feeling strange and lonely... 
everything. And when I had good times, my feeling of happiness was never complete until I see her eyes smiling, sometimes even tearing with joy. I can never thank her enough or do enough to fulfill her right. Mom, it is your successes not mine. Thanks for being in my life. She is such an enormous bless! May God bless her.

All my respect and gratitude goes to all my family who was always there for me and gave me love, strength and support, my aunts wafaa and alia who were just like moms to me and used to thank "google" for connecting us (;), my sisters wafaa and Heba who is so kind and patient with me, and her kids who gave me a big laugh each time, yousef and shima, my brother hany who was always there for providing me help when I needed it and for always checking on me, with all his kind lovely family and children Mohammed and Malak. Thanks for all my cousins especially Mona, Neveen and Rasha, for my grand fathers for all their unique love and prayers and extremely sweet words....for each and every one of my family.

I would like to express my honest gratitude to all my Lab. colleagues who were very kind to give me all the help I needed whenever I asked for. Enric, Eduardo, Marcos, my neighbor, for being so polite, friendly and helpful, there were also Lola and Felix. I have so much sincere gratitude to Jesus for being unbelievably modest, and for giving me a great very patient help with the construction of GST-Sit4 which cost us almost a year :) and several plasmid constructions, Gaitano for being so kind and more than willing to help whenever I needed his help or opinion, for helping me with the semi qRT-PCR and also with the so helpful tricks about using softwares. Also, I would like to thank Guillem with whom I had worked for a short period and he was a great help and a very modest, kind person.

I would like to give him my eternal gratitude for all his continuous support and help through my whole career, for being so patient, helpful, modest and kind to offer me all the help I needed whenever I did, Dr.Mohammed Mabrouk abou el wafa, I had a very rough start with my scholarship, my acquaintance to being away and alone, and even thought of giving up everything and his words were of an extreme help to continue.

I would like to thank all my friends from Egypt, with whom I was always connected through what's app and facebook, they were a big support. I would like to thank Rasha, for listening and standing by me during hard times, Selwan for taking care of my papers in Egypt and being a true friend and sister, Shima Ewais, Lamis, Mohammed Omar, Mohammed Said, Mohammed salah and also Shima khater for never forgetting me and always sending me so sweet prayers and hopes. 
I would like to thank all my friends whom I met here in Valencia and helped me to sooth the very hard feeling of being away from my family and friends, thanks for being there for me when I was sick and needed you. Abeer, I will never forget when you came to my place just to give me a pat on the shoulder and of course for all your help, you were the first one I met in Spain and since then you have been a terrific friend and sister. I would like to thank Zoulikha, for being so fun and a great help whenever I needed one and for giving me an unforgettable birthday party, Amal for being so kind and calm, for listening to me and trying to sooth me with her words. Mai, Asmaa, Neveen, Hanan, Aya, Rima and Noha...girls you were my family when I didn't have one, I thank each and every one of you and wish you all the best of the best. 



\section{SUMMARY}

The plasma membrane $\mathrm{H}^{+}$-ATPase (Pma1) is essential for yeast growth and is activated by glucose metabolism by an unknown mechanism involving double phosphorylation of a regulatory site at the C-terminus (Ser911 Thr912). In this thesis we have investigated in Saccharomyces cerevisiae the role of two protein phosphatases, type $1 \mathrm{Glc} 7$ and type 2A Sit4, and of an essential atypical protein kinase, TORC1, in the activation of Pmal by glucose. The regulatory site of activated Pmal can be dephosphorylated "in vitro" by recombinant Glc7 and Sit4, but inhibition "in vivo" of these phosphatases does not activate Pma1. Inhibition of Glc7 by regulated expression of a dominant-negative truncated form (the null mutant is not viable) had no effect on Pmal activity while deletion of SIT4 gene decreased both Pmal activity and double phosphorylation of the regulatory site. Inhibition of TORC1 protein kinase by treatment of yeast cells with the drug rapamycin or by exposure to non-permissive temperature of a temperature-sensitive mutant (torl $\Delta$ tor $2^{\text {ts }}$ ) inhibited Pmal and decreased double phosphorylation of the regulatory site. We conclude that Sit4 and TORC1 are required for full activation of Pmal by glucose while Glc7 either does not participate or is redundant with other phosphatases. 



\section{RESUMEN}

La $\mathrm{H}^{+}$-ATPasa de la membrana plasmática (Pma1) es esencial para el crecimiento de la levadura y se activa por metabolismo de glucosa por un mecanismo desconocido que lleva consigo la doble fosforilación de un sitio regulador en el extremo C-terminal (Ser911 Thr912). En la presente tesis hemos investigado en Saccharomyces cerevisiae la participación de dos proteína fosfatasas, Glc7 de tipo 1 y Sit4 de tipo 2A, y de una proteína kinasa atípica esencial, TORC1, en la activación de Pma1 por glucosa. El sitio regulador de Pmal en su estado activo puede defosforilarse "in vitro" por Glc7 y Sit4 recombinantes pero la inhibición "in vivo" de estas fosfatasas no activa Pma1. La inhibición de Glc7 mediante la expresión regulada de una forma truncada que actúa como dominante-negativa (el mutante nulo no es viable) no tiene efecto en la actividad de Pmal mientras que la deleción del gen SIT4 disminuye tanto la actividad de Pma1 como la doble fosforilación del sitio regulador. Inhibición de la proteína kinasa TORC1 mediante tratamiento de las células de levadura con el fármaco rapamicina o exponiéndolas a temperatura no permisiva en el caso de un mutante termosensible $\left(\right.$ tor $1 \Delta$ tor $2^{\text {ts }}$ ) resulta en inhibición de Pmal y disminución de la doble fosforilación del sitio regulador. Estos resultados indican que Sit4 y TORC1 son necesarias para la máxima activación de Pmal por glucosa mientras que Glc7 podría no participar o hacerlo de forma redundante con otras fosfatasas. 



\section{RESUM}

$\mathrm{L}^{\prime} \mathrm{H}^{+}$-ATPasa de la membrana plasmàtica (Pma1) és essencial per al creixement dels llevats i s'activa gràcies al metabolisme de glucosa per un mecanisme desconegut que porta associat la doble fosforilació d'una regió reguladora a l'extrem C-terminal (Ser911 Thr912). En aquesta tesi hem investigat en Saccharomyces cerevisiae la participació de dos proteïnes fosfatases, Glc7 de tipus 1 i Sit4 de tipus 2A, i d'una proteïna quinasa essencial atípica, TORC1, en l'activació de Pmal per glucosa. La regió reguladora de Pma1, en seu estat activat, pot desfosforar-se "in vitro" per Glc7 i Sit4 recombinants, però la inhibició "in vivo" d'aquestes fosfatases no activa Pma1. La inhibició de Glc7 mitjançant l'expressió regulada d'una forma truncada que actua com a dominant-negativa (el mutant nul no és viable) no té cap efecte en l'activitat de Pma1 mentre que la deleció del gen SIT4 disminueix tant l'activitat de Pma1 com la doble fosforilació de la regió reguladora. La inhibició de la proteïna quinasa TORC mitjançant un tractament de cèlllules de llevat amb el fàrmac rapamicina o la seua exposició a temperatures no permissives en el cas d'un mutant termosensible (tor $1 \Delta$ tor $2^{t_{5}}$ ) resulta en la inhibició de Pma1 i la disminució de la doble fosforilació de la regió reguladora. Aquests resultats indiquen que Sit4 i TORC1 són necessàries per a l'activació màxima de Pma1 per glucosa, mentre que Glc7 podria no participar o fer-ho d'una forma redundant amb altres fosfatases. 



\section{INDEX}

\section{SUMMARY}

\section{RESUMEN}

\section{RESUM}

\section{INTRODUCTION}

$\begin{array}{ll}\text { Plasma membrane } \mathrm{H}^{+} \text {-ATPase } & 1\end{array}$

Types of ion pumps $\quad 3$

P-type ion-pumping ATPases $\quad 5$

$\begin{array}{ll}\text { Regulation of Pma1 activity } & 7\end{array}$

Protein kinases and Phosphatases $\quad 12$

$\begin{array}{ll}\text { The atypical TOR protein kinase } & 13\end{array}$

Regulation of and by TORC1 14

Regulation of and by TORC2 19

Protein phosphatases $\quad 20$

Glc7 protein phosphatase $\quad 22$

Sit4 protein phosphatase $\quad 24$

OBJECTIVES

MATERIALS AND METHODS 26

1. Materials $\quad \mathbf{2 6}$

1.1 Strains and culture conditions of bacteria 26

$\begin{array}{lll}1.2 & \text { Strains and culture conditions of yeast } 26\end{array}$

$\begin{array}{lll}1.3 & \text { Plasmids } & 28\end{array}$

2. Isolation of yeast membranes and "in vitro" determination of Pma1 32 activity

$\begin{array}{lll}2.1 & \text { Isolation of yeast membranes } & 32\end{array}$

2.1.1 Culture preparation $\quad 32$

2.1.2 Membrane isolation $\quad 32$

2.2 Protein determination by the method of Bradford 33

2.3 Determination of Pmal activity 33

3. Assay for Pma1 activity in membrane preparations of cells treated with 33 PP1 inhibitors

3.1 Treatment of yeast cells with the phosphatase inhibitor 33

$\begin{array}{ll}3.2 & \text { Growth inhibition test } \\ \end{array}$

4. Assay for yeast tolerance to toxic cations $\quad 34$ 
5. Purification and manipulation of nucleic acid 34

5.1 Isolation of plasmid DNA from E. coli 34

$\begin{array}{ll}5.2 & \text { Isolation of yeast genomic DNA } \\ 5.35\end{array}$

5.3 DNA electrophoresis 36

5.4 Preparation of RNA from S. cerevisiae 36

$\begin{array}{lll}\text { 5.4.1 Culture preparation } & 36\end{array}$

5.4.2 RNA Isolation $\quad 36$

$\begin{array}{lll}5.5 & \text { RNA gel electrophoresis } & 37\end{array}$

$\begin{array}{lll}5.6 & \text { Synthesis of cDNA } & 37\end{array}$

$\begin{array}{lll}5.7 & \text { PCR } & 37\end{array}$

$\begin{array}{lll}5.8 & \text { Plasmid construction } & 38\end{array}$

6. Genetic transfer 41

6.1 Transformation of E. coli 41

6.2 Transformation of yeast 41

6.2.1 Preparation of competent yeast cells 41

6.2.2 Yeast Transformation 41

7. Extraction, electrophoresis and detection of proteins 41

7.1 Extraction of soluble proteins 41

7.1.1 Method of boiling with Laemmli buffer 41

7.1.2 Method of $\mathrm{NaOH} \quad 42$

7.1.3 Method of TCA 42

$\begin{array}{lll}7.2 & \text { Extraction of Pmal }\end{array}$

7.3 Electrophoresis and detection techniques of proteins 43

7.3.1 Electrophoresis of proteins 43

7.3.2 Protein detection with Coomassie Brilliant Blue R-250 43

7.3.3 Membrane transfer 43

7.3.4 Direct Blue staining of the membrane 43

7.3.5 Immunodetection of the proteins transferred to the membrane 44

8. Recombinant protein expression and purification 45

8.1 GST-Glc7 protein expression and purification from E. coli 45

8.2 GST-Sit4 protein expression and purification from yeast 45

8.2.1 Check the expression of Sit4 in Soluble fraction 45

8.2.2 Soluble protein fraction purification 46

9. “Invitro" dephosphorylation of Pma1 by Glc7 or Sit4 46

10. Measurement of $\mathrm{pH}$ changes of yeast suspensions induced by glucose $\quad 47$

11. Investigation of the effect of inhibiting PP1 by regulated expression of 47

Glc7'on Pma1 activity

11.1 Determination of the best doxycycline concentration to control gene 47 expression of $G L C 7$,

$\begin{array}{lll}11.2 & \text { Doxycycline removal and Pmal assay } & 47\end{array}$

11.3 Investigation of inhibition of Glc7 by expression of Glc7' under 48 doxycycline promoter by detecting the phosphorylation level of eIF $2 \alpha$

12. Dephosphorylation rate experiment 


\section{RESULTS}

- Typical chemical inhibitors of protein phosphatases do not affect Pma1 activity

- Expression of a dominant-negative form of GLC7 does not affect Pma1 activity

- Expression of GLC7' under control of a doxycycline-regulated promoter

- Expression of a dominant-negative form of GLC7 does not affect dephosphorylation of Pmal after removal of glucose

- Phenotype $G L C 7$ ' transformants with hygromycin B and acetic acid

- Mutants in GLC7 exhibit altered ion homeostasis

- Effect of expression of a dominant-negative form of GLC7 and of glucose metabolism on phosphorylation of eIF $2 \alpha$

- Effect of sit4 null mutation on the activity of Pma1

- "In vitro" dephosphorylation of Pma1 by Glc7

- "In vitro" dephosphorylation of Pma1 by Sit4

- TOR kinase is a positive regulator of Pmal activity

\section{DISCUSSION}

- Lack of effect of typical chemical inhibitors of protein phosphatases on Pma1 activity

- Effect of expression of a dominant-negative form of GLC7 on Pma1 activity

- Expression of GLC7' under control of a doxycycline-regulated promoter

- Mutants in GLC7 exhibit altered ion homeostasis

- A plausible role for protein phosphatases in the activation of Pmal by glucose metabolism

- Effect of expression of a dominant-negative form of GLC7 and of glucose metabolism on phosphorylation of eIF $2 \alpha$

- Effect of sit4 null mutation on the activity of Pmal 86

- "In vitro" and "in vivo" effects of Glc7 and Sit4 on Pmal 86

- TORC1 kinase is a positive regulator of Pmal activity 87

- CONCLUSIONS 90

- REFERENCES 91 


\section{Abbreviation list:}

BSA: Bovine Serum Albumine

DTT: Dithiothreitol

eIF2 $\alpha$ : Eukaryotic initiation factor $2 \alpha$ (Sui2)

FW: Fresh weight

GLC7': truncated GLC7

GST: glutathione S-transferase

GTED 20: 20\% Glycerol, Tris-HCl pH 7.6, EDTA, DTT buffer

IPTG: Isopropyl $\beta$-D-1-thiogalactoside

MCS: Multi Cloning Site

MES: 2-(N-morpholino) ethane sulphonic acid

MOPS: 3-(N-morpholino) propane sulphonic acid

OD: optical density (absorbance, extinction)

PCl: Phenol/Chloroform/Isoamyl alcohol (25:24:1)

PK: Protein kinase

Pma1: Plasma membrane $\mathrm{H}^{+}$-ATPase from Saccharomyces cerevisiae

Protein phosphatase: PP

PMSF: Phenylmethylsulfonyl fluoride

RT- PCR: Reverse transcriptase - polymerase chain reaction

S. cerevisiae: Saccharomyces cerevisiae

SCD: Synthetic Complete Dextrose medium

SD: Synthetic Dextrose medium

SDS-PAGE: Sodium Dodecyl Sulfate-PolyAcrylamide Gel Electrophoresis

SDS: Sodium Dodecyl Sulphate

TAE: Tris-acetate-EDTA buffer

TBE: Tris borate EDTA

TBS-T: Tris-buffered saline-Tween 20

TBS: Tris-buffered saline

TCA: Trichloroacetic acid

TE: Tris EDTA buffer

TEMED: Tetramethylethylenediamine

TOR: Target of rapamycin

TORC1: Target of rapamycin complex 1

$\mathrm{X}$-Gal: 5-bromo-4-chloro-3-indolyl- $\beta$-D-galactoside

YNB: Yeast Nitrogen Base

YPD: Yeast Peptone Dextrose medium

$\alpha$-pS899: antibody against phosphorylated serine 899

$\alpha$-pST: antibody against double phosphorylation of serine 911 and threonine 912 


\section{INTRODUCTION}





\section{INTRODUCTION}

Plasma membrane $\mathrm{H}^{+}$-ATPase (Pma1) is an extremely important enzyme for yeast cell growth and metabolism and on the other hand it is a very expensive one in terms of ATP consumption, which makes its regulation a vitally important subject. Until now complete understanding of Pmal regulation is not accomplished and the systems that modulate the activity of Pma1 remain largely unknown. Knowing that almost all eukaryotic proteins are regulated by phosphatases and kinases, in this thesis we have tested two major protein phosphatases and one protein kinase of yeast cells for their possible role in regulation of Pma1.

\section{Plasma membrane $\mathrm{H}^{+}$-ATPase}

The yeast plasma membrane $\mathrm{H}^{+}$-ATPase (in the following "Pma1") is a proton pump that plays a crucial role in the physiology of Saccharomyces cerevisiae (in the following "yeast") (Serrano, 1985). It is encoded by PMA1 gene (YGL008c) and composed of a polypeptide of about $100 \mathrm{kDa}$ (Serrano, 1985; Serrano et al., 1986). There is another Pmal gene, PMA2, but it is expressed at very low levels and is not essential for growth (Schlesser et al., 1988). As indicated in Figure 1, Pma1 energizes the plasma membrane by generating an electrical membrane potential (positive outside) and a $\mathrm{pH}$ gradient (acid outside) to drive active nutrient influx and sodium efflux. It also regulates intracellular $(\mathrm{pHi})$ and extracellular $\mathrm{pH}$ for yeast growth and external acidification, respectively (Serrano, 1985 and 1991). Pma1 is a major transport system, accounting for $25-50 \%$ of yeast plasma membrane protein (Serrano, 1991) and consuming $15-50 \%$ of the ATP produced in yeast cells (Gancedo and Serrano, 1988).

Changes in $\mathrm{pHi}$ are of high importance to control the cell growth and proliferation and rates of DNA and RNA synthesis appear to increase with higher pHi within the normal physiological range (Nuccitelli and Deamer, 1982). Also, key glycolytic enzymes are believed to be regulated by $\mathrm{pHi}$, particularly phosphofructokinase (Holyoak et al., 1996). Accordingly, the PMA1 gene is essential for yeast life (Serrano et al., 1986) and there is an impressive correlation between the activity of the enzyme and yeast growth (Portillo and Serrano, 1989; Vallejo and Serrano, 1989). Finally, the electrical membrane potential of yeast plasma membranes, negative inside, drives the uptake of toxic cations such as sodium, lithium, aminoglycosides and polyamines and it is set by the relative activities of Pmal and of the major potassium uptake system Trk1 (see Figure 2 and Goossens et al., 2000). 


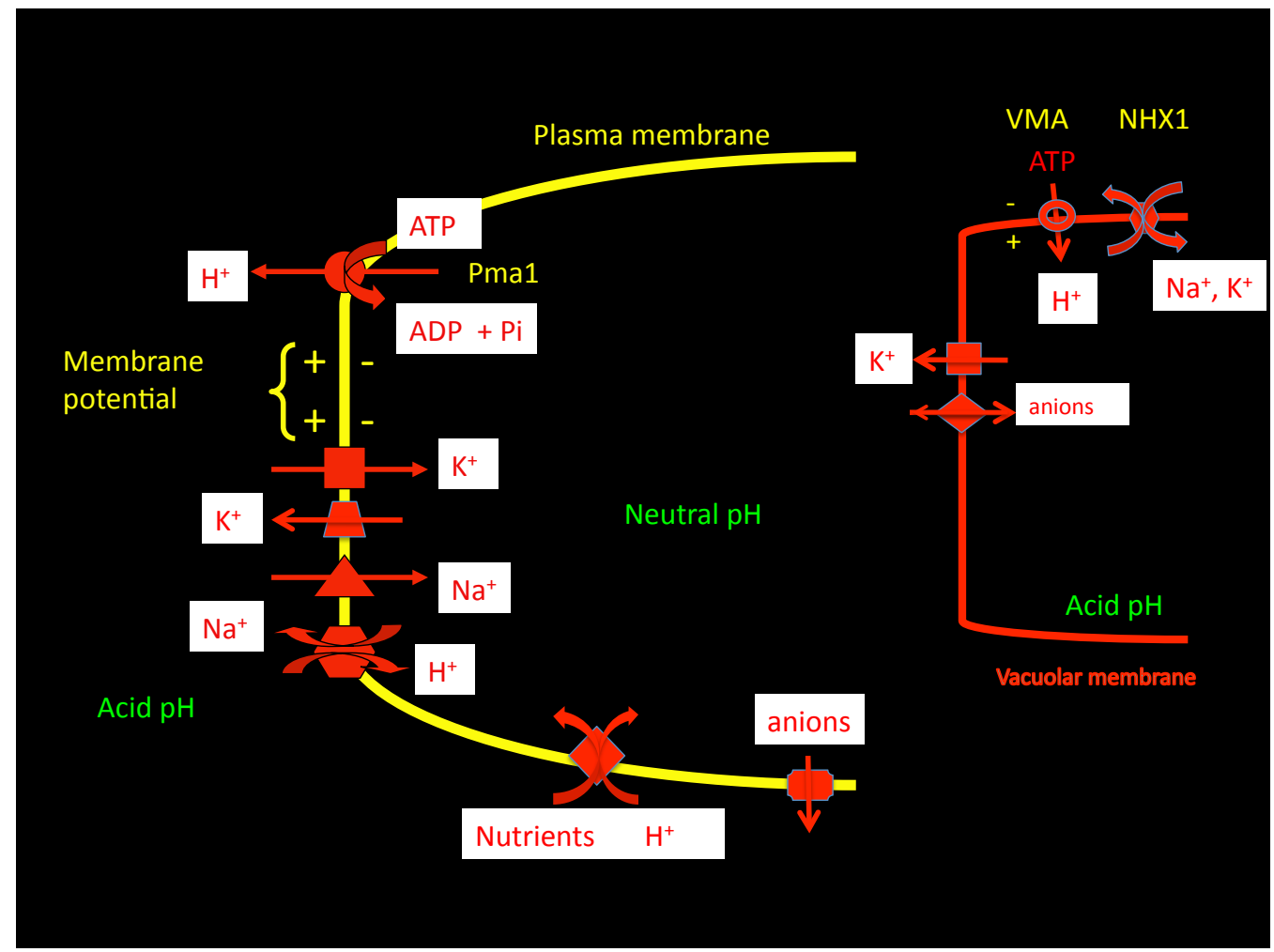

Figure 1. Scheme of ion homeostasis in yeast. The proton pumping $\mathrm{H}^{+}$-ATPase Pmal utilizes the energy of ATP hydrolysis to pump protons out of the cell. This generates a $\mathrm{pH}$ gradient, acid outside, and a membrane potential, positive outside. Both components of the electrochemical proton gradient drive nutrient uptake and extrusion of sodium and anions. The vacuolar $\mathrm{H}^{+}$-ATPase (VMA) energizes the vacuolar membrane by generating a $\mathrm{pH}$ gradient (acid inside) and a membrane potential (positive inside). Influx and efflux $\mathrm{K}^{+}$channels are indicated as well as systems involved in nutrient uptake and sodium and anion efflux.

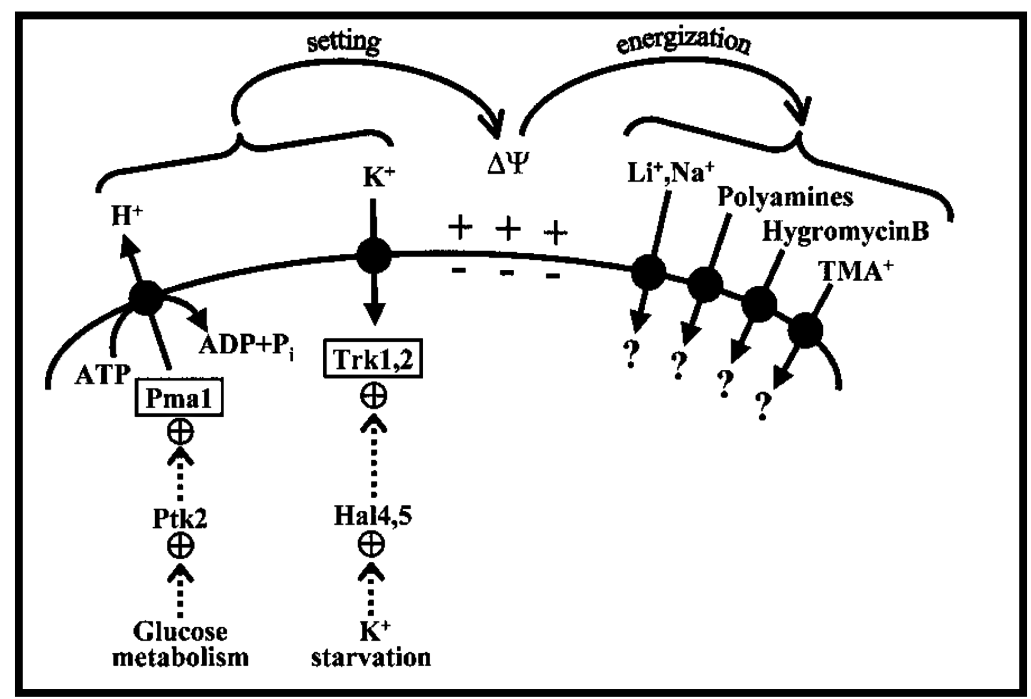

Figure 2. Model for the role of Pmal and Trk1, 2 on yeast tolerance to toxic cations by modulation of the electrical membrane potential $(\Delta \Psi)$, which determines the uptake of toxic cations by different voltage-sensitive channels (from Goossens et al., 2000). 
From an applied point of view, growth of yeasts in the presence of weak-acid preservatives is a major concern in the food industry. It is well known that the principal inhibitory mode of action of these preservatives is to lower pHi, causing growth arrest and cell death. Despite the presence of the maximum permitted level of preservative and good manufacturing practice, yeast and mold spoilage still happens. Actually, the resistance of the spoilage yeast Zygosaccharomyces bailii to such preservatives has become a huge problem to the food industry in products, which rely on low $\mathrm{pH}$ and weak acids for preservation. Mechanisms of resistance to weak organic acids seem to involve increased activity of either Pma1 or Trk1 (Holyoak et al., 1996). The concerted activity of the two systems modulating $\mathrm{pHi}$ is needed for electrical balance during proton efflux (see Figures 1 and 2).

We will make a brief introduction to cellular ion pumps before describing the regulation of Pma1, which constitutes the subject of this thesis.

\section{Types of ion pumps}

As indicated in Figure 3, living cells must maintain a set of major ion concentrations in the cytosol for proper operation of cellular systems despite variable external concentrations. In the course of evolution cells developed ion pumps to energize the membranes and maintain intracellular ion homeostasis (Maloney and Wilson, 1985). In addition to pumps energized by light and by red-ox reactions, ionpumping ATPases of two major kinds (Figure 4) were developed by ancestor cells, more than $2 \times 10^{9}$ years ago: the P-ATPases (also called $\mathrm{E}_{1} \mathrm{E}_{2}$-ATPases) and the rotary ATPases (also called $\mathrm{F}_{0} \mathrm{~F}_{1}, \mathrm{~A}_{0} \mathrm{~A}_{1}$ or $\mathrm{V}_{\mathrm{o}} \mathrm{V}_{1}$-ATPases). The rotary ATPases are present in bacteria and derived mitochondria and chloroplasts $\left(\mathrm{F}_{\mathrm{o}} \mathrm{F}_{1}\right)$, archaea $\left(\mathrm{A}_{\mathrm{o}} \mathrm{A}_{1}\right)$ and vacuolar or lysosomal membranes $\left(\mathrm{V}_{\mathrm{o}} \mathrm{V}_{1}\right)$. These are very complex reversible enzymes with many subunits (up to 20) and structured into a membrane embedded domain $\left(\mathrm{X}_{\mathrm{o}}\right.$; involved in transport of $\mathrm{H}^{+}$and more rarely of $\mathrm{Na}^{+}$) and a membrane-protruding domain $\left(\mathrm{X}_{1}\right.$; catalyzing ATP hydrolysis or synthesis). The atomic structure and mechanism of these enzymes has been determined and the name of this type of pumps makes reference to their operation as a rotary motor (see the schematic drawing of Figure 5), with a central rotor within a surrounding stator. Rotation of the proton-binding site changes the accessibility of the site to the two sides of the membrane mediated by two half-channels in the transmembrane part of the stator (Muench et al, 2011). 


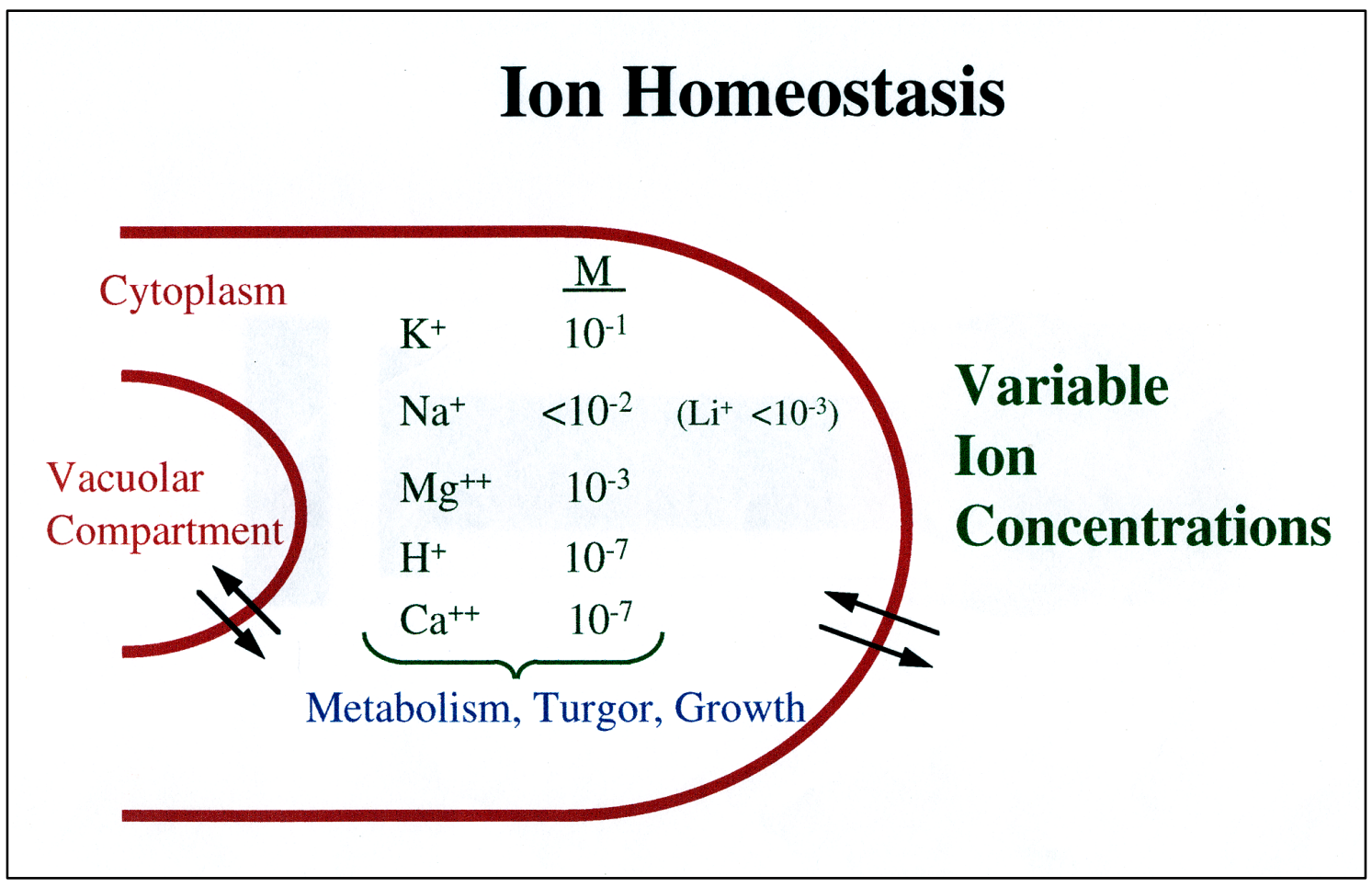

Figure 3. Scheme of cellular ion homeostasis in most living cells. The cytosol must maintain a set of major ion concentrations for the proper operation of cellular machineries despite variable external concentrations. $\mathrm{K}^{+}$is the major cation but $\mathrm{Mg}^{2+}$ and $\mathrm{Ca}^{2+}$ also play important roles. $\mathrm{Na}^{+}$and $\mathrm{H}^{+}$are toxic at high concentrations.

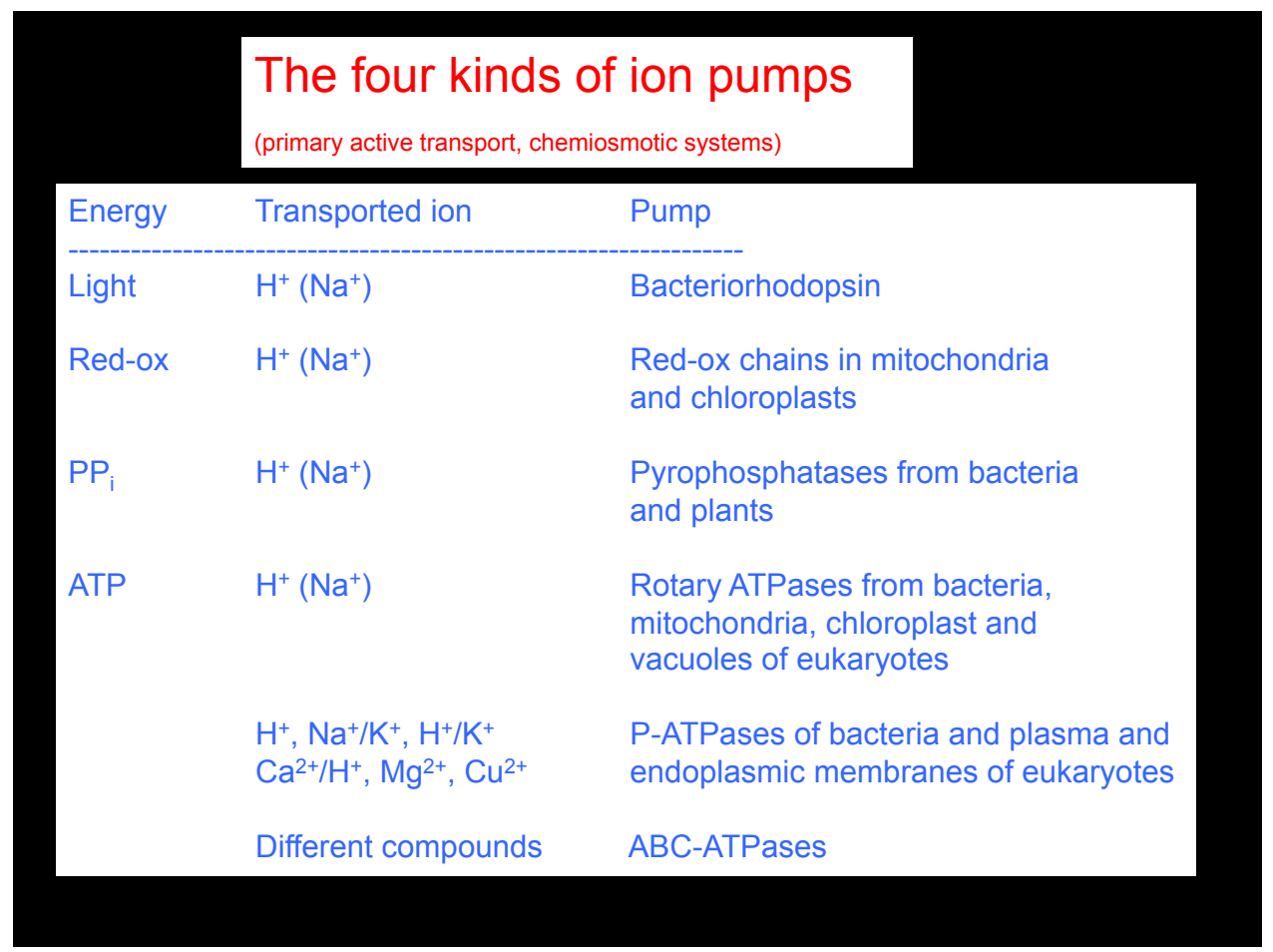

Figure 4. Types of ion pumps in living cells. Within the ATPases the so called ABC are not typical ion pumps and can transport many different molecules. 


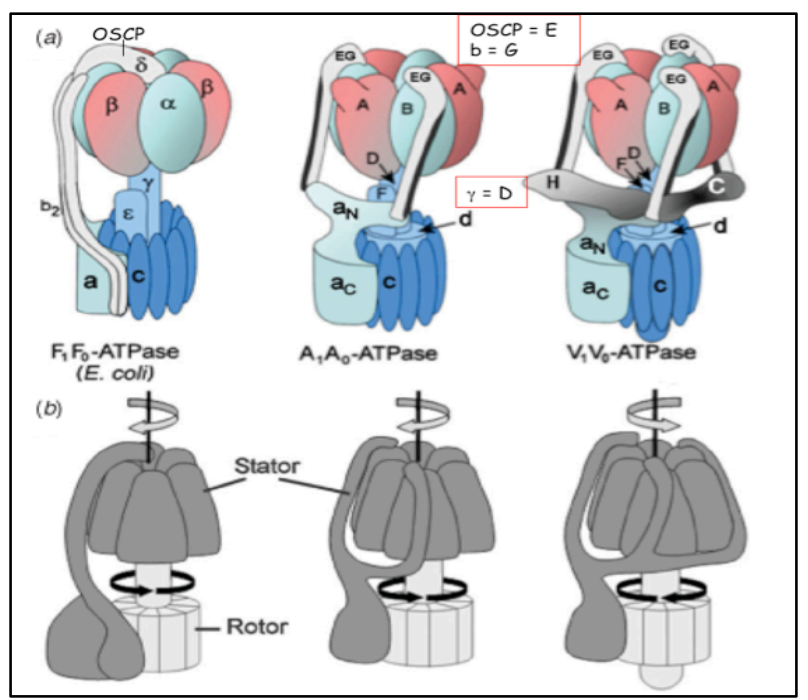

Figure 5. Schematic structure of rotary ion-pumping ATPases (Modified from Muench et al., 2011). Part (a) indicates the complex structure of these pumps and part (b) the division into stator and rotor pieces.

\section{P-type ion-pumping ATPases}

Pmal belongs to the P-type ion-pumping ATPases, a versatile family of enzymes made of a single subunit and with different members pumping $\mathrm{H}^{+}, \mathrm{Na}^{+}, \mathrm{K}^{+}$, $\mathrm{Ca}^{2+}, \mathrm{Mg}^{2+}$ and $\mathrm{Cu}^{2+}$ (Axelsen and Palmgren, 1998; Kühlbrandt, 2004). The family is termed P-type because the mechanism of transport involves direct phosphorylation of a conserved aspartyl residue by ATP followed by hydrolysis of this aspartyl phosphate intermediate as a necessary part of the transport cycle. This has not to be confused with regulatory phosphorylations on serine and threonines by protein kinases acting on regulatory sites. More than 50 members of this class of membrane transport proteins have been sequenced and the family has been divided into five distinct classes based on their sequence, ion specificity and biological occurrence (Axelsen and Palmgren, 1988; Green, 1992). P-type ATPases are present in all species from bacteria to mammals but in fungi and plants the dominant plasma membrane ATPases are P-type proton pumps $\left(\mathrm{H}^{+}\right.$-ATPases $)$while in animal cells a P-type $\mathrm{Na}^{+} / \mathrm{K}^{+}$-ATPase is the dominant pump (Serrano, 1985). Also, the $\mathrm{H}^{+}$-ATPases of yeast and other fungi do not contain a glycosylated $\beta$-subunit that is found in mammalian $\mathrm{Na}^{+} / \mathrm{K}^{+}$and $\mathrm{H}^{+} / \mathrm{K}^{+}$-ATPases (Lutsenko and Kaplan, 1995). All P-ATPases have a catalytic mechanism based in four conformational states of the enzyme and a model based on the insight of William P. Jencks (1989) is shown in Figure 6. These are "linear" motors whose structure has been determined at the atomic level in some cases (Bublitz et al., 2010), including the plant proton pump that is highly homologous to yeast Pmal (Pedersen et al., 2007). A representation of various structures of P-ATPases is shown in Figure 7. 


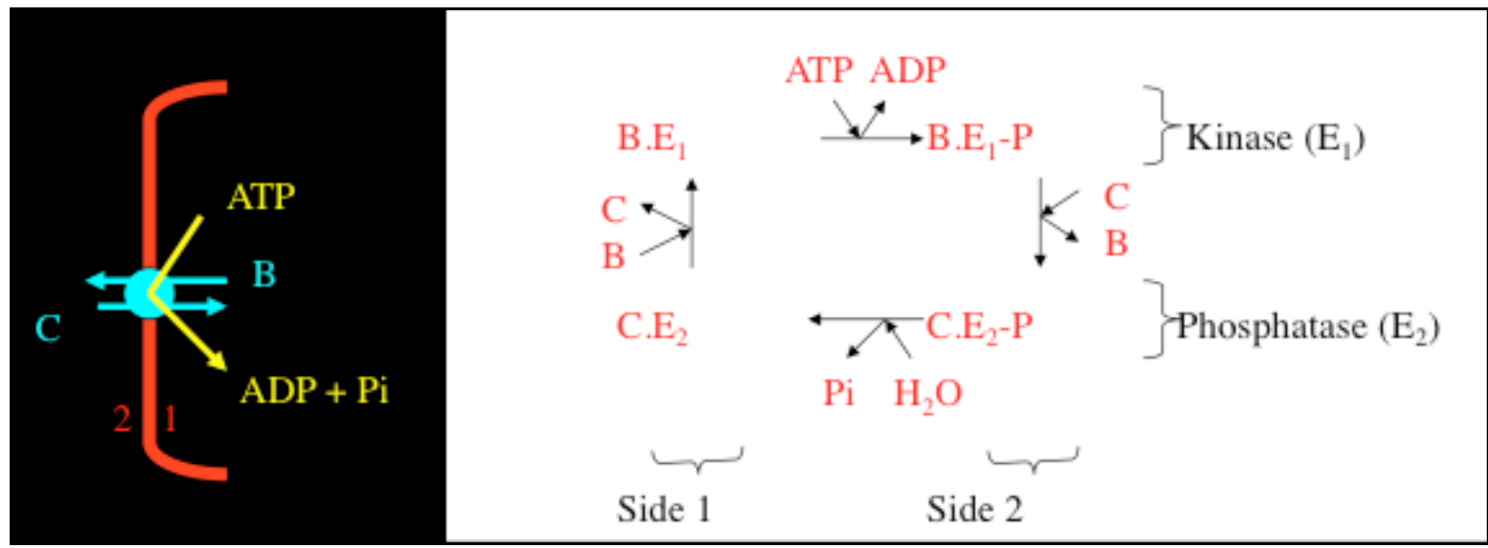

Figure 6. The catalytic cycle of P-ATPases. The cycle for a generic enzyme pumping cation "B" out of the cell and cation " $C$ " into the cells is shown. Yeast Pmal only pumps protons $\left(B=\mathrm{H}^{+}\right)$out. After binding "B" from the cytosolic side (side 1), the enzyme acts as an "auto-kinase" $\left(\mathrm{E}_{1}\right)$ and phosphorylates himself at the catalytic site, making a covalent phosphorylated intermediate (aspartyl-phosphate; E-P). This has not to be confused with regulatory phosphorylations on serine and threonines by protein kinases acting on regulatory sites. This auto-phosphorylation triggers a conformational change that shifts the sideness and specificity of the cation binding site, now exposed to side 2 (outside the cell) and with decreased affinity for cation $B$ to exchange " $B$ " by " $C$ ". Binding of the latter cation then determines a new catalytic activity as an auto-phosphatase $\left(\mathrm{E}_{2}\right)$, releasing the phosphate $\left(\mathrm{P}_{\mathrm{i}}\right)$ from E-P. This again triggers a conformational change that shifts the sideness and specificity of the cation binding site to side 1 (inside the cell) and exchange of "C" by "B", completing the cycle. After Jencks (1989).

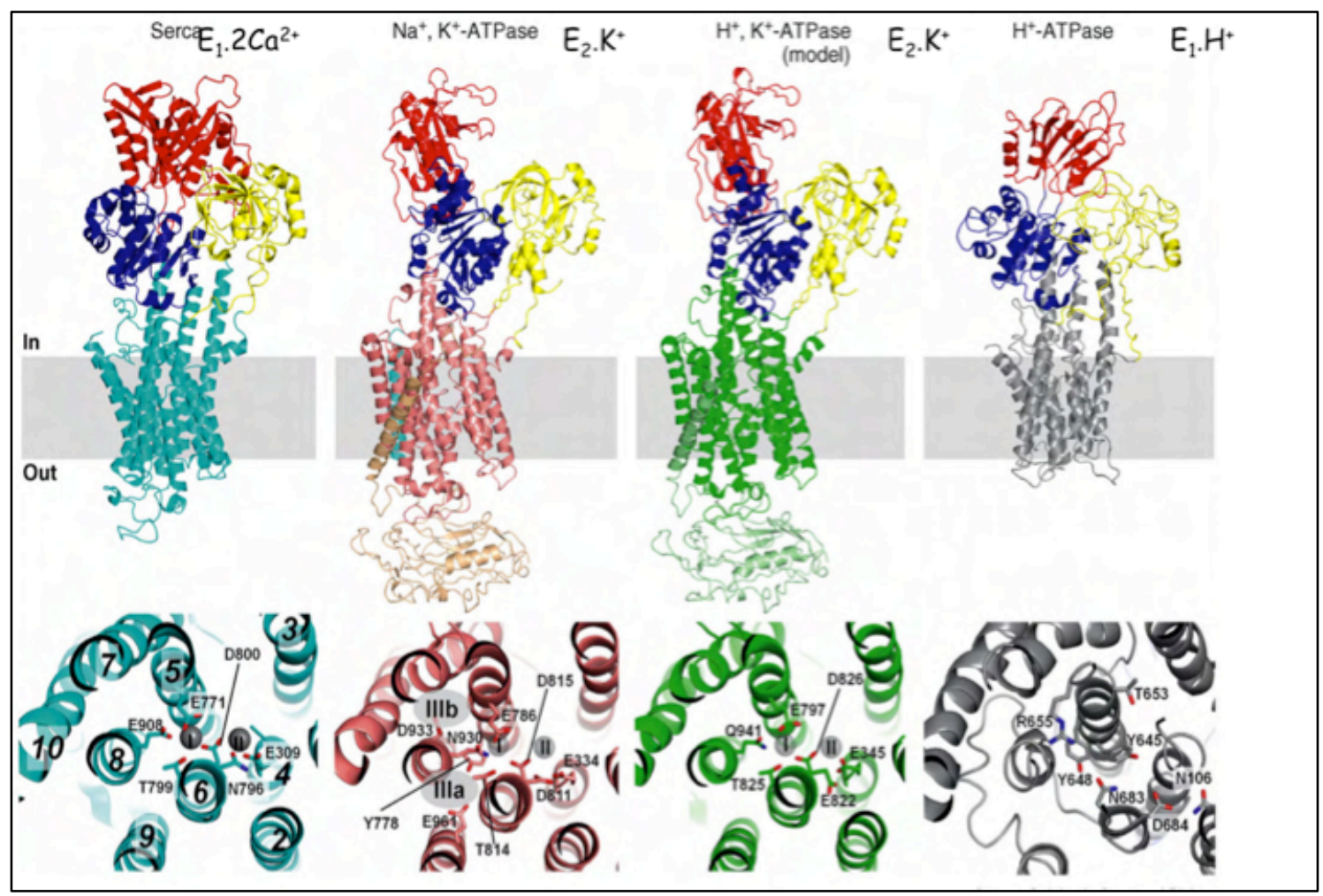

Figure 7. Schematic structure of several P-ATPases in different conformations. $\mathrm{Ca}^{2+} / \mathrm{H}^{+}$-ATPase from sarcoplasmic reticulum (Serca), $\mathrm{Na}^{+} / \mathrm{K}^{+}$-ATPase and $\mathrm{H}^{+} / \mathrm{K}^{+}$-ATPase from mammalian plasma membranes and $\mathrm{H}^{+}$-ATPase from plant plasma membranes. Modified from Bublitz et al., (2010). The upper part represents the overall structure of different P-ATPases by $\alpha$-helices and $\beta$-sheets. The lower part represents the transmembrane helices with the cation binding sites. The accessibility of these sites to the two sides of the membrane and their affinity changes depending on the auto-phosphorylation of the ATPases (see Figure 6). 


\section{Regulation of Pma1 activity}

The regulation of Pma1 activity was shown for the first time by Serrano (1983), who discovered that incubation of yeast cells with glucose resulted in a reversible several-fold enhancement of the enzyme's activity, a decrease in $\mathrm{Km}$, and an increase in Vmax. Sugars utilized by the glycolytic pathway (glucose, fructose and mannose) were shown to lead to the enhancement of activity. Sugars metabolized through other pathways (galactose), as well as non-metabolized glucose analogs (xylose, 3-Omethylglucose and deoxyglucose), did not result in any enhancement (Serrano, 1983).

Concerning regulation of expression, glucose metabolism, through the Rap1/TUF and Gcr1 transcription factors, increases the expression of the PMA1 gene together with that of genes of glycolytic enzymes, ribosomal proteins and translation factors, all of them important for fast growth in glucose medium (Capieaux et al., 1989; Portillo, 2000). However, this transcriptional regulation of Pma1 is relatively small, less than 2-fold, and regulation occurs mostly at the level of activity, not amount of the enzyme (Portillo, 2000). In other words, regulation of Pmal is mostly due to posttranslational modification. Pmal activity is increased by conditions that stimulate yeast growth, such as good carbon sources like glucose (Serrano, 1983) and by stress conditions that can be alleviated by the activity of the enzyme, such as intracellular acidification induced by low external pH (Eraso and Gancedo, 1987), nitrogen starvation (Benito et al., 1992) and supraoptimal growth temperature (Viegas et al., 1995). In the case of glucose the activation of proton pumping is much greater than the activation of ATP hydrolysis because it increases the number of protons pumped per ATP hydrolyzed (Venema and Palmgren, 1995). The activation by glucose requires metabolism of the sugar and it is independent of the plasma membrane glucose receptors Snf3/Rgt2 and Gpr1 (Belinchón and Gancedo, 2007).

The regulation of Pmal activity by glucose metabolism and acidification described above depends on a regulatory domain of Pmal present at the C-terminus of the enzyme (Benito et al., 1992). In the scheme of Figure 8 it is shown the domain structure of Pmal and at the C-terminus is the regulatory domain identified by deletion analysis of the enzyme (Portillo et al., 1989; Serrano and Portillo, 1990). The last 21 amino acids of this domain (from Arg898 to Thr918) mediate the activation of the enzyme by glucose metabolism and by acidification. 


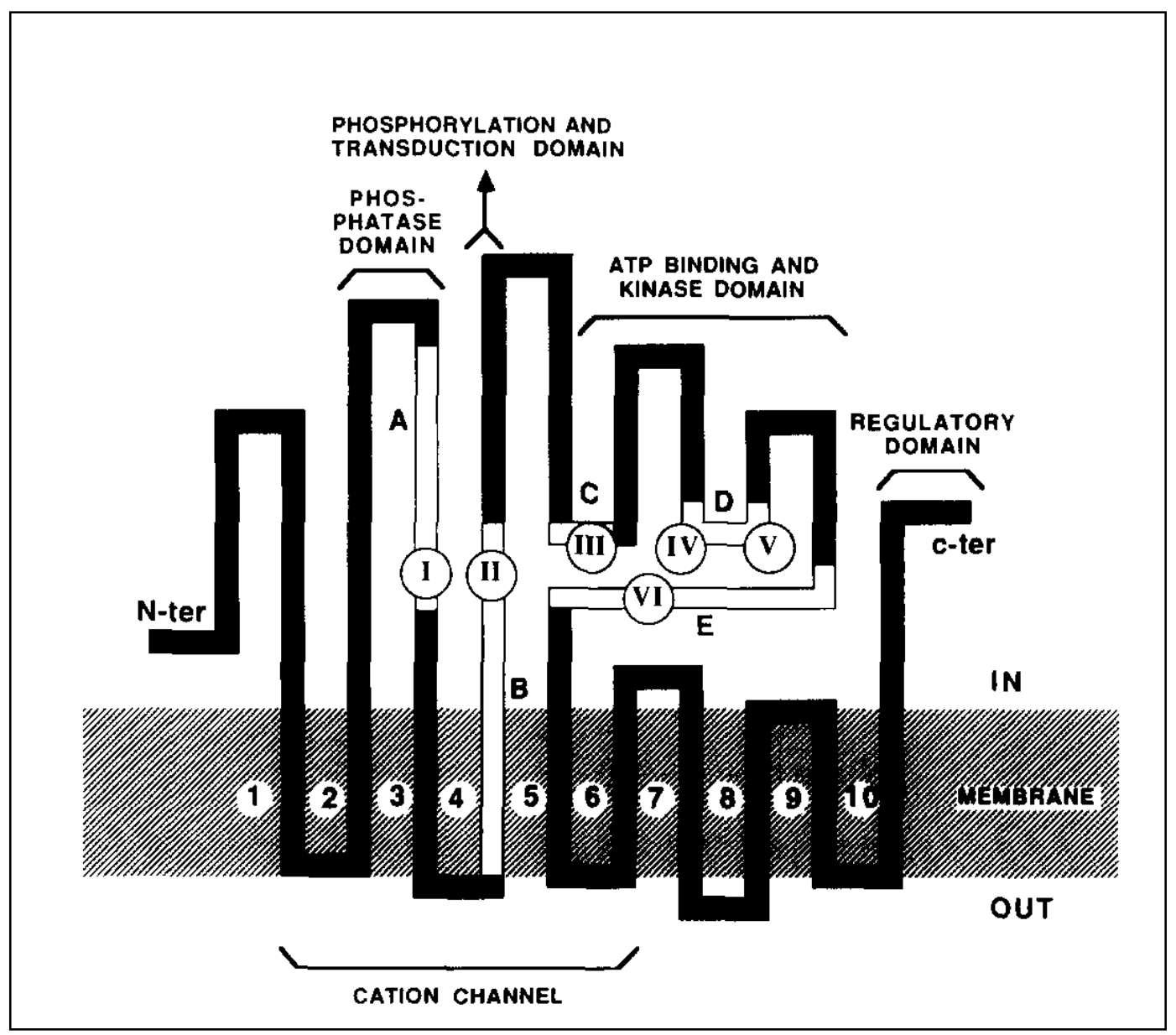

Figure 8. Model for the domain structure of yeast Pma1. The ten transmembrane helices and the conserved motifs I to VI of P-ATPases are indicated. Motif I (TGES) is the active site of the autophosphatase domain, motif II (D[K,R]TGT[L,I]T) include the aspartate (D) auto-phosphorylated in the reaction intermediate and motifs III (KGAP), IV (DPPR), V (M[L,I,V]TGD) and VI (GDGXND) are involved in ATP binding for the auto-kinase reaction. From Serrano and Portillo (1990). The regulatory domain is at the C-terminus of the enzyme and is not conserved in different types of P-ATPases. Its conformation is unstableand is not visible in the crystal structures of Figure 7. 
The suggested mechanism (Portillo, 2000) is that this regulatory domain in the inactive state blocks the binding to the enzyme of both the transported proton and ATP. Upon some modification induced by glucose metabolism or acidification the regulatory domain is displaced and allows access of both proton and ATP to the enzyme (Figure 9).

In the case of activation by glucose metabolism this modification has been shown to correspond to phosphorylation of two sites: Ser899 and double phosphorylation at Ser911 and Thr912. The sequence of the regulatory domain is shown in Figure 10, with the two phosphorylation sites important for activation by glucose metabolism indicated. Although an inhibitory phosphorylation of Ser507 (within the kinase domain) by casein kinase I (Yck1) has been described, this site has a minor effect on the activation by glucose of Pmal (Estrada et al., 1996). Phosphorylation of Ser899 by protein kinase Ptk2 slightly activates Pma1 by improving the affinity of the enzyme for ATP (Eraso and Portillo, 1994; Goossens et al., 2000, Eraso et al., 2006). However, the most important regulation of Pmal by glucose metabolism is mediated by double phosphorylation of Ser911 and Thr912, which greatly affects the maximal rate of the enzyme (Portillo et al., 1991; Lecchi et al., 2007). As Ser911 is phosphorylated in the absence of glucose (Lecchi et al., 2007), the phosphorylation of Thr912 is the crucial modification of Pmal during activation by glucose metabolism.

At present the protein kinases phosphorylating Pmal at Thr912 in response to glucose metabolism remains unknown. A scheme of the regulatory pathways triggered by glucose in yeast is shown in Figure 11 (modified from Belinchón and Gancedo, 2007). A major yeast protein kinase activated by glucose, protein kinase A, is not involved in glucose activation of Pmal (Mazón et al., 1989; dos Passos et al., 1992). Protein kinase $\mathrm{C}$ and $\mathrm{Ca}^{2+} /$ calmodulin-dependent protein kinases have been proposed to regulate Pmal in response to glucose metabolism (Brandao et al., 1994) but a demonstration that these kinases phosphorylate Pma1 remains to be reported.

Campetelli et al., (2005) have reported that in glucose starved cell Pma1 forms a complex with acetylated tubulin that is disrupted when the enzyme is activated by glucose metabolism. This change in interaction of Pma1 with acetylated tubulin as well as the changes in distribution of Pmal in the membrane surface observed by Permyakov et al., (2012) using immunoglod labeling may be structural consequences of the conformational changes triggered by phosphorylation of the regulatory domain of Pma1. 


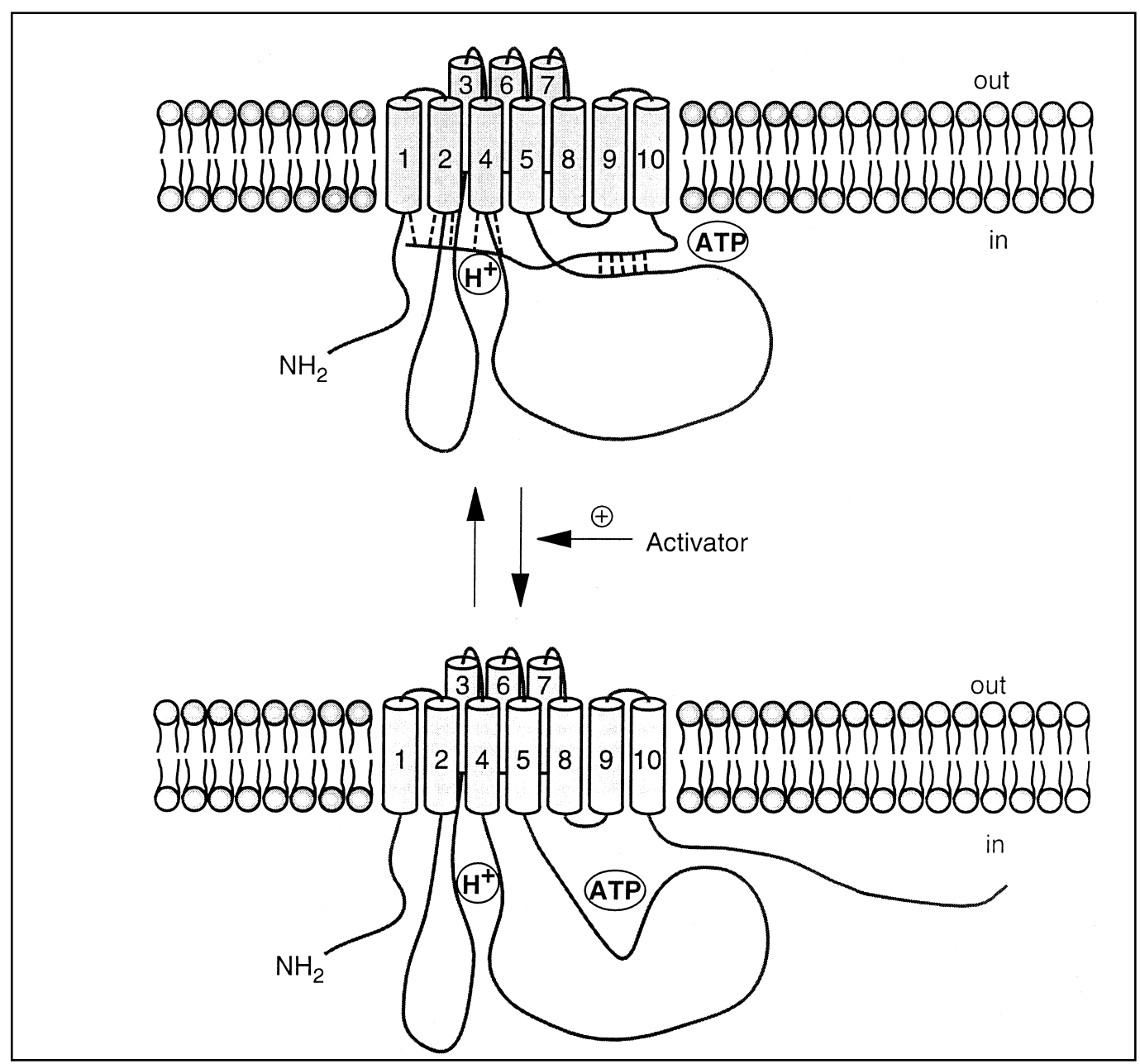

Figure 9. Model for the activation of Pma1. In the low-activity state (upper), the C-terminus would interact with the active site of the enzyme, limiting access of the protons and ATP substrates. The activators would trigger a modification of the C-terminus, releasing the inhibitory interaction and allowing the ATPase to adopt a more active conformation (bottom). From Portillo (2000).

\section{${ }_{898}$ RSLEDFMAAMQRVSTQHEKET $_{918}^{p}$}

Figure 10. Amino acid sequence of the last 21 amino acids of Pma1. The two activating phosphorylation sites, Ser899 and Ser911 Thr912 are indicated. p: $\mathrm{O}-\mathrm{PO}_{3} \mathrm{H}$ 


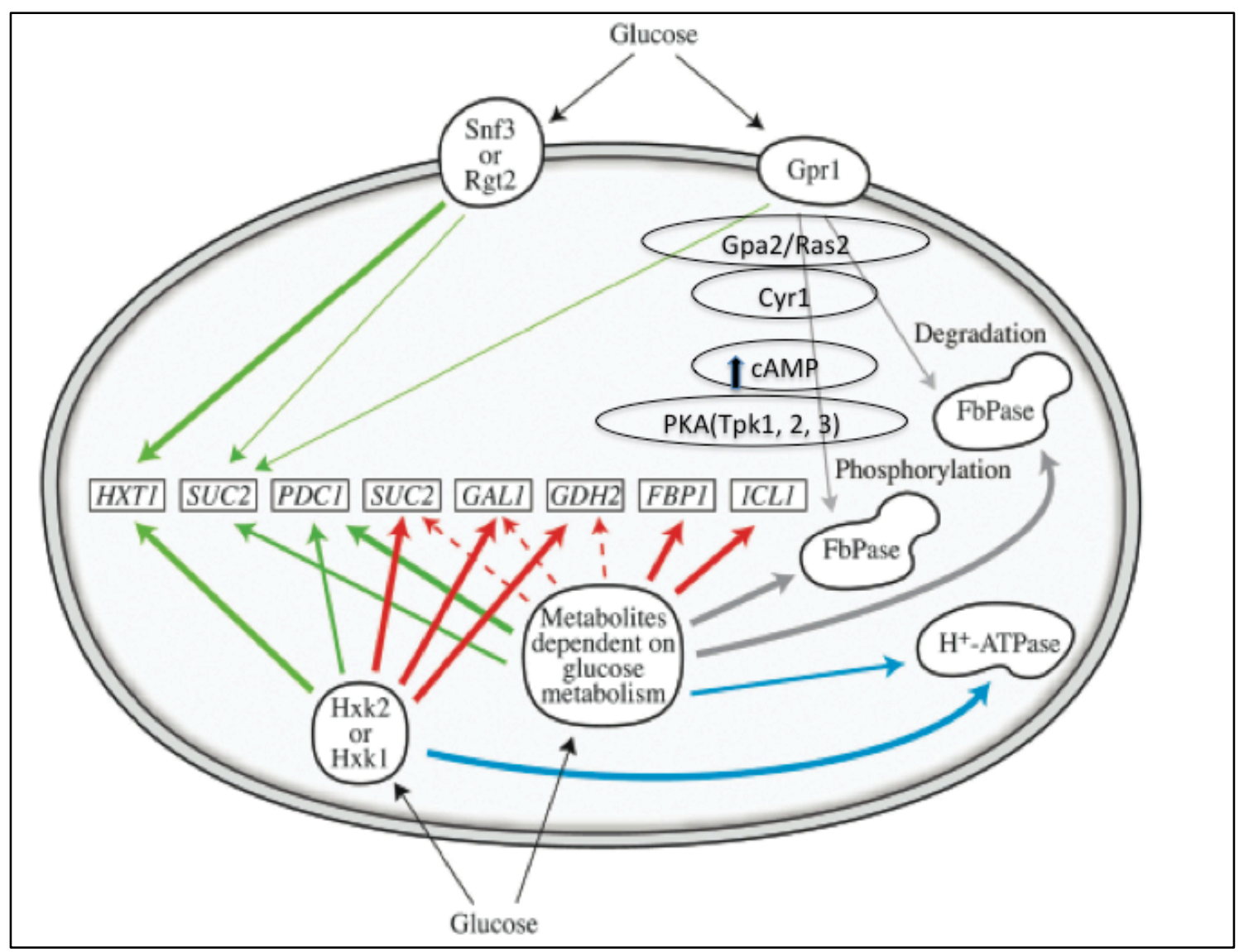

Figure 11. The effects of glucose on different processes in yeast depend on different combinations of early signals. Induction of SUC2 by low glucose depends partially on the glucose sensors, and requires glucose metabolism; in the absence of metabolism, induction requires high glucose and is fully dependent on Gpr1. Induction of HXT1 requires Snf3 or Rgt2, and is partially dependent on Hxk2. Induction of PDC1 is independent of the glucose sensors, has some dependence on Hxk2 or Hxk1, and requires glucose metabolism. Repression of different genes is independent of the glucose sensors; for SUC2, GAL1 and GDH2, Hxk2 or Hxk1 are required, and presumably glucose metabolism; for FBP1 and ICL1, glucose metabolism is necessary, but any glucose-phosphorylating enzyme sustains repression. In the absence of glucose metabolism, phosphorylation of FbPase is impaired, and the effect is reinforced by lack of Gpr1; degradation of FbPase depends on glucose metabolism, and is decreased when Gpr1 is lacking. Activation of $\mathrm{H}^{+}$-ATPase Pmal is independent of the glucose sensors, and has a strong dependence on Hxk2 or Hxk1; it is nearly blocked in the absence of glucose metabolism. The interactions between the initial elements of signaling and their targets are indicated by arrows; the width of the arrows is related to the strength of the signal, and putative interactions are indicated by dashed lines. Green color for induction; red, for repression; , blue for activation; grey for inactivation (by phosphorylation or degradation). (Modified from Belinchón and Gancedo, 2007) 


\section{Protein kinases and Phosphatases}

Regulation of protein activities by phosphorylation is one of the most important regulatory mechanisms in eukaryotic cells (Hanks and Hunter, 1995). The process of phosphorylation and dephosphorylation of a protein serves as an "on-and-off" switch in the regulation of cellular activities. For optimal regulation, protein kinases and phosphatases have to reach a balance in any given cell (Luan, 2003). A large fraction of eukaryotic proteins, about one-third, are controlled by phosphorylation of specific serine, threonine, and/or tyrosine residues (Ceulemans and Bollen, 2004). Adding or removing a phosphate group from a protein often has profound effects on the structure and thereby the functional properties of it. For example, phosphorylation can regulate an enzyme activity by initiation of allosteric conformational changes that may affect the access to its active site (Johnson and O'Reilly, 1996). The interaction among protein partners that must form complexes in order to function is also affected by phosphorylation (Pawson, 1995). Some proteins need to be phosphorylated to be able to target a certain destination site in the cell where they function. Almost all aspects of cell function involve reversible phosphorylation: metabolism, cell cycle progression, ion transport, developmental control, and stress responses. This diversity in cellular functions is reflected by the large number of intracellular proteins subjected to reversible phosphorylation and the large number of protein kinases and phosphatases that catalyze these reactions (Luan, 2003).

There are about a hundred protein tyrosine kinases and the same number of protein tyrosine phosphatases in mammalian cells. In fungi and plants tyrosine phosphorylation is much less important and there are only a few kinases and phosphatases for this modification. Concerning protein serine/threonine (Ser/Thre) phosphorylation, mammalian cells have about 400 protein kinases and 25 protein phosphatases (Plowman et al., 1999), and this suggest distinct diversification strategies during evolution (Ceulemans et al., 2002). At variance with mammalian cells, the yeast genome encodes and expresses 106 protein phosphatases (Stark, 1996) and 113 protein kinases (Hunter and Plowman, 1997), the number of protein kinases and phosphatases is similar. The true diversity of protein Ser/Thre phosphatases is only seen at the holoenzyme level because of the variety of regulators that can interact with a given catalytic subunit (Ceulemans and Bollen, 2004). 


\section{The atypical TOR protein kinase}

There are also a few non-conventional, atypical protein kinases. These are enzymes more related by sequence to metabolic kinases that phosphorylate metabolites but behave in cells as kinases that phosphorylate proteins. One of these rare enzymes is TOR (Target Of Rapamycin), an atypical protein kinase sensitive to the drug rapamycin that plays a crucial role in nutrient signaling and growth control. It was discovered in yeast and is homologous to phosphatidylinositol kinases involved in lipid metabolism although it phosphorylates proteins at serine and threonine residues. (Loewith and Hall, 2011). TOR is a highly conserved protein kinase among eukaryotes but S. cerevisiae is unusual in having two TOR genes (TOR1 and TOR2) whereas almost all the other eukaryotes, including plants, worms, flies, and mammals, have a single TOR gene (Loewith and Hall, 2011). In yeast Tor1 and Tor2 proteins both have $282 \mathrm{kDa}$ (2470 and 2474 amino acids, respectively) and are 67\% identical. They are the founding members of the PIKK family of atypical Ser/Thr-specific kinases related to phosphatidylinositol kinases (Keith and Schreiber, 1995). Disruption of both TORI and TOR2 genes in yeast leads to growth arrest similar to that caused by rapamycin treatment, suggesting that Tor 1 and Tor 2 are the ultimate targets of rapamycin, a potent inhibitor of yeast growth (Kunz et al., 1993).

Tor1 and Tor2 have a central role in controlling yeast growth as part of two separate signaling branches. They are functionally different despite being structurally similar (Helliwell et al., 1994). Disruption of only TORl has little or no effect but disruption of TOR2 alone causes cells to arrest growth within a few generations and to have a randomized actin cytoskeleton (Schmidt et al., 1996). TOR2 has two essential functions: one function is redundant with TORl and the other function is unique to TOR2 (Helliwell et al., 1998). This is explained because Tor1 and Tor2 are found as part of two essential complexes, TORC1 and TORC2, conserved in eukaryotes (Loewith and Hall, 2011). In yeast TORC1 contains either Tor1 or Tor2 but only Tor2 can form part of TORC2 (Figure 12). 


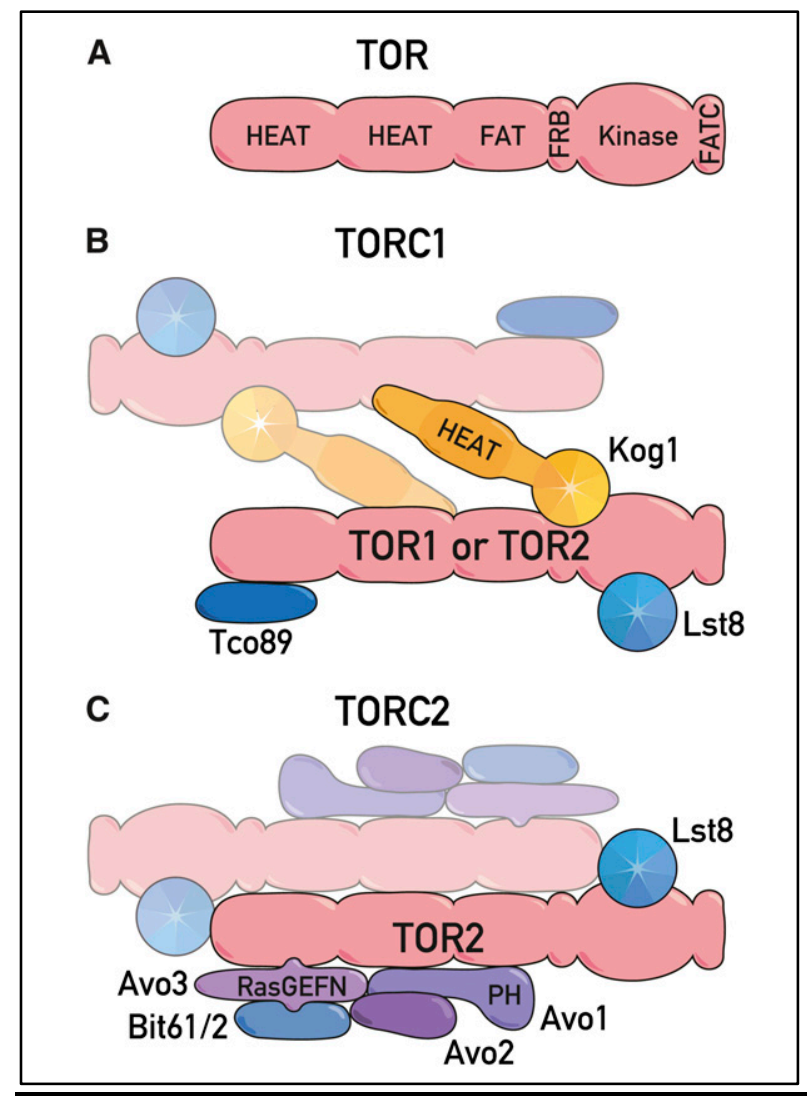

Figure 12. Conserved domain structure of TOR. The N-terminal half of TOR is composed of two blocks of 20 HEAT repeats, 40 aa that form pairs of interacting antiparallel a-helices. The 500-aa FAT (FRAPATM- TRRAP) domain contains modified HEAT repeats. Missense mutations in the 100-aa FRB (FKBP12-rapamycin-binding) domain confer complete resistance to rapamycin. The kinase domain phosphorylates Ser/Thr residues in protein substrates, but at the sequence level resembles the catalytic domain of phosphatidylinositol kinases. (B) Composition of TOR complex 1. TORC1 is 2 MDa in size and contains Kog1, Tco89, Lst8, and either Tor1 or Tor2. The HEAT repeats found in Kog1 and the seven-bladed propellers of the WD-40 repeats found in Kog1 and Lst8 are depicted. The binding of Kog1 to TOR is complex, involving multiple domains on each protein. Lst8 binds to the kinase domain of TOR. Each component is likely present in two copies. (C) Composition of TOR complex 2. TORC2 is 2 MDa in size and contains Avo1, Avo2, Avo3, Bit61, and/or its paralog Bit2, Lst8, and Tor2 but not Tor1. The RasGEFN domain of Avo3 and the PH domain of Avo1 are indicated. Each component is likely present in two copies (Loewith and Hall, 2011).

\section{Regulation of and by TORC1}

Both TOR complexes have a dual localization, cytoplasmic and membranebound, with TORC1 partially bound to the vacuolar membrane and TORC2 partially bound to the plasma membrane (Sturgill et al., 2008). TORC1 signaling is responsive to nutrients, which are mainly stored in the yeast vacuole; this makes such localization of TORC1 very logical (Figure 13). The EGO complex resides on the vacuolar/lysosomal membrane and is thought to couple amino acid signals to TORC1. It is an important regulator of TORC1 (Binda et al., 2009). Under inappropriate conditions of growth, 
cells enters a quiescence (G0) state in which they stop dividing, slow their metabolism, induce the expression of stress-responsive proteins, and accumulate energy stores.

Genetic disruption of TORC1 or rapamycin treatment mimics starvation, (De Virgilio and Loewith, 2006a; Loewith and Hall, 2011). Both starvation and exposure of yeast cells to rapamycin result in a high drop in protein synthesis, induction of autophagy, and exit from the cell cycle and entrance into a quiescent G0 state (Figure 14). The transcriptional response of yeast cells exposed to rapamycin, nutrient starvation, or noxious stressors is similar (Gasch and Werner-Washburne, 2002).

TORC1 does not only respond to extracellular signals, it can sense the intracellular amino acids and also the outputs from distal effectors can regulate TORC1 by feed back mechanism (Loewith and Hall, 2011). Example to this feedback, TORC1 activity stimulates translation initiation (Wullschleger et al., 2006) and inhibiting the translation with cycloheximide leads to high increase in TORC1 activity in response to increased concentration of free amino acids in the cytoplasm (Binda et al., 2009). Another example of the feedback is the regulation of ribosome biogenesis; TORC1 regulates this through two substrates, Sch9 and the transcription factor Sfp1 (Loewith and Hall, 2011).

As shown in Figure 13, one important direct substrate of yeast TORC1 is a protein kinase called Sch9 (Powers, 2007) this substrate gets phosphorylated by TORC1 and becomes active as a result (Urban et al., 2007). TORC1 also regulates type 2A and 2A-related protein phosphatases like Sit4. Zheng and Jiang (2005) showed that when TORC1 is active, Tap42 is phosphorylated and bound tightly to the Sit4 phosphatase. On the other hand, TORC1 inactivation results in Tap42 dephosphorylation and a weakened association with phosphatases which finally results in their activation and/or change in substrate preference (Yan et al., 2006).

As a rule, under appropriate growth conditions, TORC1 is active and its signals promote the accumulation of cellular mass i.e., growth, via regulation of several processes (Loewith and Hall, 2011), a scheme of them is represented in Figure 14. 


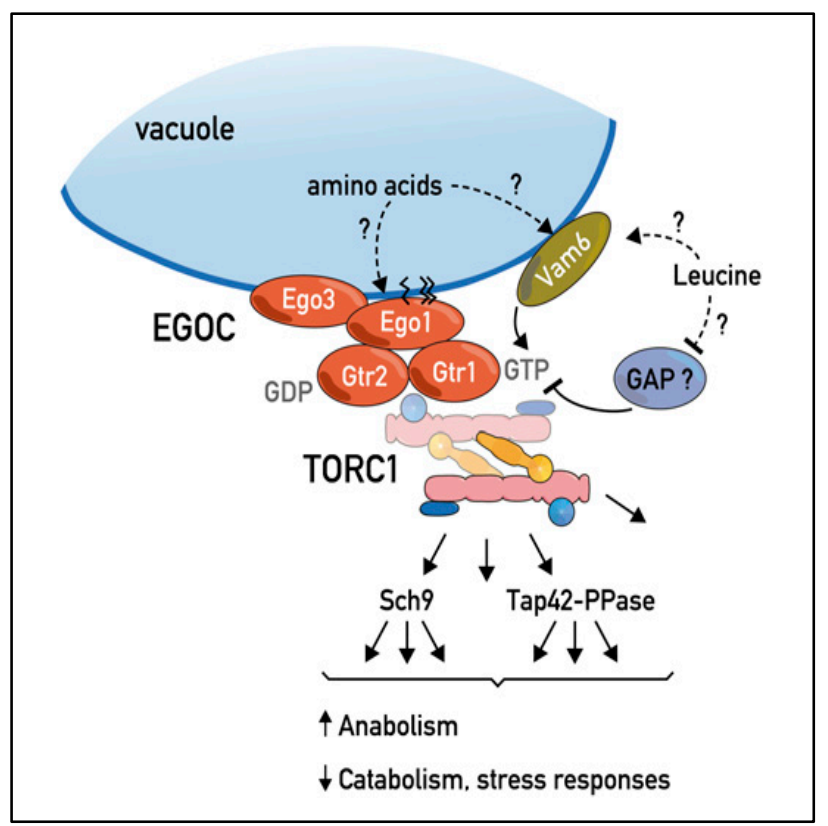

Figure 13. The EGO complex is a major regulator of TORC1. This complex is composed of four proteins (in red), binds to the vacuolar membrane and activates TORC1. Activated TORC1, via its two main effector branches, the AGC kinase Sch9 and the Tap42-PP2A and PP2A-like protein phosphatases, stimulates growth by favoring anabolic processes and by antagonizing catabolic processes and stressresponse programs (Loewith and Hall, 2011).

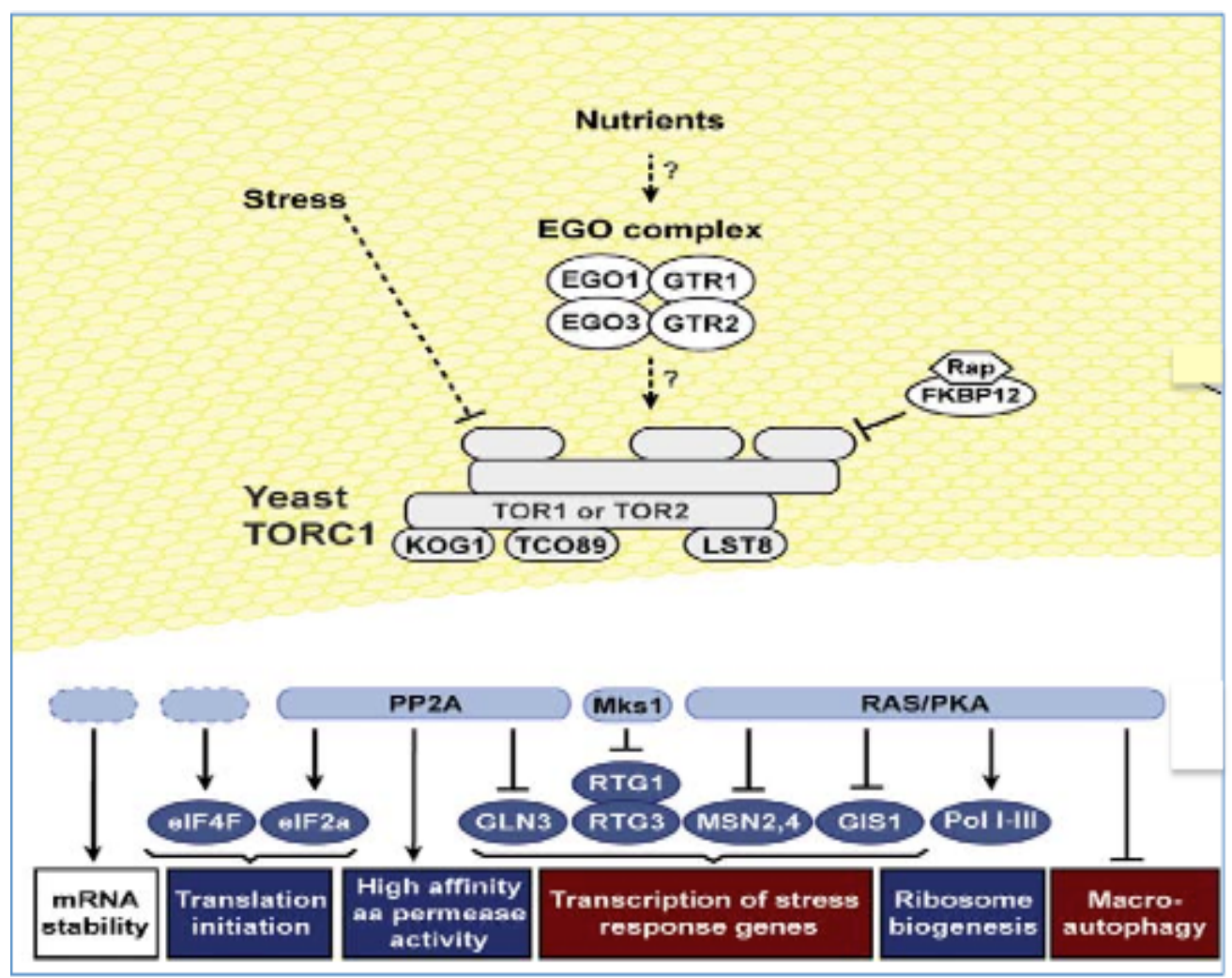

Figure 14. Rapamycin-sensitive yeast TORC1 (TORC1) couples growth to nutrients and stresses that are sensed by signaling pathways that impinge upon TORC1. TORC1-regulated processes that promote growth are boxed in dark blue; TORC1-regulated processes that inhibit growth are boxed in dark red. Arrows and bars denote positive and negative interactions, respectively, and dashed arrows and bars refer to potential interactions (De Virgilio and Loewith, 2006a) 
Rapamycin treatment elicits a high drop in protein synthesis by blocking translation initiation (Barbet et al., 1996). As indicated in Figure 15 (Ashe et al., 2000) this regulation occurs mainly through the translation factor eIF2. Amino acid starvation or rapamycin treatment leads to phosphorylation of the $\alpha$-subunit of eIF2 (Hinnebusch, 2005). TORC1 signals to eIF2a through both the Sch9 and Tap42-PP2A branches. The only eIF2- $\alpha$ kinase is the conserved Gen2 protein. Gen2 is activated when bound to uncharged tRNAs that accumulate when cells are starved for an amino acid. Gen2 activity is also regulated by phosphorylation on Ser577. This reduces tRNA binding and, consequently, kinase activity. Treating cells with rapamycin elicits a rapid, Tap42PP2A-dependent dephosphorylation of Ser577 and, consequently, an increase in Gen2 activity and a reduction in translation (Cherkasova and Hinnebusch, 2003).

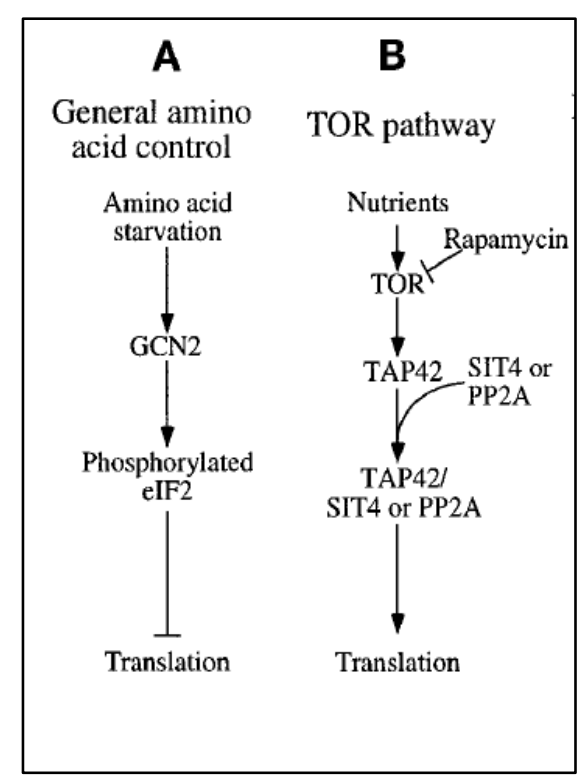

Figure 15. Control of translation in S. cerevisiae by the Gen2 and TORC1 protein kinases (Ashe et al., 2000).

In the following I will list some of the many functions of TORC1.

- Ribosome biogenesis: TORC1 plays a central role in regulating ribosome biogenesis at both transcriptional and posttranscriptional levels (Loewith and Hall, 2011). TORC1 also regulates various catalytic steps of ribosome assembly per se (Loewith, 2010).

- $\quad$ Cell cycle/cell size: Cell growth and cell division are two distinct, yet highly linked processes. In yeast, cells start a new round of cell division only after reaching a critical size (Cook and Tyers, 2007). Poor growth conditions reduce the activity of TORC1 and subsequently the activities of Sfp1 and Sch9. Consequently, this would 
decrease ribosome biogenesis, which would lower the cell-size threshold required for cell division. In contrast, acute inhibition of TORC1 with high concentrations of rapamycin leads to an arrest in G1 (Barbet et al., 1996) and a paradoxical increase in cell size. The increased cell size is due to swelling of the vacuole as a consequence of increased autophagy.

- TORC1 promotes growth also via inhibiting the stress responses. Activation of stress-responsive pathways is incompatible with rapid growth, and constitutive activation of these pathways results in cell death (Loewith and Hall, 2011).

- $\quad$ Nutrient uptake and intermediary metabolism. In response to the availability of different nutrients yeast cells express different permeases in order to compete with other microorganisms for growth. TORC1 regulates these permeases primarily via Tap42PP2A (Breitkreutz et al., 2010). Many nutrient and cation permeases have been identified as rapamycin-sensitive phosphoproteins (Huber et al., 2009). TORC1 regulates not only permease localization but also expression (Shamji et al., 2000). One effect on metabolism is through affecting the Gcn4 transcription factor, which gets activated upon amino acid starvation (Hinnebusch, 2005). Rapamycin treatment or amino acid starvation results in a rapid decrease in translation initiation by phosphorylating the $\alpha$-subunit of eIF2 which results in the repression of bulk translation and transcriptional induction of nearly all genes encoding amino acid biosynthetic enzymes (Loewith and Hall, 2011).

- TORC1 inhibits autophagy. When cells are exposed to starvation conditions they express stress-responsive proteins to help them. The energy and amino acids required for this new synthesis are obtained by inducing autophagy. Autophagy is conserved across eukaryotes (Yang and Klionsky, 2010) and it refers to the different mechanisms by which cytoplasmic material, including proteins and lipids, is translocated to the vacuole and catabolized. The produced amino acids and fatty acids are, respectively, used to synthesize new proteins and to produce ATP. Yeast has two different modes of autophagy: one is microautophagy, in which the cytoplasm is directly transferred into the vacuole via invaginations of the vacuolar membrane. The other mode is macroautophagy, which involves the "de novo" formation of double-membrane vesicles called autophagosomes, which encapsulate cytoplasm and then fuse with the vacuole. The two forms of autophagy are regulated by TORC1 (De Virgilio and Loewith, 2006b). - TORC1 accelerates aging: Aging is the progressive deterioration of cell, tissue 
and organ function. The genetic or chemical inhibition of TORC1 has been demonstrated to increase life span in yeast (Vellai et al., 2003) mostly through the multiple TORC1 effector pathways (Blagosklonny and Hall, 2009). Yeast life span can be assayed in two ways. RLS or replicative life span is defined as a measure of the number of progeny that a single mother cell can produce before senescence. Chronological life span (CLS) is a measure of the length of time a population of yeast cells can remain in stationary phase and keep the ability to restart growth following reinoculation into fresh media. RLS increases upon TORC1 inhibition. TORC1 and Sch9 inhibition and also induction of macroautophagy increases both RLS and CLS (Madeo et al., 2010). Since TORC1, Sch9, and Gcn2 homologs are found in most eukaryotes, the aging pathway appears to be conserved (Kaeberlein and Kennedy, 2011).

\section{Regulation of and by TORC2}

The majority of Tor2, almost 90\%, is in TORC2 (vs. TORC1) and that is why Tor2 localization studies presumably detect mainly, if not only, TORC2. As described above, TORC2 seems to be located both at the cytoplasm and at the plasma membrane (Sturgill et al., 2008). Localization at the plasma membrane is consistent with the role of TORC2 in controlling the actin cytoskeleton and endocytosis (Loewith and Hall, 2011).

TORC2 is rapamycin insensitive and its regulation is poorly characterized (Cybulski and Hall, 2009). There is a lack of reported evidence to support that TORC2 is controlled by nutrients. Knockout of TORC2 does not induce a starvation-like phenotype, and EGO, the nutrient-sensitive complex, appears not to be affecting TORC2. In mammalian cells, and perhaps also in yeast cells TORC2 is activated by direct association with the ribosome. Such a mechanism ensures that TORC2 is active only in growing cells because ribosomes determine the growth capacity of a cell (Loewith and Hall, 2011).

The first described and best-characterized TORC2 readout is the actin cytoskeleton (Figure 16). TORC2 also regulates sphingolipid biosynthesis (Powers et al., 2010). Sphingolipids serve as essential structural components in lipid bilayers and as signaling molecules. There is a mutual antagonism between TORC2 and the stressresponsive calcium-calcineurin pathway in yeast (Mulet et al., 2006). 


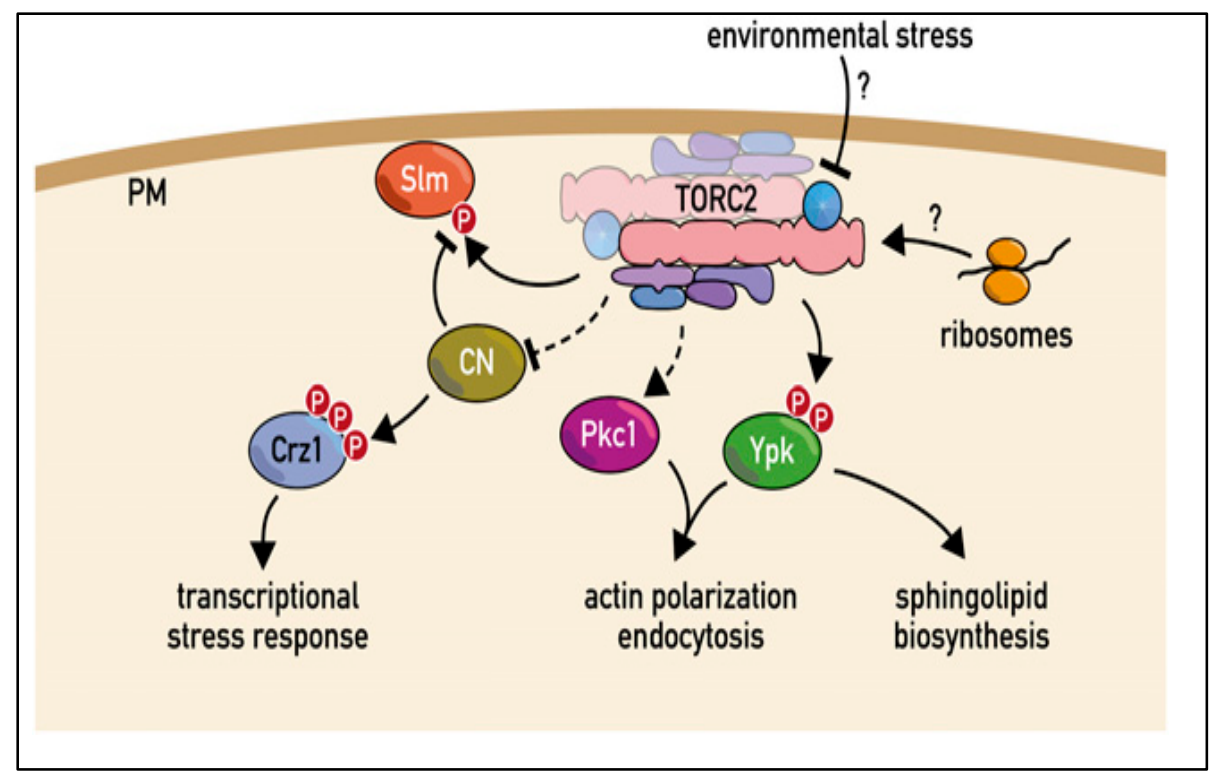

Figure 16. Signaling by TORC2. TORC2 directly phosphorylates the AGC kinase family member Ypk (Ypk1 and 2) and the PH domain containing protein Slm (Slm1 and -2). Downstream effectors include the phosphatase calcineurin, the transcription factor Crz1, and Pkc1. TORC2 controls organization of the actin cytoskeleton, endocytosis, sphingolipid biosynthesis, and stress-related transcription. The effector pathways by which TORC2 controls these processes are incompletely understood (Loewith and Hall, 2011).

\section{Protein phosphatases}

In the cellular regulations by phosphorylation protein kinases have been considered as the controlling part, with protein phosphatases (Cohen, 1989) being considered as mere "reset buttons", to put cells back in the resting state when protein kinases are inactivated (Ceulemans and Bollen, 2004). However, the recent discovery of the receptors of the plant hormone abscisic acid and its mechanism of action as inhibitors of protein phosphatases (Santiago et al., 2012) has shown that regulation of protein phosphatases can also control phosphorylation signaling cascades. More recently, the plasma membrane $\mathrm{H}^{+}$-ATPase of the plant Arabidopsis thaliana has been reported to be activated by auxin by a mechanism consisting on the inhibition of PP2CD phosphatases by some SAUR proteins induced by the hormone (Spartz et al., 2014).

Typical protein phosphatases catalyze the dephosphorylation of the hydroxyl group on amino acid residues and are classified into two major groups, protein Ser/Thre (Ser/Thr) and protein tyrosine phosphatases. There is a significant structural diversity inside each family generated by the presence of unique regulatory and targeting domains or by the attachment of regulatory subunits to the catalytic subunits. These enzymes have very broad substrate specificities "in vitro" and the function of these regulatory domains or subunits is to modulate their catalytic activity and, most 
important, to target the catalytic subunit to a specific subcellular compartment to determine the "in vivo" substrate specificity of protein phosphatases (Cohen, 1989; Luan, 2003).

As indicated in Figure 17, there are two major types of protein Ser/Thr phosphatases, based on their substrate specificity and pharmacological properties: Type 1 (PP1) and Type 2 (PP2). There are two main differences and the first one is the subunit of phosphorylase kinase that is acted on as substrate. PP1 acts on the beta subunit while PP2 dephosphorylates the alpha subunit. The second difference is the effect of nanomolar concentrations of two small peptide inhibitors; inhibitors 1 and 2 inhibit PP1 while PP2 is insensitive to them. PP2 enzymes are further divided according to their dependence on external divalent cations: PP2A, like PP1, does not require them for activity while PP2B and PP2C are activated by $\mathrm{Ca}^{2+}$ and $\mathrm{Mg}^{2+}$, respectively. Okadaic acid and calyculin A are considered as potent inhibitors of PP1 and PP2A but are not effective with PP2B and PP2C. PP1 and PP2A sequences are highly conserved among eukaryotes and are about 50\% identical (Cohen, 1989; Luan, 2003). The crystal structure shows that some intrinsic metal ions are important for the catalytic reaction such as $\mathrm{Mn}^{2+}$ for PP1 (Egloff et al., 1995).

More than $90 \%$ of protein Ser/Thr phosphatase activity in eukaryotic cells is contributed by PP2A and PP1 enzymes, so they are considered as main regulators of a variety of important cellular processes in yeast and other eukaryotes (Ceulemans and Bollen, 2004; Castermans et al., 2012). PP1s can be considered as a "green" enzyme because it promotes the rational use of energy, a reversal of the cell to a basal and/or energy-conserving state and the recycling of protein factors. When nutrients are abundant PP1s promote the storage of energy in the form of glycogen. PP1s also play a role in the recycling of transcription and splicing factors and the return to basal patterns of protein synthesis; moreover, it has a main role in the recovery from stress but promotes apoptosis when cells cannot be repaired. In addition, PP1 downregulates ion pumps and transporters in different tissues and finally, stimulate exit from mitosis, modulate actin organization and keep cells in the G1or G2 phases of the cell cycle. Finally, in yeast PP1s modulate sporulation and glucose repression (Santangelo, 2006; Stark, 1996 and 2004).

In this respect there are two yeast protein phosphatases that may participate in the regulation of Pma1: the major PP1 Glc7 has been connected with ion homeostasis (Williams-Hart et al., 2002), and the PP2A Sit4 controls yeast growth in a similar way 
that Pma1, promoting progression through the START or restriction point of the G1 phase of the cell division cycle (Cid et al., 1987; Sutton et al., 1991; Johnson and Skotheim, 2013; Dechant et al., 2014).

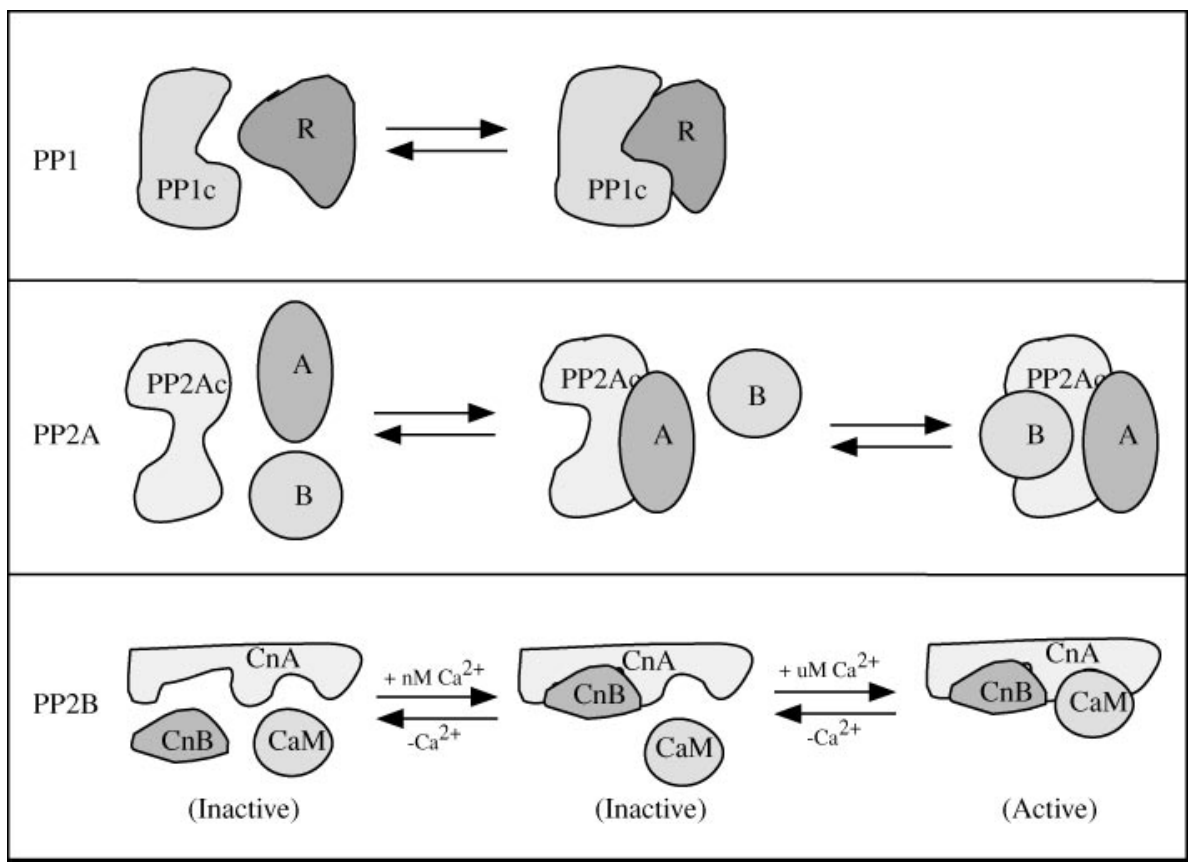

Figure 17. Subunit composition and regulation of PPP family enzymes. PP1 holoenzymes are heterodimers composed of catalytic PP1c and regulatory R subunit. PP2A holoenzymes exist in either heterodimer or heterotrimer form the $\mathrm{C}$-subunit (PP2Ac), and a scaffolding protein, the A subunit. The substrate specificity of PP2A as well as its intracellular localization are defined by an array of distinct groups of B-type regulatory subunits that bind to the AC dimeric core to form a variety of heterotrimeric complexes (Mumby and Walter, 1993). PP2B is often present in a heterodimer form with low activity (catalytic $\mathrm{CnA}$ and regulatory $\mathrm{CnB}$ ) under "resting" levels of calcium. Elevated levels of calcium recruit calmodulin (CaM) into the heterodimer to form highly active trimeric enzymes (Luan, 2003).

\section{Glc7 protein phosphatase}

In yeast, Glc7 is a Ser/Thr PP1 that was first discovered upon examination of glycogen synthase activity in a collection of glycogen-deficient mutants, glc1-glc 8 , where the glc7 mutant strain had the greatest effect. Upon cloning and sequencing it was found that GLC7 encodes a major PP1 enzyme and the decreased protein phosphatase activity in the $g l c 7$ strain was partly restored by transformation with a plasmid carrying the GLC7 gene (Feng et al., 1991). Glycogen synthase is activated by dephosphorylation (Rothman-Denes and Cabib, 1971) and decreased Glc7 activity impairs the activation of glycogen synthase. The GLC7 gene has 1,464 bp with a 525-bp intron after codon 59. There is a single copy of GLC7 in $S$. cerevisiae, its mRNA length is 1.4-kilobase and it increases 4-fold at the end of exponential growth, suggesting that 
activation of glycogen synthase is mediated by increased expression of PP1 as cells reach stationary phase (Feng et al., 1991). GLC7 deletion is lethal yet the essential function is not the regulation of glycogen synthase because disruptions in both known genes encoding this enzyme still produce a viable mutant. More experiments are required to identify targets of the Glc7 phosphatase in S. cerevisiae .

Glc7 has an important role in regulating the expression of amino acid biosynthetic genes in yeast cells, through dephosphorylation of eIF-2 $\alpha$ (see Figure 15). In $S$. cerevisiae, amino acid starvation, or a defective aminoacyl-tRNA synthetase, leads to increased transcription of more than 30 genes encoding amino acid biosynthetic enzymes, in a mechanism known as "general amino acid control" or "general control of nitrogen metabolism" (GCN). The immediate effector of the general control response is the Gcn4 protein, a transcriptional activator that binds upstream of all the amino acids biosynthetic genes that are subject to the general control. Expression of Gen 4 itself is regulated by amino acid availability; on amino acid starvation Gen2 stimulates Gen4 expression by phosphorylating eIF-2 $\alpha$ and increasing translation of its mRNA (Hinnebusch, 2005).

Some important regulatory subunits of Glc7 and their functions (between brackets) are: Gip1 (sporulation), Reg1 (glucose repression), Gac1 and Pig1 (glycogen metabolism), Scd5 (actin organization) and Reg2 and Sds22 (cell cycle progression) (Santangelo, 2006). The glycogen accumulation defect of $g l c 7-1$ is due at least in part to the inability of the mutant protein phosphatase to interact with its regulatory subunit Gac1 (Stuart et al., 1994). A short motif present in most known regulatory subunits is very important in the interaction with a hydrophobic groove in PP1 (Egloff et al., 1997). The multiple regulatory subunits compete for Glc7 binding in vivo and almost all of them interact with more than one site on the PP1 surface (Wu and Tatchell, 2001). The Glc7 localization pattern dynamically changes throughout the yeast cell cycle due to the effect of the regulatory subunits (Bloecher and Tatchell, 2000). 


\section{Sit4 protein phosphatase}

Yeast has two PP2A catalytic subunits, Pph21and Pph22 and three PP2A-like catalytic subunits: Sit4, Pph3 and Ppg1. PP2As are involved in a lot of cellular processes, including signal transduction, metabolism, cell cycle progression, gene expression, and protein translation (Stark, 1996 and 2004; Castermans et al., 2012). Sit4 promotes progression through G1, via regulation of G1 cyclin production (Sutton et al., 1991). The regulatory subunits of Sit4 include several members of the SAP family (Luke et al., 1996) and a novel regulatory subunit termed Tap42 in yeast (Di Como and Arndt, 1996). This regulatory subunit interacts with Sit4 when TORC1 is active and it disassociates from the phosphatase when TORC1 is inhibited (Di Como and Arndt, 1996) (see Figure 13). The interaction of Sit4 with Tap42 is required for the function of Sit4 (Wang et al., 2003). 
OBJECTIVES 



\section{OBJECTIVES}

Taking in consideration the background information presented at the introduction, the objectives of the present thesis are as follows:

1- Determine if Glc7, the major PP1 protein phosphatase of yeast and also implicated in ion homeostasis, has a role in the activation of yeast plasma membrane $\mathrm{H}^{+}$ATPase (Pma1) by glucose

2- Determine if Sit4, a PP2A protein phosphatase implicated in yeast growth, has a role in the activation of Pmal by glucose

3- Investigate the participation of the growth-promoting protein kinase TORC1 in the activation of Pmal by glucose 

MATERIALS AND METHODS 

MATERIALS AND METHODS

\section{Materials}

\subsection{Strains and culture conditions of bacteria}

Strain DH5 $\alpha$ of Escherichia coli, E. coli, was used for the isolation and propagation of plasmids. Standard methods were used for bacterial culture and manipulation (Sambrook and Russell, 2001). Cells were grown at $37^{\circ} \mathrm{C}$ in LB (Luria Bertani) medium ( $0.5 \%$ yeast extract, $1 \%$ tryptone, $1 \% \mathrm{NaCl}$ adjusted to $\mathrm{pH} 7$ with $\mathrm{NaOH}$ ). If solid medium was required $1.5 \%$ agar was added. For plasmid selection, $50 \mu \mathrm{g} / \mathrm{ml}$ ampicillin was added and if applicable: X-Gal (isopropyl $\beta$-D-1-thiogalactopyranoside) and IPTG (isopropyl $\beta$ D-1-thiogalactopyranoside) were also added to a final concentration of $10 \mu \mathrm{g} / \mathrm{ml}$.

\subsection{Strains and culture conditions of yeast}

Strains of Saccharomyces cerevisiae used in this work are represented in Table 1.

\begin{tabular}{|c|c|c|}
\hline $\begin{array}{c}\text { Collection } \\
\text { of R. } \\
\text { Serrano }\end{array}$ & Genotype & Reference \\
\hline \multirow[t]{5}{*}{ RS-58 } & $\begin{array}{l}\text { BWG1-7A (MATa ade1-100 ura3-52 leu2-3112 } \\
\text { his4-519) }\end{array}$ & $\begin{array}{l}\text { Guarente et al., } \\
1982\end{array}$ \\
\hline & RS-58 /YEp24 & G. Hueso \\
\hline & RS-58/YEp24-GLC7' & G. Hueso \\
\hline & RS-58/YEp352 & This study \\
\hline & RS-58 /YEp352-GLC7' & This study \\
\hline \multirow[t]{5}{*}{ RS-132 } & RS-58 transformed with $L E U 2$ fragment & R. Serrano \\
\hline & RS-132 / pUN50 & This study \\
\hline & RS-132 / pUN50-GLC7' & This study \\
\hline & RS-132 / YEp352 & This study \\
\hline & RS-132 / YEp352-GLC7' & This study \\
\hline RS-259 & $\begin{array}{l}\text { BY4741 (MATa ura3- } \Delta 0 \text { leu2- } \Delta 0 \text { his3- } \Delta 1 \text { meth15- } \\
\Delta 0) \text { (derived from S288C) }\end{array}$ & Euroscarf \\
\hline RS-119 & RS-259 / PCM262 & G. Hueso \\
\hline RS-120 & RS-259 / PCM262-GLC7'-HA3-His6 & G. Hueso \\
\hline RS-121 & RS-259 / PCM262-GLC7' & G. Hueso \\
\hline
\end{tabular}


MATERIALS AND METHODS

\begin{tabular}{|c|c|c|}
\hline & RS-259 / pYEX 4T-1 & This study \\
\hline & RS-259 / pYEX 4T-1-SIT4 & This study \\
\hline RS-1373 & KT1112 (MATa ura3-52 leu2 his3) & Stuart et al., 1994 \\
\hline RS-1376 & RS-1373 glc7-109 & $\begin{array}{l}\text { Williams-Hart et } \\
\text { al., } 2002\end{array}$ \\
\hline RS-1377 & RS-1373 glc7-132 & $\begin{array}{l}\text { Williams-Hart et } \\
\text { al., } 2002\end{array}$ \\
\hline RS-1379 & RS-1373 glc7-1 & Stuart et al., 1994 \\
\hline RS-624 & $\mathrm{BY} 4741 G C N 2^{c}$ & $\begin{array}{l}\text { Menacho-Marquez } \\
\text { et al., } 2007\end{array}$ \\
\hline & BY4741 Sit4A & Euroscarf \\
\hline SH221 & $\begin{array}{l}\text { MATa leu2-3,112 trp1 ura3 rme1 his } 4 \text { HMLa } \\
\text { ade2 his } 3 \text { HIS4 tor }::: \text { HIS3 tor } 2:: A D E 2 / \\
\text { YCplac111::tor2-21 }\end{array}$ & $\begin{array}{l}\text { Helliwell et al., } \\
1998\end{array}$ \\
\hline SH100 & $\begin{array}{l}\text { MATa leu2-3,112 trp1 ura3 rme1 his } 4 \text { HMLa } \\
\text { ade2 tor } 2:: A D E 2 \text { / YCplac111::TOR2 }\end{array}$ & $\begin{array}{l}\text { Helliwell et al., } \\
1998\end{array}$ \\
\hline
\end{tabular}

Yeast cells were cultured and manipulated following standard methods (Sherman, 1991). Temperature was $28^{\circ} \mathrm{C}$ unless otherwise mentioned, with shaking $(180-200 \mathrm{rev} / \mathrm{min})$ in the media described below:

\section{Minimal medium (SD)}

Synthetic Dextrose: $2 \%$ glucose, 0.7\% Yeast Nitrogen Base (YNB) without amino acids, $50 \mathrm{mM}$ MES-Tris $\mathrm{pH} 5.5$. Whenever required, amino acids $(0.10 \mathrm{mg} / \mathrm{ml}$ methionine, 0.10 $\mathrm{mg} / \mathrm{ml}$ leucine, $0.03 \mathrm{mg} / \mathrm{ml}$ histidine $)$ and nitrogen bases $(0.03 \mathrm{mg} / \mathrm{ml}$ adenine, $0.03 \mathrm{mg} / \mathrm{ml}$ uracil) were added.

Minimal complete medium (SCD)

Synthetic Complete Dextrose: $2 \%$ glucose, $0.7 \%$ YNB, 50 mM MES-Tris $\mathrm{pH}$ 6. This medium contains all amino acids and nitrogen bases except when there is a need for plasmid selection, then some of them such as uracil or leucine were removed.

$\underline{\text { YPD }}$

Rich (complete) medium: 1\% Yeast extract, 2\% Bacto Peptone, 2\% glucose. Agar 2\% is added whenever solid media was required. 


\subsection{Plasmids}

All plasmids used in this study are listed in Table 2:

\begin{tabular}{|c|c|c|}
\hline Plasmid & Description & Reference \\
\hline YEp24 & $\mathrm{Amp}^{\mathrm{r}}, 2 \mu, U R A 3$ & Botstein et al., 1979 \\
\hline YEp352 & $\mathrm{Amp}^{\mathrm{r}}, 2 \mu, U R A 3$ & Hill et al., 1986 \\
\hline pUN50 & $\mathrm{Amp}^{\mathrm{r}}, \mathrm{CEN}, U R A 3$ & $\begin{array}{c}\text { Elledge and Davis, } \\
1988\end{array}$ \\
\hline pCM262 & $\mathrm{Amp}^{\mathrm{r}}, 2 \mu, U R A 3$ & $\begin{array}{c}\text { Ariño and Herrero, } \\
2003\end{array}$ \\
\hline pYEX 4T-1 & $A m p^{r}$ & $\begin{array}{c}\text { Amrad Biotech } \\
\text { (Ward et al., 1994) }\end{array}$ \\
\hline pGEX-3X & $A m p^{r}$ & $\begin{array}{c}\text { Smith and Johnson, } \\
1988\end{array}$ \\
\hline pCM262-GLC7'-HA3-His6 & & $\begin{array}{l}\text { G. Hueso (see } \\
\text { methods) }\end{array}$ \\
\hline pCM262-GLC7' & & $\begin{array}{l}\text { G. Hueso (see } \\
\text { methods) }\end{array}$ \\
\hline pGEX-3X-GLC7 & & $\begin{array}{c}\text { Rodriguez-Hernandez } \\
\text { et al., } 2012\end{array}$ \\
\hline YEp24-GLC7' & & Hueso et al., 2012 \\
\hline YEp352-GLC7' & & This study \\
\hline pUN50- GLC7' & & This study \\
\hline pYEX 4T-1-SIT4 & & This study \\
\hline
\end{tabular}

The restriction maps of several plasmids utilized in the present study are shown in Figures (18-19-21-22) 


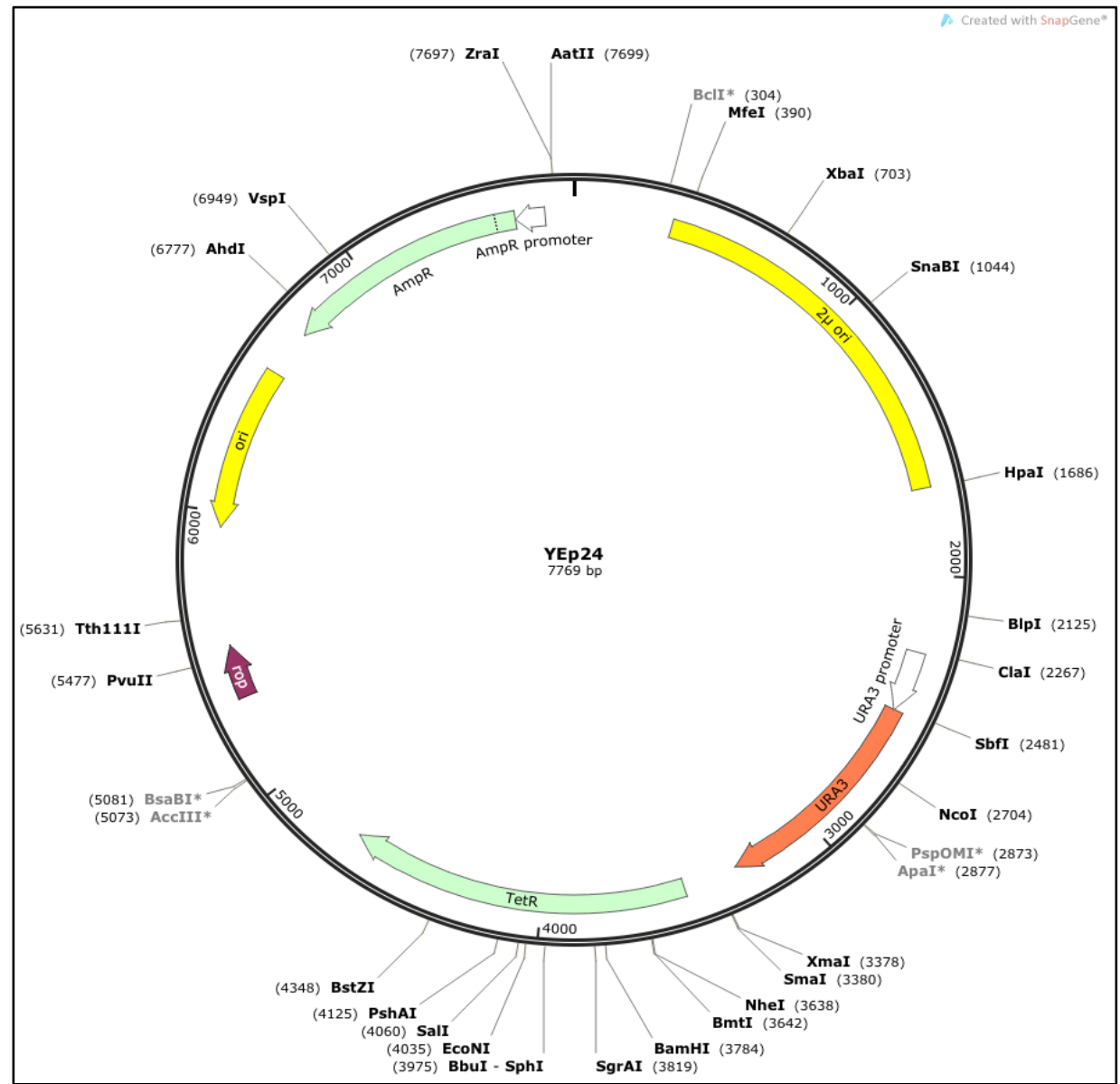

Figure 18. Restriction map of YEp24, an episomal ( $2 \mu$ origin, high-copy number) vector with a URA3 marker for selection in yeast. Confers ampicillin resistance for selection in E. coli. (Botstein et al., 1979). http://www.snapgene.com/resources/plasmid_files/yeast_plasmids/YEp24/ 


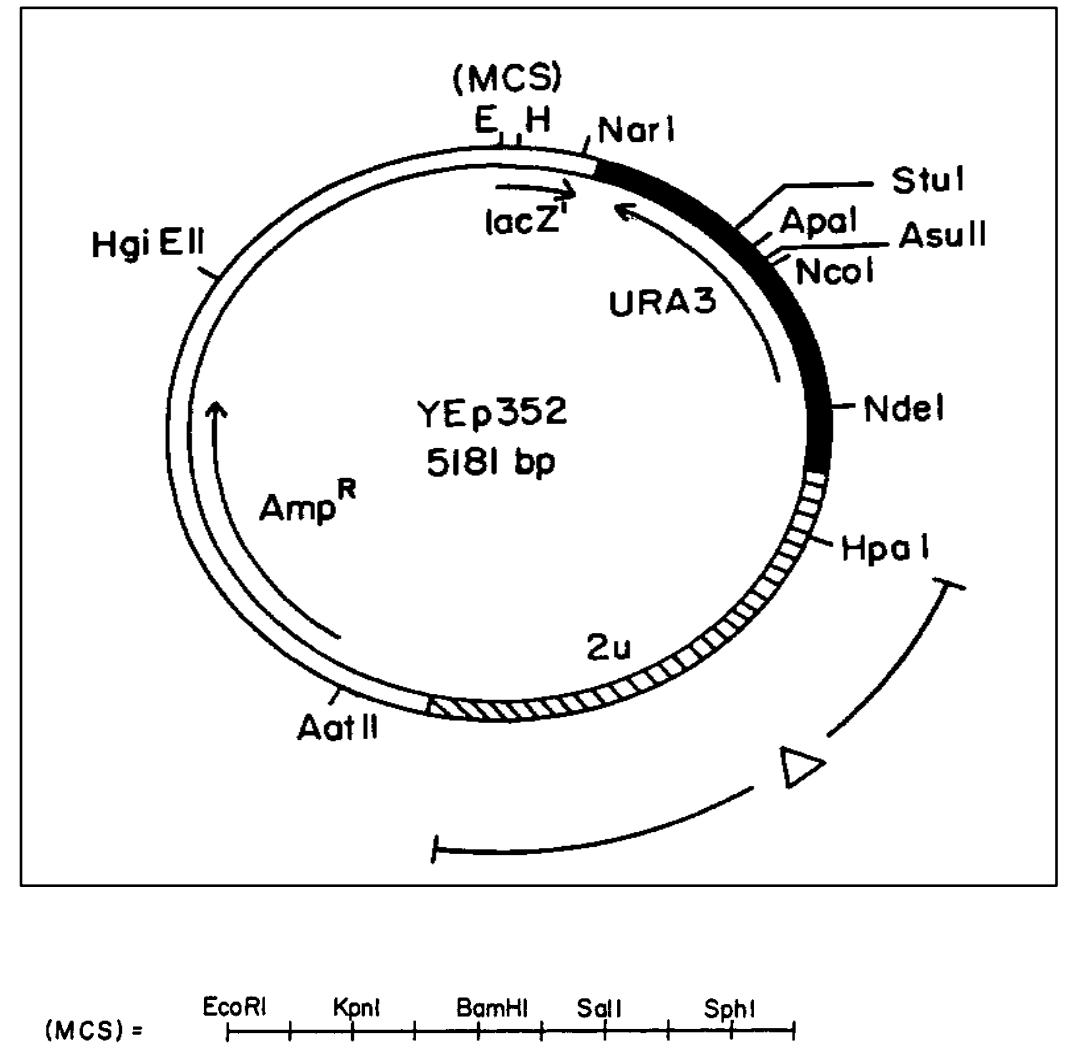

Figure 19. Restriction map of YEp352. An episomal ( $2 \mu$ origin, high-copy number) cloning vector with a URA3 marker for selection in yeast. Contains the $\beta$-lactamase gene that confers ampicillin resistance for selection in E. coli (Hill et al. 1986).

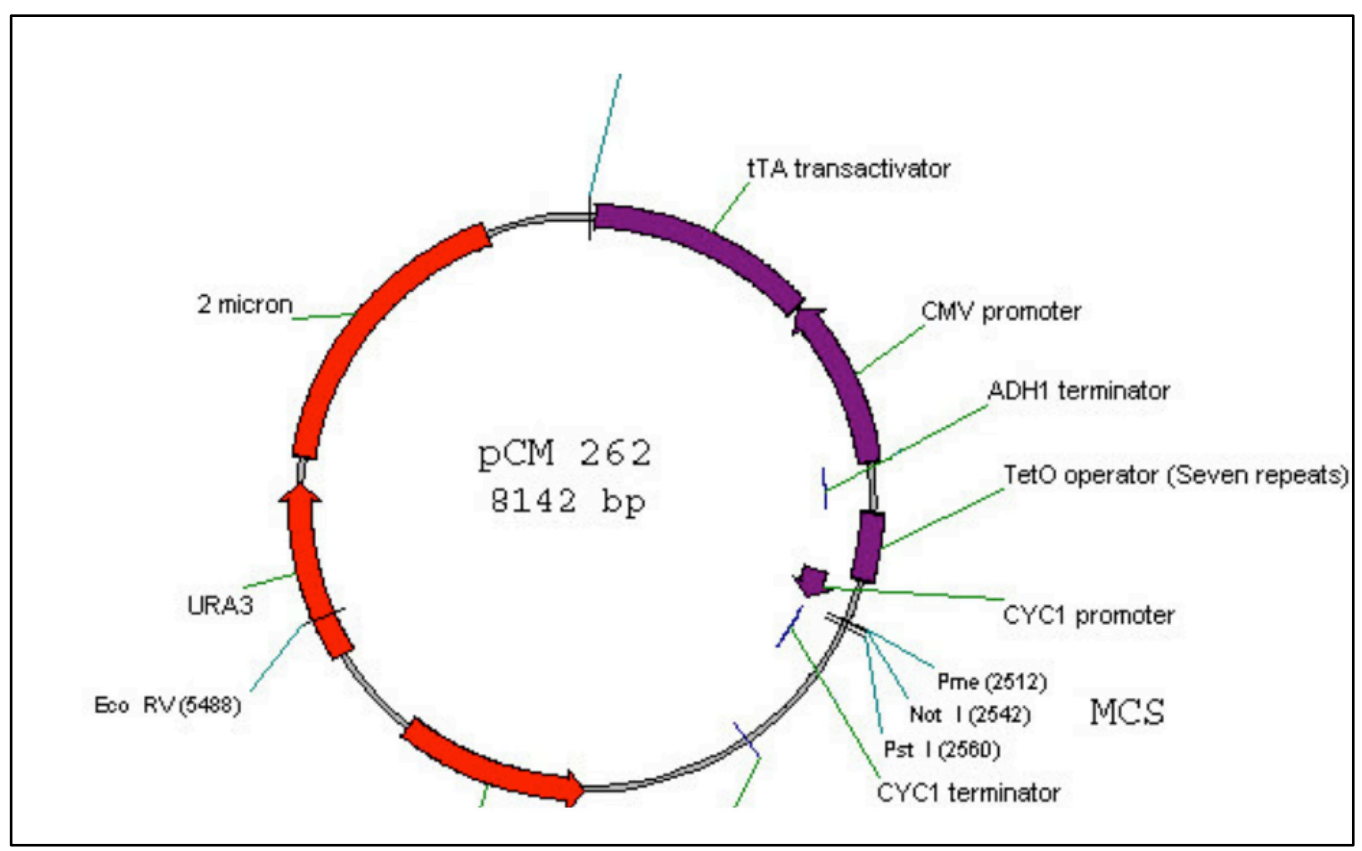

Figure 20. Restriction map of pCM262, an episomal ( $2 \mu$ origin, high-copy number) plasmid used for expression and isolation of recombinant proteins in yeast. It contains a cloning site that allows cloning a gene in reading frame with six histidine and three copies of epitope HA under control of a doxycycline regulated promoter (Ariño and Herrero, 2003). 


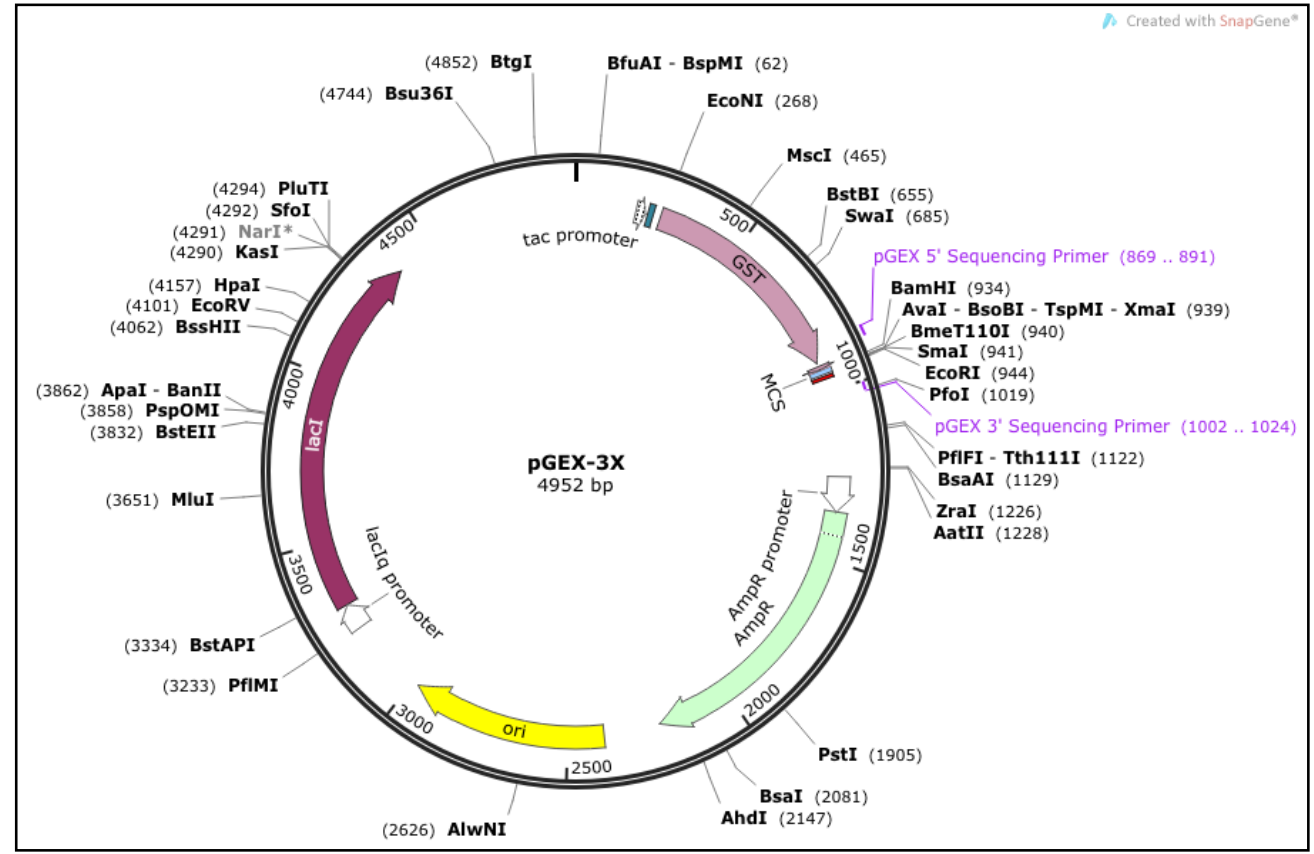

Figure 21. pGEX-3X is a GST-fusion vector for expression in E. coli under control of tac promoter and with ampicillin resistance for selection (Smith and Johnson, 1988).

http://www.snapgene.com/resources/plasmid_files/pgex_vectors_\%28ge_healthcare\%29/pG EX-3X/

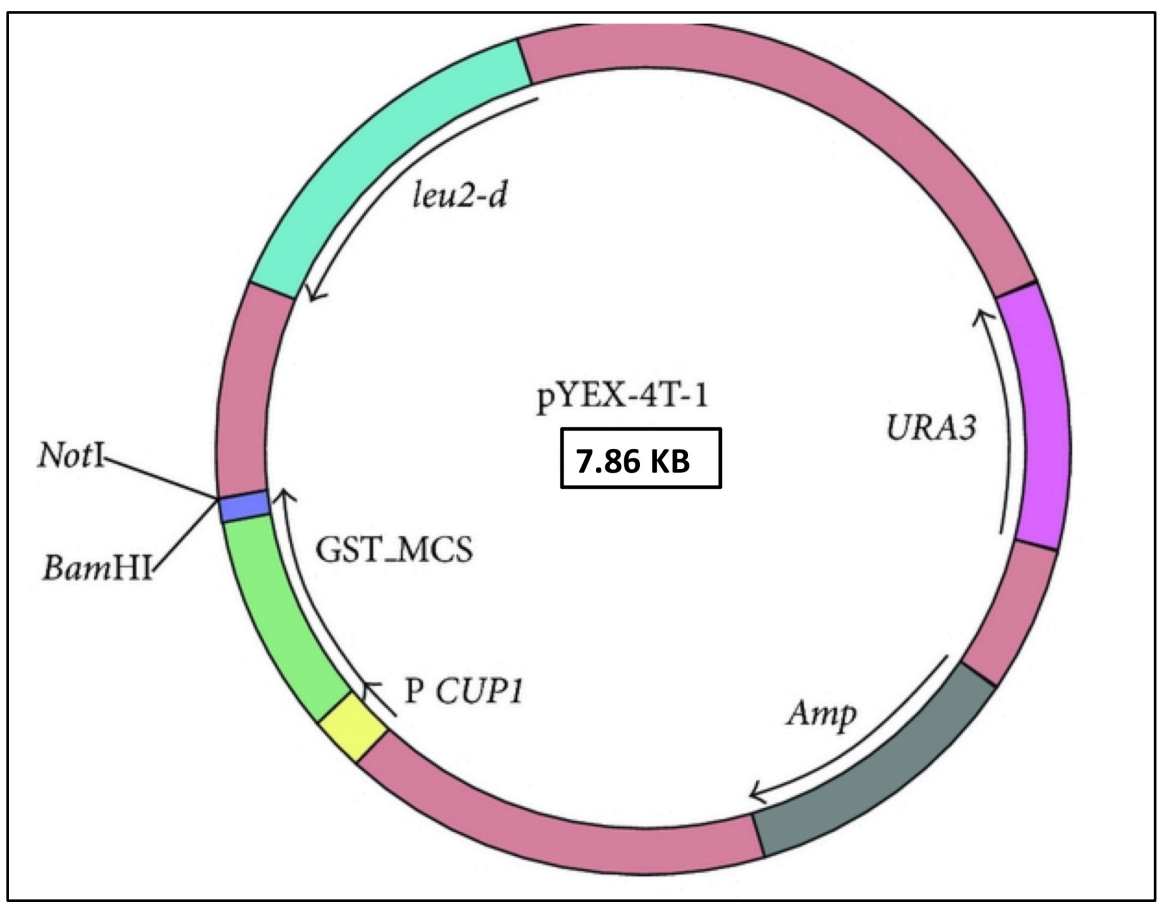

Figure 22. pYEX 4T-1 is a GST-fusion vector for protein expression in yeast under control of the $\mathrm{Cu}^{2+}$-inducible $C U P 1$ promoter. The GST coding region encodes a protein of approximately 27.5 $\mathrm{kDa}$. It includes the E. coli $\mathrm{Amp}^{\mathrm{r}}$ gene and the yeast selectable marker URA3. It is maintained at high copy number by leu2-d (a LEU2 gene with a truncated, inefficient promoter) during growth selection on media lacking leucine (Ward et al., 1994).

http://apps2.bvl.bund.de/vectorwww/protected $/$ main/vector.do? $\mathrm{method}=$ detail\& theId $=438 \& d$ $-49653-p=9$ 
2. Isolation of yeast membranes and "in vitro" determination of Pma1 activity (Modified from Serrano, 1983 and 1988)

\subsection{Isolation of yeast membranes}

\subsubsection{Culture preparation}

A single yeast colony was inoculated in $2 \mathrm{ml}$ medium and grown to stationary phase at $30^{\circ} \mathrm{C}$ with shaking at $200 \mathrm{rev} / \mathrm{min}$. This culture was stored in the cold and used as inoculum. A flask of $250 \mathrm{ml}$ with $50 \mathrm{ml}$ medium was inoculated with the saturated culture (50-500 $\mu \mathrm{l})$ and incubated at $30^{\circ} \mathrm{C}$ with shaking at $200 \mathrm{rev} / \mathrm{min}$ to reach exponential phase or stationary phase as specified in each experiment.

\subsubsection{Membrane isolation}

The $50 \mathrm{ml}$ culture (50-100 $\mathrm{mg}$ FW cells) was centrifuged during $5 \mathrm{~min}$ at 3,000 $\mathrm{rev} / \mathrm{min}$ in a Nahita 2655 centrifuge and resuspended in $25 \mathrm{ml}$ sterile water, centrifuged again and finally resuspended in $2 \mathrm{ml}$ sterile water. The concentrated and washed cells were incubated for $15 \mathrm{~min}$ at $30^{\circ} \mathrm{C}$ and $1 \mathrm{ml}$ was taken and frozen in liquid nitrogen (Glucose Starved or GS sample). Then 2\% final glucose was added to the other $1 \mathrm{ml}$ which was then incubated for $10 \mathrm{~min}$ at $30^{\circ} \mathrm{C}$ and frozen in liquid nitrogen (Glucose Fermenting or GF sample). For cell homogenization, $200 \mu \mathrm{L}$ of protein extraction buffer $5 \mathrm{x}(0.25 \mathrm{M}$ Tris- $\mathrm{HCl} \mathrm{pH}$ 8, $0.3 \mathrm{M} \mathrm{KCl}, 25 \mathrm{mM}$ EDTA, $10 \mathrm{mM}$ DTT and protease inhibitor cocktail from Roche) was added to $1 \mathrm{ml}$ cell suspension, $1.5-2 \mathrm{ml}$ of glass beads ( $0.5 \mathrm{~mm}$ diameter) were added and vortexed for six cycles of $30 \mathrm{sec}$ vortex and $30 \mathrm{sec}$ incubation in ice. Cell debris was removed by centrifugation of the homogenate $2 \mathrm{~min}$ at $3,000 \mathrm{rev} / \mathrm{min}$ at $4^{\circ} \mathrm{C}$ in an Eppendorf R5426 centrifuge and a membrane fraction was obtained from the supernatant by centrifugation $20 \mathrm{~min}$ at $13,000 \mathrm{rev} / \mathrm{min}$ and $4{ }^{\circ} \mathrm{C}$ in the same refrigerated centrifuge as before. The pellet was resuspended with a Dounce-type manual homogenizer in $100 \mu \mathrm{L}$ of cold GTED 20 solution (20\% glycerol, $10 \mathrm{mM}$ Tris $\mathrm{HCl} \mathrm{pH} 7.6,1 \mathrm{mM}$ EDTA and $1 \mathrm{mM} \mathrm{DTT}$ ) and diluted with $900 \mu \mathrm{L}$ cold distilled water to lyse the membranes and wash free of inorganic phosphate. After a final centrifugation of $30 \mathrm{~min}$ at 13,000 rev/min at $4^{\circ} \mathrm{C}$ membranes were resuspended in $150 \mu \mathrm{L}$ cold GTED 20, divided into several micro tubes and kept at $-80^{\circ} \mathrm{C}$. 


\subsection{Protein determination by the method of Bradford (1976)}

In a microtiter plate, duplicates of $0,2,4,6,8,10 \mu \mathrm{L}$ of the standard bovine- $\gamma$ globulin $1 \mu \mathrm{g} / \mu \mathrm{L}$ were placed in the wells. Triplicates of the membrane preparations (2-10 $\mu \mathrm{L}$ ) were also placed. Then $150 \mu \mathrm{L}$ of the freshly diluted $5 \mathrm{X}$ BioRad Protein assay reagent (BioRad) was added to each well, gently mixed and left 25 minutes for the blue color to stabilize. Finally, the absorbance was measured at $595 \mathrm{~nm}$ using an iMark ${ }^{\mathrm{TM}}$ Microplate Absorbance Reader (BioRad). Protein concentration in the membrane preparations was calculated from the calibration curve.

\subsection{Determination of Pma1 activity}

Triplicates of 3-10 $\mu$ g protein in less than $5 \mu \mathrm{L}$ of yeast membranes were placed in two rows of wells of microtiter plates. The reaction was started in one row by adding preheated $\left(10 \mathrm{~min}, 30^{\circ} \mathrm{C}\right) 65 \mu \mathrm{L}$ of ATPase reaction buffer (50 mM MES-Tris $\mathrm{pH} 5.7,5 \mathrm{mM} \mathrm{MgSO}_{4}$, $50 \mathrm{mM} \mathrm{KNO}_{3}, 5 \mathrm{mM}$ sodium azide, $0.3 \mathrm{mM}$ ammonium molybdate, $2 \mathrm{mM}$ ATP, the latter added at the moment of use). To the other row, the same preheated buffer but containing $0.15 \mathrm{mM}$ sodium orthovanadate $\left(\mathrm{Na}_{3} \mathrm{VO}_{4}\right)$ was added. The plate was incubated (30 min, $\left.30^{\circ} \mathrm{C}\right)$. The reaction with terminated by adding $130 \mu \mathrm{L}$ of phosphate reagent $\left(2 \% \mathrm{H}_{2} \mathrm{SO} 4\right.$, $0.5 \%$ ammonium molybdate, $0.5 \%$ SDS, $1 \%$ ascorbic acid, the latter added at the moment of use). As standard, duplicates were prepared with $0,2,4,6,8,10$ and $20 \mu \mathrm{L}$ of $5 \mathrm{mM}$ inorganic phosphate (Pi) to which ATPase reaction buffer was added followed by phosphate reagent in the same manner as the tested samples. The microplate was left for 25 minutes for the blue color to stabilize and then the absorbance was measured at $750 \mathrm{~nm}$ using an iMark $^{\mathrm{TM}}$ Microplate Absorbance Reader (BioRad). Pi concentration was calculated from the calibration curve with standard Pi. Pmal activity was defined as the vanadate-sensitive component of the total ATPase activity and it corresponded to 80-90\% of the latter.

3. Assay for Pma1 activity in membrane preparations of cells treated with PP1 inhibitors

\subsection{Treatment of yeast cells with the phosphatase inhibitor}

S. cerevisiae strain RS-58 was used for this experiment and it was grown in YPD medium to stationary phase. Cells were washed, concentrated and preincubated in $\mathrm{H}_{2} \mathrm{O}$ as 
described above and then protein phosphatase 1 inhibitors were added as described below. The stock solutions were: okadaic acid $(\mathrm{MW}=805) 0.1 \mathrm{mM}$ in methanol, calyculin A $(\mathrm{MW}=805) 0.2 \mathrm{mM}$ in methanol and tungstate $(\mathrm{MW}=330) 1 \mathrm{M}$ in water. Harvested and washed cells were divided into 4 portions, $1 \mathrm{ml}$ each. Two portions did not receive any inhibitor, and glucose was only added to one of them and processed as described above. To the other two portions, one inhibitor was added (final concentration $0.5 \mu \mathrm{M}$ okadaic acid, 1 $\mu \mathrm{M}$ calyculin $\mathrm{A}$ and $10 \mathrm{mM}$ tungstate) together with glucose to one portion and without glucose to the other one. Then all samples were incubated for $20 \mathrm{~min}$ at $30^{\circ} \mathrm{C}$ and Pma1 activity determined as described above. Okadaic acid was obtained from Kamiya Biomedical Company (Seattle, USA), calyculin A from LC Laboratories (Woburn, MA, USA) and tungstate from Fisher Scientific (Madrid, Spain).

\subsection{Growth inhibition test}

To detect the effect on yeast growth of every phosphatase inhibitor, an stationary phase culture of RS-58 was used to inoculate $2 \mathrm{ml}$ of YPD (initial OD of about 0.1 ) and okadaic acid $(0,0.1$ and $0.5 \mu \mathrm{M}$, calyculin $\mathrm{A}(0,2 \mu \mathrm{M})$ or methanol (as a control) were added. All tubes were incubated ( $\left.24 \mathrm{hrs}, 200 \mathrm{rev} / \mathrm{min}, 30^{\circ} \mathrm{C}\right)$ and $\mathrm{OD}$ was measured at 660 $\mathrm{nm}$.

\section{Assay for yeast tolerance to toxic cations}

Serial dilutions of stationary phase cultures of the specified strain were spotted (about $3 \mu \mathrm{L}$ ) with either a replicator (Sigma) or by micropipetting on a plate of solid medium with the indicated toxic cations (see Goossens et al., 2000). Plates were incubated for 2-3 days at $28^{\circ} \mathrm{C}$.

\section{Purification and manipulation of nucleic acid}

\subsection{Isolation of plasmid DNA from $E$. coli}

A modified small-scale alkaline lysis method (Birnboim, 1983) was employed. 1.5 $\mathrm{ml}$ of overnight culture in LB with amplicillin was pelleted by centrifugation for $1 \mathrm{~min}$ at 13,000 rev/min in an Eppendorf D5425 centrifuge. Pellet was resuspended in $200 \mu \mathrm{L}$ of GTE buffer (50 mM glucose, 25 mM Tris, pH 8, 10 mM EDTA, pH 8). $300 \mu \mathrm{L}$ of freshly prepared solution with $0.2 \mathrm{~N} \mathrm{NaOH}$ and $1 \%$ SDS was added, mixed by tube inversion and left on ice for $5 \mathrm{~min}$. Then $300 \mu \mathrm{L}$ of $3.0 \mathrm{M}$ potassium acetate taken to $\mathrm{pH} 4.8$ with acetic acid was added, mixed by inversion and left on ice for $5 \mathrm{~min}$. The tube was centrifuged for 


\section{MATERIALS AND METHODS}

10 min as before and the supernatant transferred to a new tube. RNAse A was added to 20 $\mu \mathrm{g} / \mathrm{ml}$ and incubated $20 \mathrm{~min}$ at $37^{\circ} \mathrm{C}$. A chloroform extraction was made using 2 volumes of organic solvent, mixed by shaking then spinned for $1 \mathrm{~min}$ in top speed and the aqueous phase saved to a new tube. DNA was precipitated by adding an equal volume of isopropanol, incubation in ice for 1 hour or more and centrifuged $10 \mathrm{~min}$ at top speed. The pellet was washed with $500 \mu \mathrm{L}$ of $70 \%$ etanol, which was then poured after centrifugation for 1 min. Finally the pellet was dried in a vacuum centrifuge and resuspend in $25 \mu \mathrm{L}$ TE buffer.

\subsection{Isolation of yeast genomic DNA}

A modified small-scale protoplast method (Winston et al., 1983) was employed. Yeast was inoculated in $5 \mathrm{ml} \mathrm{YPD}$ and incubated till reaching late exponential phase (OD at $660 \mathrm{~nm}=1-2$ measured in a DINKO SP8001 spectrophotometer, Barcelona, Spain). Cells were harvested by centrifugation $5 \mathrm{~min}$ at 3,000 rev/min (Eppendorf D5425 centrifuge), resuspended in $1 \mathrm{ml}$ SoE solution (0.9 M sorbitol, 0.1 M EDTA, pH 8 with $\mathrm{NaOH}$ ), centrifuged again and resuspended in $200 \mu \mathrm{L}$ SoE to which $10 \mu \mathrm{L}$ of DTT $0.5 \mathrm{M}$ and $25 \mu \mathrm{L} \mathrm{1 \%}$ zymolyase $100 \mathrm{~T}$ (Miles) were added, mixed and incubated $30 \mathrm{~min}$ at $37^{\circ} \mathrm{C}$ to make protoplasts. Then $500 \mu \mathrm{L}$ of TCES (0.2 M Tris, $0.2 \mathrm{M} \mathrm{NaCl}, 50 \mathrm{mM}$ EDTA, $2 \%$ SDS adjusted to $\mathrm{pH} 8$ with $\mathrm{HCl}$ ), $2 \mu \mathrm{L} \beta$-mercaptoethanol and $4 \mu \mathrm{L}$ of $2 \%$ protease $\mathrm{K}$ were added and incubated $30 \mathrm{~min}$ at $65^{\circ} \mathrm{C}$. Protoplasts were extracted with $0.7 \mathrm{ml} \mathrm{PCI}$ (phenol: chloroform: isoamyl alcohol, 25: 24: 1) followed by centrifugation $5 \mathrm{~min}$ at $11000 \mathrm{rev} / \mathrm{min}$. DNA was precipitated from the aqueous phase by adding an equal volume of isopropanol and incubation in ice for $15 \mathrm{~min}$ or more. The pellet was washed with $500 \mu \mathrm{L} 70 \%$ etanol which was then poured after centrifugation. The pellet was resuspended in $400 \mu \mathrm{L} \mathrm{H}_{2} \mathrm{O}$ with $5 \mu \mathrm{L}$ RNAase $1 \%$ and incubated $30 \mathrm{~min}$ at $37^{\circ} \mathrm{C}$. Then extraction was made with an equal volume of PCI and centrifugation to take the aqueous phase. DNA was precipitated by adding $1 \mathrm{ml}$ etanol:ammonium acetate 6:1 (6 volumes of absolute etanol+ 1 volume ammonium acetate $7.5 \mathrm{M}$ ) and incubation in ice for $15 \mathrm{~min}$ or more. After centrifugation during $15 \mathrm{~min}$ at 13,000 rev/min, the pellet was washed with $1 \mathrm{ml} \mathrm{70 \%}$ ethanol which was then poured after centrifugation. The pellet was dried by leaving the tube open in RT for $20 \mathrm{~min}$ and resuspended in $30 \mu \mathrm{L}$ TE by shaking for about $30 \mathrm{~min}$. 


\subsection{DNA electrophoresis}

To detect the integrity of isolated genomic DNA and the result of PCR or restriction endonuclease reactions, we made an electrophoresis of DNA. An agarose gel at $0.7 \%$ was prepared in electrophoresis buffer TBE 0.5X (45 mM Tris-base, $45 \mathrm{mM}$ boric acid, $1 \mathrm{mM}$ EDTA pH 8). The electrophoresis buffer and also the gel buffer contained $0.5 \mu \mathrm{g} / \mathrm{ml}$ ethidium bromide. Before injecting the samples into the wells they were mixed with loading buffer $6 \mathrm{X}$ (0.25\% bromophenol blue, $40 \%$ sucrose, 0.1 M EDTA). Markers used were $1 \mathrm{~KB}$ or $\lambda$ DNA digested with Hind III (Invitrogen). Bands were detected under UV light of $254 \mathrm{~nm}$ wavelength.

To purify DNA fragment from preparative gels a "NucleoSpin DNA purification" kit (Macherey-Nagel) was used.

\subsection{Preparation of RNA from $S$. cerevisiae}

Steps were basically according to (Li et al., 2009).

\subsubsection{Culture preparation}

To detect the expression of GLC7' in strain RS-121 after doxycycline removal, an exponential phase culture of $15 \mathrm{ml}$ was prepared in medium with doxycycline as described above. Cells were harvested by centrifugation ( $1 \mathrm{~min}$ at 13,000 rev/min), washed with water twice and resuspended in the same volume of medium. Then divided into 4 portions of $5 \mathrm{ml}$ and $2 \mu \mathrm{g} / \mathrm{ml}$ doxycycline final concentration was added to two of them. Two tubes with doxycycline and two tubes without were incubated for 1.5-2 h before RNA isolation.

\subsubsection{RNA Isolation}

Cells were harvested by centrifugation ( $1 \mathrm{~min}$ at 13,000 rev/min), resuspended in 100 $\mu \mathrm{L}$ RNA extraction buffer (50 mM tris $\mathrm{pH}$ 6, $10 \mathrm{mM}$ EDTA, 5\% SDS) and incubated (5 $\left.\min , 65^{\circ} \mathrm{C}\right)$. Then $50 \mu \mathrm{L}$ of $\mathrm{K}$ buffer $(\mathrm{KCl} 0.3 \mathrm{M}+10 \mathrm{mM}$ MES -Tris $\mathrm{pH} 6)$ were added to precipitate denatured proteins and SDS, mixed thoroughly and the tube incubated $5 \mathrm{~min}$ in ice. After centrifugation ( $5 \mathrm{~min}, 13,000 \mathrm{rev} / \mathrm{min}$ ) the supernatant was transferred to new microtubes and an equal volume of acidic phenol was added and well mixed for phase partition. To remove any remaining proteins, another centrifugation (5 min, 13,000 $\mathrm{rev} / \mathrm{min}$ ) was made and the upper phase was taken, to which 0.1 volume of $\mathrm{NaAc} 3 \mathrm{M} \mathrm{pH}$ 5.2 and 2.5 volumes absolute ethanol were added followed by incubation (15 $\mathrm{min}$ at $20^{\circ} \mathrm{C}$ ). RNA was precipitated by centrifugation (10 $\left.\mathrm{min}, 13,000 \mathrm{rev} / \mathrm{min}\right)$, the pellet was 
washed with $70 \%$ ethanol which was then removed after centrifugation. The microtube was left open in the air to dry the pellet which was finally resuspended in $20 \mu \mathrm{L}$ RNAasefree water and stored at $-80^{\circ} \mathrm{C}$ till further processing.

\subsection{RNA gel electrophoresis}

To test the integrity of the RNA preparation samples were applied to a $1 \%$ agarose gel prepared in TAE buffer (40 mM Tris-acetic acid pH 8.0 and $1 \mathrm{mM}$ EDTA). The samples and the ladder standard (0.5-10 kb RNA ladder) were prepared with loading buffer $1.25 \mathrm{X}$ [12.5\% MAE 10X (0.2 M MOPS, $50 \mathrm{mM} \mathrm{Na}$ Acetate, $10 \mathrm{mM}$ EDTA, pH 7), 55\% formamide, $20 \%$ formaldehyde, $8 \%$ glycerol, $0.05 \%$ bromophenol blue, $0.001 \%$ ethidium bromide] and incubated $\left(10 \mathrm{~min}, 56^{\circ} \mathrm{C}\right)$ before loading into the wells. The electrophoresis was run in TAE buffer.

\subsection{Synthesis of cDNA}

The extracted RNA was purified with a NucleoSpin RNA kit and checked again for integrity. This purification also eliminated contaminating DNA in the RNA samples by a treatment with DNAase when the RNA is bound to the silica gel plate

The RNA eluted from the silica gel plate $(20 \mu \mathrm{L})$ was mixed with $6 \mu \mathrm{L}$ of $5 \mathrm{X}$ Reaction Mix and $2 \mu \mathrm{L}$ of Maxima Enzyme Mix (Thermo Scientific) in a final reaction volume of $30 \mu \mathrm{L}$ and incubated in two steps, first for $10 \mathrm{~min}$ at $25^{\circ} \mathrm{C}$ then for $30 \mathrm{~min}$ at $50^{\circ} \mathrm{C}$. Finally the reaction was inactivated by heating at $85^{\circ} \mathrm{C}$ for 5 minutes.

\subsection{PCR}

For PCR or semi-quantitative RT-PCR, the following PCR reaction mixture was made:

- $0.5 \mu \mathrm{L}$ cDNA (see above) or 10 ng DNA template

- $2 \mu \mathrm{L}$ PCR buffer 10X (with $1.5 \mathrm{mM} \mathrm{MgCl} 2$ )

- $2 \mu \mathrm{L}$ dNTPs $10 \mathrm{mM}$

- $0.5 \mu \mathrm{L}$ Forward primer $20 \mu \mathrm{M}$

- $0.5 \mu \mathrm{L}$ Reverse primer $20 \mu \mathrm{M}$

- $0.5 \mu \mathrm{L}$ polymerase (Taq) $1 \mathrm{U} / \mu \mathrm{L}$

- Complete to $20 \mu \mathrm{L}$ with sterile miliQ $\mathrm{H}_{2} \mathrm{O}$

For reactions that required DNA amplification of high fidelity, the enzyme Phusion High-Fidelity DNA polymerase (New England Biolabs) was applied with all the conditions and PCR program mentioned in the company booklet. 
All the PCR reactions were made in Mastercycler personal (Eppendorf), those with Taq received the following PCR program:

- 1 cycle of initial denaturation at $95^{\circ} \mathrm{C}$ for $5 \mathrm{~min}$

- 25 cycles, for semi-quantitative RT-PCR, or 30-35cycles, for normal PCR, of:

- Denaturation at $95^{\circ} \mathrm{C}$ for $30 \mathrm{sec}$

- Hybridization for $30 \mathrm{sec}$ at an annealing temperature 2 degrees lower than the $\mathrm{Tm}$ of the primers

- Extension at $72^{\circ} \mathrm{C}$ for $1 \mathrm{~min}$ for $1 \mathrm{~KB}$.

- 1 cycle of final extension at $72^{\circ} \mathrm{C}$ for $3-5 \mathrm{~min}$

- Hold at $4^{\circ} \mathrm{C}$

Table 3: Primers used for PCR reactions. See Figure 23 for explanation.

\begin{tabular}{|c|c|c|}
\hline Name & Sequence (restriction sites underlined) & $\begin{array}{l}\text { Product size } \\
(\mathrm{kb})\end{array}$ \\
\hline $\begin{array}{l}G L C 7^{\prime} c \mathrm{~F} \\
G L C 7^{\prime} \mathrm{C} \mathrm{R}\end{array}$ & $\begin{array}{l}\text { CCGGAATTCATTTCTTGTGAGCACAACCTC } \\
\text { CGCGGATCCTTATGGATCTGACCACAATAAGTCA }\end{array}$ & 1.6 \\
\hline $\begin{array}{l}G L C 7^{\prime} d, \text { e } \mathrm{F} \\
G L C 7^{\prime} d \mathrm{R}\end{array}$ & $\begin{array}{l}\text { TATGCGGCCGCTATGGACTCACAACCAGTT } \\
\text { ATAAGCGGCCGCCTAGATCTGTTCCATACTATT }\end{array}$ & 1.1 \\
\hline $\begin{array}{l}\text { GLC7'd, e F } \\
\text { GLC7'e R }\end{array}$ & $\begin{array}{l}\text { see above } \\
\text { ATAAGCGGCCGCGATCTGTTCCATACTATT }\end{array}$ & 1.1 \\
\hline $\begin{array}{l}G L C 7{ }^{\prime} f \mathrm{~F} \\
G L C 7 f^{\prime} \mathrm{R}\end{array}$ & $\begin{array}{l}\text { GAGGGAACCATGAATGTGCTTC } \\
\text { CTGGTGATCCGTCGACCTGCA }\end{array}$ & 0.23 \\
\hline $\begin{array}{l}U B C 6 \mathrm{~F} \\
U B C 6 \mathrm{R} \\
\end{array}$ & $\begin{array}{l}\text { CGGCAAATACAGGTGATGAAAC } \\
\text { TTCAGCGCGTATTCTGTCTTC }\end{array}$ & 0.11 \\
\hline $\begin{array}{l}\text { SIT4 F } \\
\text { SIT4 R }\end{array}$ & $\begin{array}{l}\text { GCGGAATTCATGGTATCTAGAGGCCCCG } \\
\text { GCG } \underline{\text { CTCGAGGTTATAAGAAATAGCCGGCTC }}\end{array}$ & 1 \\
\hline
\end{tabular}

For semi-quantitative RT-PCR, a cDNA from wild type yeast, non-transformed with a $G L C 7$ ' plasmid, was used to check the primer specificity. Other than GLC7' primers, $U B C 6$ primers were applied on the samples cDNA for another PCR reaction mixture as a control. UBC6 is a house-keeping gene with constant levels of expression. RT-PCR product samples were checked by DNA electrophoresis using $2 \%$ agarose gel. The length of the amplified sequence is $227 \mathrm{bp}$ for GLC7' and $107 \mathrm{bp}$ for UBC6.

\subsection{Plasmid construction}

$G L C 7^{\prime} C$ (truncated $G L C 7$ under control of its own promoter) of $1.6 \mathrm{~kb}$ was produced by PCR using yeast genomic DNA as a template and primers $G L C 7^{\prime} \mathrm{C}$ F and $G L C 7^{\prime} \mathrm{C}$ R, containing sites for EcoRI and BamHI, respectively (Table 3). The fragment of $1.6 \mathrm{~kb}$ was 
inserted into centromeric plasmid pUN50. An episomal version was produced by blunt end ligation with plasmid YEp352 after cutting with SmaI.

Starting from the $1.9 \mathrm{~kb} G L C 7$ ' fragment isolated by Hueso et al. (2012), two 1.1 $\mathrm{kb}$ fragments containing the ORF of the truncated gene (GLC7'd and $\left.G L C 7^{\prime} e\right)$ were amplified with Phusion High-Fidelity DNA polymerase (New England BioLabs) and primers $G L C 7^{\prime} d$, e F and $G L C 7^{\prime} d$ R (for GLC7'd gene) and primers GLC7'd, e $\mathrm{F}$ and GLC7'e R (for GLC7'e gene). All primers contained NotI restriction sites and in the first case the GLC7'd ORF contained a stop codon but in the second (GLC7'e) there was no stop codon. The amplified fragments were digested with NotI and cloned into the NotI site of plasmid pCM262, resulting in doxycycline-regulated expression of the simple truncated protein $\left(G L C 7^{\prime} d\right)$ or expression of a C-terminal in-frame fusion with 3 repetitions of the HA antigen and 6 histidine codons (GLC7'e) (Ariño and Herrero, 2003).

SIT4 was produced by PCR using yeast genomic DNA as a template and primers SIT4F and SIT4R, containing sites for EcoRI and XhoI, respectively (Table 3). The fragment $(\approx 1 \mathrm{~kb})$ was inserted into plasmid pYEX $4 \mathrm{~T}-1$ to be expressed in yeast.

There were many previous trials to express Sit4 in E. coli in the soluble fraction but in all of them the protein always was produced in the inclusion bodies. The SIT4 fragment was inserted into plasmid pGEX-KG. Because of the slight difference in the reading frame of the two plasmids (pGEX-KG and pYEX 4T-1) the forward primer was different: SIT4 F GCGGAATTCTAATGGTATCTAGAGGCCCCG while the reverse primer was the same. Then several trials were made, using different IPTG concentrations and induction temperature and times $\left(37^{\circ} \mathrm{C}, 0.4 \mathrm{mM}\right.$ IPTG for $17,30,40,50,60,90$ minutes and $20^{\circ} \mathrm{C}$, $0.4 \mathrm{mM}$ IPTG with sorbitol 0,500 and $333 \mathrm{mM}$ for 17, 30, 45 minutes and 1, 2, 3, 4, 5 hours). We tried also to transform the plasmid to another strain (BL21) by electroporation; again the expressed Sit4 was in the inclusion bodies. The second construct was by cutting SIT4 from pGEX-KG and putting it directly on pMAL plasmid, then trying to express Sit4 under different conditions $\left(37^{\circ} \mathrm{C}, 0.4 \mathrm{mM}\right.$ IPTG for $0.5,1,2$ hours; $22^{\circ} \mathrm{C}, 0.4 \mathrm{mM}$ IPTG for $0.5,1,2$ hours) induction occurred at both temperature tested but never in soluble proteins. 
TGATCCTATTACATTATCAATCCTTGCGTTTCAGCTTCCACTAATTTAGATGACTATTTC TCATCATTTGCGTCATCTTCTAACACCGTATATGATAATATACTAGTAACGTAAATACTA GTTAGTAGATGATAGTTGATTTTTACTCCAACAAAAGAATTACAGTCAGTGGCTGTTTGC TGACATTTCATTGCTTCCCTTACAACCTGATTTCCATTCGAGTTGAAAGGTTGAGAAAAA TTGCAAGACTTCTCTCTCATCTACСTTCCССTTTTCTTGAAGACAAGGTGAGAGACAATT TAGTACTAAAGCTTTTGCGGTTGTTATTCAATTGAGGTAGATACCTGGCAAAACATTTCT TGTGAGCACAACCTCAATTAAAGTTAGACAAGTAGGTGCACTATTGGTTGCTTGTTGGCT CATCTCGTTGAGGAATGTAATAACTACTTGTTATTAACCTGTTTTTGTGCCATCTATAGT GGAGAGCTTATTGCAATTTGTTTTTTATTTCTTGACTGCATATATCAGTCTTTGACAGGC TGCATGGGGATGACAGTTAGAAACTAGCCAAATTACCCСTTATGTAGATAACAATCATTG СTTATTCGCTCTTCCCCСATTTTTTTTCTTGCTCTTGCTGTTTTTTCTTTTAGCGTTCGT TTCAAGGAACAAGAGAGGGAAAAAAAAATCAAAAGTAGAAAAGAAGAAGAAAAAAACAAC GTAACACAAGTTAACACCACAACTGAAAAAAAAAATAAGAGGTGAACGAACGAGTAACTG GGGAGAGGAAAGCAGATTACCACAATATACATTCAAATTAAAGAAATGGACTCACAACCA GTTGACGTTGATAATATCATCGATAGATTATTGGAAGTAAGAGGATCTAAACCTGGTCAA CAAGTTGATCTAGAAGAAAATGAAATCAGATACTTATGTTCGAAAGCCAGATCTATATTC ATAAAGCAACCCATTTTACTAGAGTTAGAAGCCCCAATTAAAgtatgttaatgttgaact tcgcagtcaagagatagaatgcctagagcttcaggtgttttatgtgttctactcctgttg cggcagtaagatagttacagcagttatttccgtttgactgaaagaatttaccaagcatct gatgttagcctactcatatgtcgagatagccgagataatgtgtgtgtttagctcttcatt tttctatcttattaggcattttttaccaagatttccttatgttttgtatcatcatccgg ccggcgcctcccatattcagaaaatcccccttgctcacactaaaaaagaaggcatttt ttcgttatgaagaaaacgaatctttttttttttgagcccgagagaaaggtcggacgaaa accaagaatgtggatttgcagaaggcattgggagaaatgaagcgtttttgaCAGCAGTA ATTGTTCTCTTAAAGTCAACGGAATGAGCTAGATTTAGTGACAAATTCATTTACTAACTT АTTTTTTTCTATTTTTTTTTTTTTTAGATATGTGGTGACATTCATGGGCAATACTATGAT TTACTACGTCTATTTGAGTACGGTGGATTCCCGCCAGAATCTAATTATCTATTTTTGGGT GATTATGTCGACCGTGGTAAACAATCCTTAGAGACTATTTGTCTATTACTGGCTTACAAA ATTAAGTATCCAGAAAACTTTTTCATTTTAAGAGGGAACCATGAATGTGCTTCCATTAAT AGAATTTACGGGTTTTATGATGAATGTAAGAGACGTTATAATATCAAACTTTGGAAAACT TTCACGGATTGTTTCAATTGTTTACCAATTGCTGCAATTATTGATGAGAAAATCTTCTGT ATGCATGGTGGTCTCTCACCAGATTTGAATAGTATGGAACAGATCAGAAGGGTGATGAGG CCAACAGATATTCCCGACGTTGGCTTATTATGTGACTTATTGTGGTCAGATCCA

Figure 23. Nucleotide sequence of chromosome V from coordinates 431670 to 433643 , including the truncated GLC7' genes of Wek et al. (1992; gene GLC7'a of $1.6 \mathrm{~kb})$, Hueso et al. (2012; gene $G L C 7^{\prime} b$ of $\left.1.9 \mathrm{~kb}\right)$ and the one generated in the present work $\left(G L C 7^{\prime} c\right)$. Small letters correspond to the intron of the gene. GLC7'a extends from the Hind III site underlined (AAGCTT) to the end of the sequence (codon CCA for proline 208, underlined). GLC7'b extends from the beginning of the sequence to the underlined codon GAA (glutamate 183). GLC7' $c$ has $1.6 \mathrm{~kb}$ from the underlined ATT (40 nt after the Hind III site) to the end of the sequence (codon CCA for proline 208, underlined). $G L C 7^{\prime} d$ is the coding region of $G L C 7^{\prime} b$ plus two more codons, stop codon and Not I sites at both ends to clone into pCM262 plasmid. GLC7'e is the coding region of GLC7'b plus two more codons (but no stop codon) to fuse in frame with 3 repetitions of the HA antigen and six histidine codons. It also contains Not I sites at both ends to clone into pCM262 plasmid. GLC7' $f$ is the 227 bp fragment used to quantify $G L C 7$ ' $d$ expression from the doxycycline-regulated promoter. It extends from the GAG ... TTC primer sequence in the GLC7' gene (underlined) to the sequence in the pCM262 plasmid just after the Not I cloning site (beginning of 3xHA region; Ariño and Herrero, 2003). The complete ORF encodes 312 amino acids. The starting codon ATG is also underlined. See primers at Table 3. 


\section{Genetic transfer}

\subsection{Transformation of $E$. coli}

The method of Inoue et al. (1990) was used. DH5 $\alpha$ competent cells $(100 \mu \mathrm{L})$ were mixed with $10 \mu \mathrm{l}$ ligation reaction. The mixture was incubated for 30 minutes in ice, then $\left(1 \mathrm{~min}, 42^{\circ} \mathrm{C}\right.$ ) and finally back to ice for 2 minutes. $900 \mu \mathrm{L}$ of LB medium was added and incubated $50 \mathrm{~min}$ at $37^{\circ} \mathrm{C}$. Finally the cells were spread on LB agar with ampicillin for selection.

\subsection{Transformation of yeast (Gietz, 2014)}

\subsubsection{Preparation of competent yeast cells}

Fresh stationary phase culture was inoculated into YPD broth and incubated till reaching exponential phase. Cells were harvested and resuspended in $0.1 \mathrm{M} \mathrm{Li}$ Ac-TE (Lithium acetate $0.1 \mathrm{M}, 10 \mathrm{mM}$ Tris- $\mathrm{HCl} \mathrm{pH} 7.6,1 \mathrm{mM}$ EDTA) with 1/10 volume of the culture volume. Again centifuged, resuspended in $1 \mathrm{ml}$ of $0.1 \mathrm{M} \mathrm{Li} \mathrm{Ac-TE}$ and incubated $30 \mathrm{~min}$ at $30^{\circ} \mathrm{C}$. Then $0.23 \mathrm{ml}$ of $80 \%$ glycerol and $0.1 \mathrm{ml} 1 \%$ single stranded salmon sperm DNA was added to each $1 \mathrm{ml}$ volume of cells, mixed well then distributed into 100 $\mu \mathrm{L}$ aliquots and stored at $-80^{\circ} \mathrm{C}$ till being used.

\subsubsection{Yeast Transformation}

The competent yeast cells were mixed with $0.1-10 \mu \mathrm{g}$ of the specific plasmid, incubated 5-10 min at room temperature and then $600 \mu \mathrm{L}$ of PEG-Li Ac-TE $(40 \%(\mathrm{w} / \mathrm{v})$ PEG 4,000 in Li Ac-TE). The mixture was incubated (30 min at room temperature, then 10 $\min$, at $42^{\circ} \mathrm{C}$ ), centrifuged for 10 seconds at $13,000 \mathrm{rev} / \mathrm{min}$ and cells finally resuspended in $200 \mu \mathrm{L}$ water and spread on a plate with selective medium. The plate was incubated at $28^{\circ} \mathrm{C}$ for 2 or more days till the appearance of colonies.

\section{Extraction, electrophoresis and detection of proteins}

\subsection{Extraction of soluble proteins}

\subsubsection{Method of boiling with Laemmli buffer}

Cells from $5 \mathrm{ml}$ of exponential phase culture were harvested, washed and put under the conditions of study and harvested by centrifugation during $5 \mathrm{~min}$ at 3,000 rev/min. The pellet was resuspended in $100 \mu \mathrm{L}$ of $1 \mathrm{X}$ Laemmli sample buffer (5X: $7.5 \%$ SDS, $0.1 \mathrm{M}$ DTT, $10 \mathrm{mM}$ EDTA, 30\% sucrose, $0.25 \mathrm{mg} / \mathrm{ml}$ bromophenol blue, $0.3 \mathrm{M}$ Tris taken to $\mathrm{pH}$ 
6.8 with $\mathrm{HCl}$ ), then heated $5 \mathrm{~min}$ at $100^{\circ} \mathrm{C}$. Finally, the suspension was centrifuged during $2 \mathrm{~min}$ at $13,000 \mathrm{rev} / \mathrm{min}$ and the supernatant kept at $-20^{\circ} \mathrm{C}$ until being utilized.

\subsubsection{Method of $\mathrm{NaOH}$ (von der Haar, 2007)}

Cells were harvested from $5 \mathrm{ml}$ exponential phase culture as described above. Lysis buffer $(0.1 \mathrm{M} \mathrm{NaOH}, 0.05 \mathrm{M}$ EDTA, 2\% $\beta$-mercaptoethanol and 2\% SDS) was freshly prepared and heated at $90^{\circ} \mathrm{C}$ for 5 minutes before used $(200 \mu \mathrm{L})$ to resuspend the cells. The resulting suspension was incubated $10 \mathrm{~min}$ at $90^{\circ} \mathrm{C}$, then the lysate was brought to neutral $\mathrm{pH}$ by mixing well with $5 \mu \mathrm{L}$ of $4 \mathrm{M}$ acetic acid, and incubated $10 \mathrm{~min}$ at $90^{\circ} \mathrm{C}$ to increase solubilization. $50 \mu \mathrm{L}$ loading buffer $(0.25 \mathrm{M}$ Tris- $\mathrm{HCl}, \mathrm{pH} 6.8,50 \%$ glycerol, $0.05 \%$ Bromophenol blue) was well mixed and finally the suspension was centrifuged for $\left(1 \mathrm{~min}, 13,000 \mathrm{rev} / \mathrm{min}, 4^{\circ} \mathrm{C}\right)$. Denatured proteins in the supernatant were kept at $-20^{\circ} \mathrm{C}$ until being utilized.

\subsubsection{Method of TCA (Grassl et al., 2009)}

Equal volume of $20 \%$ trichloroaceticacetic acid (TCA) was added to exponential phase culture, mixed well then kept in ice for 30 minutes before being centrifuged ( $8 \mathrm{~min}$, $3,000 \mathrm{rev} / \mathrm{min}$ ). The pellet was resuspended in $1 \mathrm{ml}$ cold absolute ethanol and left in ice for 5 minutes then centrifuged ( $5 \mathrm{~min}, 12,000 \mathrm{rev} / \mathrm{min}, 4^{\circ} \mathrm{C}$ ) and this washing step was done twice. The pellet was dried by leaving the microtube open for 20 minutes at RT or by vacuum centrifugation and was then resuspend in $1 \mathrm{X}$ Laemmli $(200 \mu \mathrm{L})$ and heated $5 \mathrm{~min}$ at $100^{\circ} \mathrm{C}$ to solublize proteins. Finally, the suspension was centrifuged ( $2 \mathrm{~min}, 13,000$ $\mathrm{rev} / \mathrm{min}, 4^{\circ} \mathrm{C}$ ) to remove debris and the supernatant kept at $-20^{\circ} \mathrm{C}$ until being utilized.

\subsection{Extraction of Pma1}

The above methods cannot be utilized to extract Pmal because it aggregates by boiling in Laemmli sample buffer. Instead, in the case of Pma1 the extraction of a crude membrane fraction must be made in the presence of protease inhibitors as described above and then samples treated with Laemmli sample buffer by incubation during 15 min at 42 ${ }^{\circ} \mathrm{C}$. 


\section{MATERIALS AND METHODS}

\subsection{Electrophoresis and detection techniques of proteins}

\subsubsection{Electrophoresis of proteins}

The denatured proteins were separated by electrophoresis in SDS-polyacrylamide gels (SDS-PAGE) using Mini-Protean 3 (BioRad). The gel consisted of two layers above each other. The upper layer (stacking gel) consisted of (3\% acrylamide: bisacrylamide 30:0.8, 0.1 \% SDS, 125 mM Tris- $\mathrm{HCl} \mathrm{pH} 6.8$ ) and the lower layer (resolving gel) consisted of ( 8 or $10 \%$ acrylamide: bisacrylamide 30:0.8, 0.1\% SDS, $325 \mathrm{mM}$, Tris- $\mathrm{HCl} \mathrm{pH} 8.8$ ), ammonium persulphate and tetraethylmethylenediamine (TEMED) were added to both gels. Acrylamide concentration in the resolving gel was according to the protein size, $8 \%$ gel was used for Pma1 and 10\% was used for eIF2 $\alpha$, GST-Glc7 and GST-Sit4 detection. The gel can be prepared for either 0.75 or $1 \mathrm{~mm}$ thickness tray. Electrophoresis buffer used was $0.19 \mathrm{M}$ Glycine, $0.1 \% \mathrm{SDS}, \mathrm{pH}$ to 8.3 with Tris base. $25 \mathrm{~A}$ current fixed all the time was applied for separation of proteins of one gel.

\subsubsection{Protein detection with Coomassie Brilliant Blue R-250}

After protein separation on SDS-PAGE, the gels were incubated for 15 minutes in Coomassie (0.05 \% Coomassie Brilliant Blue R-250, $50 \%$ methanol, $10 \%$ acetic acid). The gel was then destained using a destaining solution (10\% methanol, 10\% acetic acid) for 1 hour up to overnight.

\subsubsection{Membrane transfer}

After being separated on the gel, proteins were transferred to nitrocellulose membrane or to PVDF membrane. This process was carried out in Mini-Protean 3 (BioRad) in the presence of Towbin buffer (14.4 g/L glycine, $2 \mathrm{ml}$ 10\% SDS, $\mathrm{pH}$ to 8.3 with Tris base, $20 \%$ Methanol) at $100 \mathrm{~V}$ for $1 \mathrm{hr}$ at $4^{\circ} \mathrm{C}$.

\subsubsection{Direct Blue staining of the membrane}

In some experiment the membrane with transferred proteins was incubated for 10 minutes in $0.008 \%$, direct blue [(Direct Blue 71, $0.1 \%$ in $\mathrm{H}_{2} \mathrm{O}$ diluted with washing solution $\left(250 \mathrm{ml} \mathrm{H} \mathrm{H}_{2} \mathrm{O}, 200 \mathrm{ml}\right.$ absolute ethanol, $50 \mathrm{ml}$ glacial acetic acid)]. Stained membrane was left in the washing solution for $10 \mathrm{~min}$ and after scanning it was destained by incubating in destaining solution $\left(175 \mathrm{ml} \mathrm{H}_{2} \mathrm{O}, 250 \mathrm{ml}\right.$ absolute ethanol, $75 \mathrm{ml} 1 \mathrm{M}$ $\left.\mathrm{NaHCO}_{3}\right)$ for 5 minutes. Finally the membrane was neutralized with TBS-T $(0.1 \%$ Tween 
$20,150 \mathrm{mM} \mathrm{NaCl}, 20 \mathrm{mM}$ Tris-HCl $\mathrm{pH}$ 7.6) for 30 minutes then could be used to continue western procedures.

\subsubsection{Immunodetection of the proteins transferred to the membrane}

After the proteins were transferred to the membrane, the membrane was blocked by $1-5 \%$ skimmed milk in TBS-T for $1 \mathrm{hr}$ with agitation. In case of applying antibodies against the phosphorylated regulatory domain of Pma1, skimmed milk was substituted with bovine serum albumin (BSA) $1 \%$ for antibody $\alpha$-pST and 5\% for antibody $\alpha$-pS899 also in this latter case, $\alpha$-pS899, the blocking time was much shorter only 5-15 minutes. The blocked membrane was incubated (overnight, $4^{\circ} \mathrm{C}$ or $1 \mathrm{hr}$, RT) with the primary antibody prepared in the same blocking solution to the dilution mentioned in Table 4. The membrane was washed three times for 10 minutes each with TBS-T then it was incubated with the specific secondary antibody ( $\alpha$-rabbit I $g$-HRP) prepared in the same blocking solution to the dilution mentioned in Table 4 for 30 minutes at room temperature, followed by three washings for 10 minutes each with TBS-T. Finally the detection was done using enhanced chemiluminescence (ECL Plus Western Blotting Detection System, Amersham Biosciences) and the images were taken by the imaging system [LAS-3000 (FUJI)] or by radioactive method. When the band intensity needed to be quantified, Image Gauge software was used. In cases where it was necessary to reuse the membrane, it was incubated for 30 minutes with agitation in stripping solution ( $5 \mathrm{ml}$ of $1 \mathrm{M}$ glycine, $1 \mathrm{ml}$ of $10 \%$ SDS, $19 \mathrm{ml} \mathrm{H}_{2} \mathrm{O}, \mathrm{pH}$ adjusted to 2.5 with $12 \mathrm{M} \mathrm{HCl}$ ), washed once, blocked and then reincubated with any desired antibody, except $\alpha-\mathrm{pS} 899$, in the same way as described above. $\alpha$-Kar2 was used in combination with $\alpha$-pST or $\alpha-p S 899$ as a control.

All antibodies used are listed in Table 4

\begin{tabular}{|l|l|l|l|l|}
\hline $\begin{array}{l}\text { Primary } \\
\text { antibody }\end{array}$ & Dilution & $\begin{array}{l}\text { Secondary } \\
\text { antibody }\end{array}$ & Dilution & Source \\
\hline$\alpha$-PeIF2 $\alpha$ & $1: 2000$ & $\alpha$-rabbit Ig-HRP & $1: 5000$ & Cell Signaling Technology \\
\hline$\alpha$-eIF2 $\alpha$ & $1: 500$ & $\alpha$-rabbit Ig-HRP & $1: 8000$ & Tom Dever \\
\hline$\alpha$-pST & $1: 2000$ & $\alpha$-rabbit Ig-HRP & $1: 5000$ & F. Portillo \\
\hline$\alpha$-pS899 & $1: 100$ & $\alpha$-rabbit Ig-HRP & $1: 5000$ & F. Portillo \\
\hline$\alpha$-Pma1 & $1: 10000$ & $\alpha$-rabbit Ig-HRP & $1: 5000$ & R. Serrano \\
\hline$\alpha$-GST & $1: 3000$ & $\alpha$-rabbit Ig-HRP & $1: 5000$ & Santa Cruz biotechnology \\
\hline$\alpha$-Kar2 & $1: 3000$ & $\alpha$-rabbit Ig-HRP & $1: 5000$ & F. Portillo \\
\hline
\end{tabular}




\section{Recombinant protein expression and purification}

\subsection{GST-GIc7 protein expression and purification from $E$. coli (García-Gimeno et al., 2003)}

Saturated culture of E. coli containing pGEX-3x-GLC7 (García-Gimeno et al., 2003; provided by Dr. Jose R. Murguía) and also of E. coli containing pGEX-3x, as a negative control were used to inoculate $50 \mathrm{ml}$ of LB-Ampicillin $(50 \mu \mathrm{g} / \mathrm{ml})$ medium with $0.5 \mathrm{mM} \mathrm{MnCl} 2$ and it was incubated 3 hours, $200 \mathrm{rev} / \mathrm{min}$ at $37^{\circ} \mathrm{C}$ (OD $0.6-0.8$ ). Expression was induced by adding 0.1-0.2 mM IPTG and incubation overnight at $25^{\circ} \mathrm{C}$. The culture was centrifuged ( $5 \mathrm{~min}, 3000 \mathrm{rev} / \mathrm{min}, \mathrm{RT}$ ) and the pellet was resuspended in 3 $\mathrm{ml}$ of sonication buffer (50 mM Tris-HCl pH 7.6, $0.2 \mathrm{mM}$ EGTA, $150 \mathrm{mM} \mathrm{NaCl}, 10 \%$ glycerol, 0.1\% Triton X-100, 2 mM DTT, 2 mM PMSF, $2 \mathrm{mM} \mathrm{MnCl}_{2}$ ). A complete mini protease inhibitor mixture 1 tablet [Roche Applied Science] was added for $7 \mathrm{ml}$. The cells were broken by sonication, three cycles for 10 seconds each at maximum intensity with 30 seconds pause and centrifuged $\left(20 \mathrm{~min}, 15,000 \mathrm{rev} / \mathrm{min}, 4^{\circ} \mathrm{C}\right)$.

For purification of the soluble proteins obtained, all the supernatant was added to the washed magnetic glutathione beads (Pierce ${ }^{\mathrm{TM}}$ Glutathione Magnetic Beads) and incubated $\left(1 \mathrm{hr}, 4^{\circ} \mathrm{C}\right)$ with rotation, then beads were harvested, washed three times with the same buffer and resuspended in GTED $20(100 \mu \mathrm{L})$ with $2 \mathrm{mM} \mathrm{MnCl}_{2}$.

\subsection{GST-Sit4 protein expression and purification from yeast}

\subsubsection{Check the expression of Sit4 in Soluble fraction}

S. cerevisiae competent cell of strain (BY4741) was transformed with pYEX 4T-1SIT4, and also pYEX 4T-1 (negative control). Transformants were cultured on plates of SD supplemented with histidine, methionine and leucine. At this stage leucine was added to the culture because if not the growth will be extremely slow. Saturated cultures of 5 different transformant colonies and one colony transformed with pYEX 4T-1 were prepared in SD supplemented with histidine and methionine, the second culture lacked leucine to increase the plasmid number and consequently the protein production. Transformants with pYEX 4T-1-SIT4) took 3 days to reach stationary phase while the negative control transformants took only 1 day. After that, fresh cultures of the same composition were inoculated and incubated to reach exponential phase. Expression was induced by adding $0.5 \mathrm{mM} \mathrm{CuSO}_{4}$ to each flask and incubating for 2 hours. The cultures 
were centrifuged ( $5 \mathrm{~min}, 3000 \mathrm{rev} / \mathrm{min}, \mathrm{RT}$ ) and The pellet was resuspended in $1 \mathrm{ml}$ of lysis buffer (50 mM Tris-HCl, pH 7.5, $150 \mathrm{mM} \mathrm{NaCl}, 5 \%$ glycerol, 0.1\% Triton X-100, 2 $\mathrm{mM}$ DTT, $0.5 \mathrm{mM}$ PMSF, $2 \mathrm{mM} \mathrm{MnCl}_{2}$, complete protease inhibitor mixture (Roche). Cells were broken by the aid of sterile glass beads ( $0.5 \mathrm{~mm}$ diameter) for 3-3.5 minutes by vortexing in $30 \mathrm{sec}$. cycles separated by ice incubation. Cell debris were removed by centrifuging the homogenate $\left(2 \mathrm{~min}, 3,000 \mathrm{rev} / \mathrm{min}, 4^{\circ} \mathrm{C}\right)$, soluble proteins were separated from insoluble ones by another centrifugation (20 $\mathrm{min}, 13,000 \mathrm{rev} / \mathrm{min}, 4^{\circ} \mathrm{C}$ ) and taking the supernatant. Proteins were denatured by Laemmli method, and checked with antibody $\alpha-G S T$.

\subsubsection{Soluble protein fraction purification}

For purification of the soluble proteins obtained, all the supernatant was added to washed glutathione Sepharose 4B (GE Healthcare, Sweden) and incubated (1 hrovernight, $4^{\circ} \mathrm{C}$ ) with rotation then slurry was harvested (5 min, 2,000 rev/min, $4^{\circ} \mathrm{C}$ ), washed three times with the same buffer and resuspended in $100 \mu \mathrm{L}$ GTED 20 (see section 2.1.2) with $2 \mathrm{mM} \mathrm{MnCl} 2$

\section{9. "In vitro" dephosphorylation of Pma1 by Glc7 or Sit4}

The purified protein fused to glutathione beads or slurry was directly distributed into 4 microtubes $(20 \mu \mathrm{L}$ each sample)

\begin{tabular}{|l|l|l|l|l|}
\hline & $\begin{array}{l}\text { Zero } \\
\text { time }\end{array}$ & $30 \mathrm{~min}$ & $1 \mathrm{hr}$ & $2 \mathrm{hrs}$ \\
\hline Bead or slurry - GST & 1 & 2 & 3 & 4 \\
\hline Bead GST - Glc7 or slurry GST- Sit4 & 5 & 6 & 7 & 8 \\
\hline
\end{tabular}

GTED 20 was discarded after putting the microtubes in magnetic rack, or harvesting the slurry by centrifugation then each one received $20 \mu 1$ of a mixture of (GTED $20+2 \mathrm{mM}$ $\mathrm{MnCl}_{2}+$ protease inhibitor $(1 \mathrm{x})+4 \mu \mathrm{g}$ activated Pmal) followed by incubation at $30^{\circ} \mathrm{C}$ with rotation. Directly after the specific time of incubation, reaction was stopped by protein denaturation with $20 \mu \mathrm{L}$ of $2 \mathrm{x}$ mixture of (Laemmli, protease inhibitor, PMSF) added to each microtube, well mixed then incubated $\left(10 \mathrm{~min}, 42^{\circ} \mathrm{C}\right)$. Samples were injected in polyacrylamide gel ( $2 \mu \mathrm{g}$ total membrane protein per lane). 
A portion of recombinant Glc7 and its control (GST) was kept without any further treatment, extracted with Laemmli to check the protein expression by staining the gel with Coomassie.

\section{Measurement of pH changes of yeast suspensions induced by glucose (Serrano,} 1980)

A stationary phase culture is used to inoculate $15 \mathrm{ml}$ fresh culture (YPD or SD supplied with required amino acids in case of plasmid transformants) in $100 \mathrm{ml}$ flask and incubated till reaching stationary phase. Cells were harvested, washed and resuspended in sterile $\mathrm{H}_{2} \mathrm{O}$ and incubated 2 hours at $200 \mathrm{rev} / \mathrm{min}$ and $30^{\circ} \mathrm{C}$ for starvation. Cells were harvested and resuspended in $2 \mathrm{ml}$ of $100 \mathrm{mM} \mathrm{KCl}$ and $10 \mathrm{mM}$ glycylglycine, adjusted to pH 4 with $1 \mathrm{M} \mathrm{HCl}$. Calibration pulses of $100 \mathrm{nmol} \mathrm{HCl}$ were added at the beginning and at the end of the experiment. Proton pumping of the cells was started by addition of 50 $\mu$ moles of glucose. A pH meter GLP22 (Crison) was used to record $\mathrm{pH}$.

\section{Investigation of the effect of inhibiting PP1 by regulated expression of GIc7' on Pma1 activity}

\subsection{Determination of the best doxycycline concentration to control gene expression of $G L C 7$}

SD medium was supplemented with leucine, histidine, methionine and $10 \mu \mathrm{g} / \mathrm{ml}$ doxycycline to inhibit expression. S. cerevisiae strains RS-119, RS-120, RS-121 were tested for the best concentration of doxycycline to control GLC7' expression. Stationary phase cultures were prepared as described in section 2.1.1. These cells were washed and resuspended in sterile distilled water then served as inocula in fresh broth containing different doxycycline concentrations and the growth was determined by measuring OD at $660 \mathrm{~nm}$ after 18 and 22 hours.

\subsection{Doxycycline removal and Pma1 assay}

Stationary phase cultures of strains RS-121 and RS-120 were prepared in the same medium described in 4.1 but doxycycline concentration was only $2 \mu \mathrm{g} / \mathrm{ml}$. They were used to inoculate fresh medium and incubated till reaching exponential phase. A portion of the culture, $20 \mathrm{ml}$, was separated and labeled zero time. Cells were harvested, resuspended in $0.8 \mathrm{ml}$ (fresh broth with $2 \mu \mathrm{g} / \mathrm{ml}$ doxycycline) and incubated for 10 minutes. Doxycycline was removed from the rest of the cells by harvesting and washing twice with water as described in section 2.1.2. Cells was resuspended in SD medium without doxycycline, then distribute into three 100-ml flasks, $20 \mathrm{ml}$ each. Each flask was incubated for a specific time 
MATERIALS AND METHODS

interval then cells were harvested, resuspended in $0.8 \mathrm{ml} \mathrm{SD}$ medium without doxycycline and incubated for 10 minutes. After the incubation period they were put in liquid $\mathrm{N}_{2}$ or immediately homogenized as described in section 2.1.2. Protein concentration was determined and ATPase activity was assayed as described in sections 2.2 and 2. 3.

\subsection{Investigation of inhibition of Glc7 by expression of GIc7' under doxycycline promoter by detecting the phosphorylation level of eIF2 $\alpha$}

Exponential phase culture of strains RS-121 was obtained just as described in section 11.2, and washed as described in section 2.1.2. Cells were resuspended in SD medium without doxycycline and a zero control with doxycycline was made. Both test and the control were incubated for $1.5 \mathrm{hr}$. After the incubation time, protein was extracted with Laemmli method (section 7.1.1) and eIF2 $\alpha$ phosphorylation levels were detected using the procedures described in section 7 .

\section{Dephosphorylation rate experiment}

Culture preparation was carried out as described in 2.1.1. The tested strain was RS132 transformed with YEp24, YEp24-GLC7', YEp352, and YEp352-GLC7' and the medium was SD supplemented with adenine and histidine. Also were tested the Sit4 null mutant and its wild type RS-259 and they were grown in YPD. Cells were grown to late exponential phase. Membrane isolation was according to the method described in section 2.1.2 except that after incubation with $2 \%$ glucose for 10 minutes and taking a sample, glucose was quickly removed by centrifugation (2 $\mathrm{min}, 3,000 \mathrm{rev} / \mathrm{min}$ ) and cells resuspended in the same volume of $\mathrm{H}_{2} \mathrm{O}$. This was followed by incubation for 10 and 20 minutes without glucose. Then the procedures of section 2. 2. were followed to determine protein concentration. Extracted Pmal samples were denatured and subjected to electrophoresis and immunodetection as described in section 7.

\section{Rapamycin effect on Pma1 activity}

Culture preparation was carried out as described in section 2.1.1. The tested strain was RS-132 and grown in YPD till exponential phase. A sample, $25 \mathrm{ml}$, was taken as zero time and to the rest of the culture $500 \mathrm{nM}$ rapamycin prepared in DMSO was added, and the culture incubated at $28^{\circ} \mathrm{C}$ and $200 \mathrm{rev} / \mathrm{min}$. Equal volume samples were taken after 2, 3 and 5 hours incubation. The membrane was isolated from the samples by the same procedures described in section 2.1.2 except that at the step of incubation before glucose, 
MATERIALS AND METHODS

the resuspended pellet of all the samples (except the zero time one) received $10 \mu \mathrm{M}$ rapamycin, approximately 25 times increased concentration to compensate for the 25 times increased concentration of cells. The Pmal activity was assayed as described in section 2. The phosphorylation level of Pmal in these samples was compared using Laemmli method to denature the protein as described in section 7 and applying antibodies $\alpha$-ST911,2 and anti total Pmal as control.

\section{TORC1 and TORC2 thermosensitive mutant}

The strains used for this experiment were SH221 (tor $1 \Delta$ tor $^{\text {ts }}$ ) and its control SH100. First the two strains were checked for the phenotype by growing three different colonies of each strain on YPD plate and incubating at $37^{\circ} \mathrm{C}$ and RT. Second the growth difference was also checked in liquid medium by inoculating fresh YPD with stationary phase culture, starting $\mathrm{OD}$ at $660 \mathrm{~nm}=0.2$, and they were incubated at $37^{\circ} \mathrm{C}$ and $24^{\circ} \mathrm{C}$. Growth was monitored by measuring the OD at $660 \mathrm{~nm}$ after 3, 6 and 24 hours.

To determine Pma1 activity "in vitro" same procedures described in section 2 were followed. Stationary phase cultures of strains SH100 and SH221 were used to inoculate fresh YPD, initial OD at $660 \mathrm{~nm}=0.2$, and both were incubated at $37^{\circ} \mathrm{C}$ for 6 hours. The phosphorylation level of Pmal in these samples was compared as described in section 7 by applying $\alpha$-pST. As control $\alpha$-Pma1 was also applied on stripped membrane and the gel was stained with Coomassie.

\section{Protein phosphatase assay (Garcia-Gimeno et al., 2003 and Silberman et al., 1984)}

The reaction buffer was (50 mM Tris- $\mathrm{HCl}, \mathrm{pH} 7.5,0.1 \mathrm{mM}$ EGTA, $2 \mathrm{mM} \mathrm{MnCl}_{2}$, and $1 \mathrm{mM} \mathrm{DTT}$ ). $p$-nitrophenylphosphate disodium salt hexahydrate (PNPP) (Roche, Germany) (Mol.Wt $=371.1 \mathrm{~g})$ stock solution was prepared (40 $\mathrm{mM}$ in phosphatase buffer) and kept at -80 . The experiment was carried out by mixing $20 \mu \mathrm{L}$ of the sample (purified GST-Glc7) or negative control (purified GST) with $180 \mu \mathrm{L}$ of PNPP $40 \mathrm{mM}$ and incubating the mixture for $10-20 \mathrm{~min}$ at $30{ }^{\circ} \mathrm{C}$. The reaction was stopped by adding $1 \mathrm{ml}$ $0.5 \mathrm{M}$ EDTA. The absorbance was measured at $405 \mathrm{~nm}$ using Microplate Reader. $p$ nitrophenol concentration was calculated from the calibration curve with standard $p$ nitrophenol. 
RESULTS 



\section{RESULTS}

\section{Typical chemical inhibitors of protein phosphatases do not affect Pma1 activity}

In order to test the role of the yeast major type 1 protein phosphatase Glc7 on the activation of Pmal by glucose metabolism, we have first tested chemical inhibition of protein phosphatases during the activation process. If Glc7 were involved in dephosphorylation of the activating site of Pma1, addition of chemical inhibitors of the protein phosphatase could increase phosphorylation and activate the enzyme. Okadaic acid and calyculin $\mathrm{A}$ are cell-permeable inhibitors of animal type 1 and $2 \mathrm{~A}$ protein phosphatases that have been shown to increase protein phosphorylation in intact animal cells (Shenolikar, 1994; Haystead et al., 1989). However, these inhibitors were never used in yeast, where only tungstate, a non-specific phosphatase inhibitor, has been utilized (Rodriguez-Hernandez et al., 2012). GLC7 is an essential gene in yeast (Stark, 1996) and therefore any inhibitor of the encoded phosphatase should inhibit yeast growth. However, at the tested concentrations of $0.5 \mu \mathrm{M}$ okadaic acid and $10 \mathrm{mM}$ tungstate no inhibition of growth was observed and also no inhibition of Pmal activity in cells with glucose metabolism (Figure 24 A and B). In the case of calyculin A growth was clearly inhibited but still no effect on Pmal activity was observed (Figure $24 \mathrm{C}$ and D). As the concentration of okadaic acid was much higher than those utilized with animal cells $(0.01$ $\mu \mathrm{M}$; Shenolikar, 1994; Haystead et al., 1989) and as Glc7 is highly homologous to animal type 1 protein phosphatases (Stark, 1996), it seems that okadaic acid is not permeable in yeast and we cannot reach conclusions with this inhibitor about the participation of Glc7 on Pmal regulation. In the case of calyculin A, however, the inhibitor is permeable because it inhibits growth but still, Pmal activity is not affected. There is evidence in another yeast strain that tungstate, at the tested concentration of $10 \mathrm{mM}$, increases phosphorylation of the Glc7 substrate eIF2 $\alpha$, although it only produced a slight inhibition of growth (Rodriguez-Hernandez et al., 2012). Therefore we may conclude from the data with calyculin A and tungstate that probably Glc7 has only a minor role in regulation of Pmal activity, perhaps because it affects only the $\mathrm{Km}$ or because other protein phosphatases are redundant with it. 
A

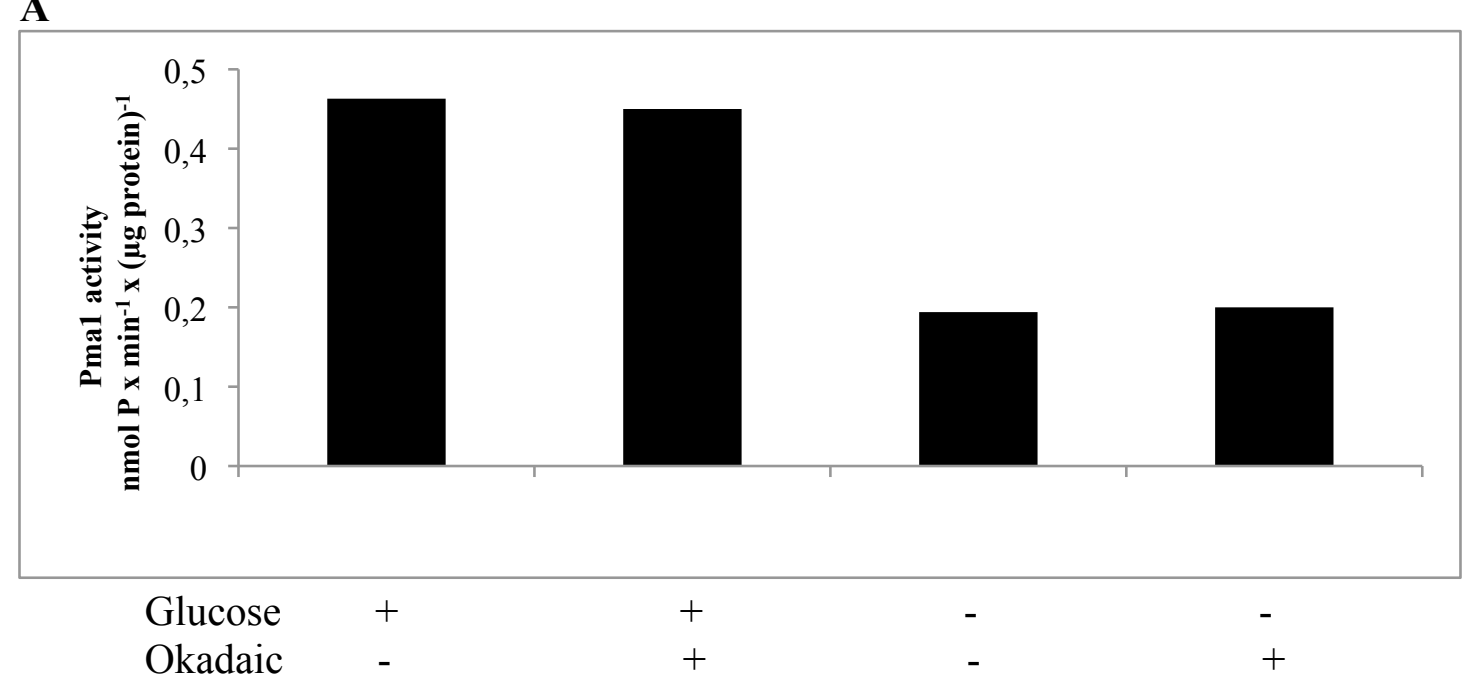

B
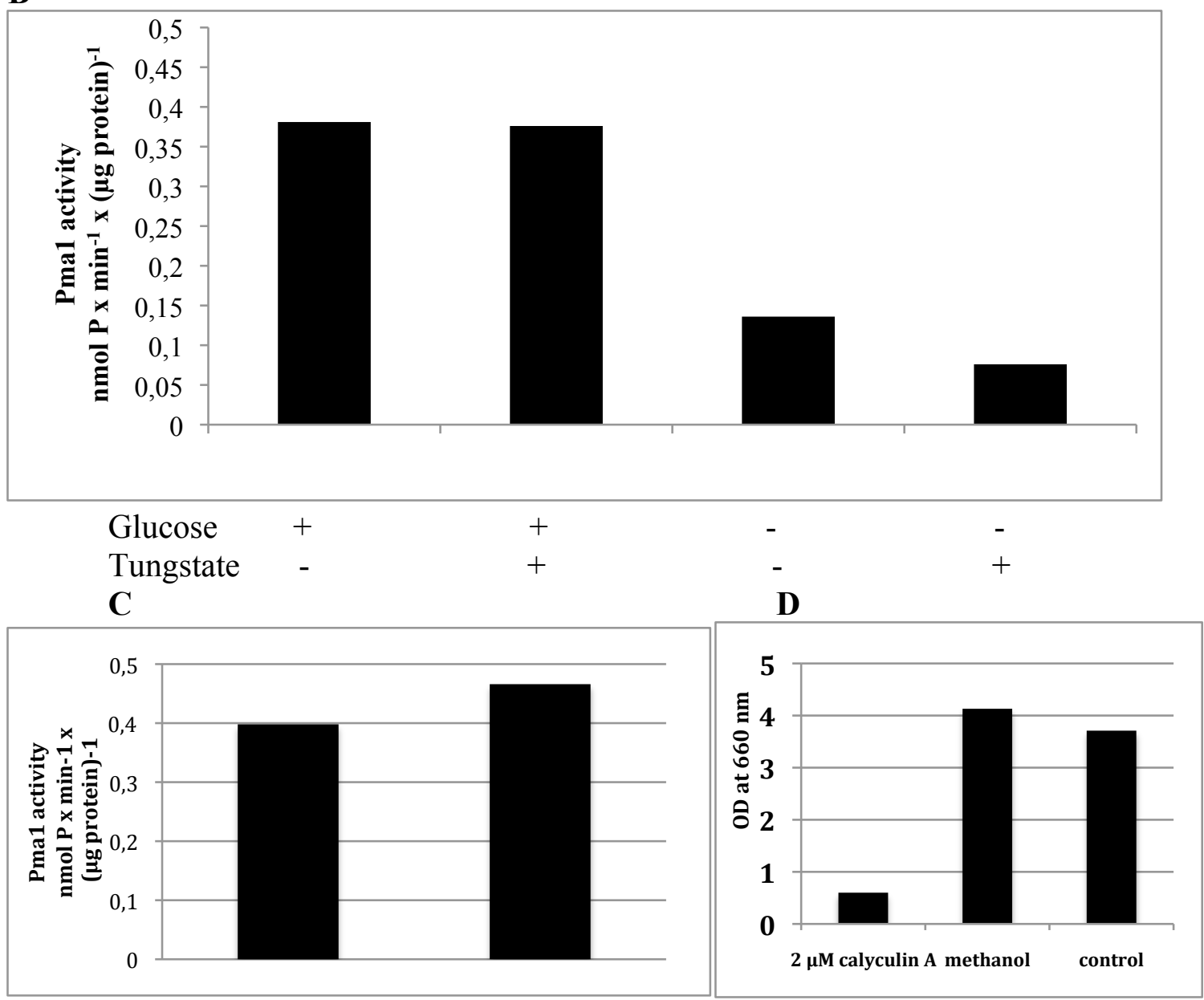

Calyculin A

$+$

Figure 24. Specific activity of Pma1 in the total membrane fraction from cells treated or not with okadaic acid (A), tungstate (B) or calyculin A (C) and growth inhibition by calyculin A (D).

S. cerevisiae strain RS-58 was grown to first stationary phase and harvested, washed and resuspended with water and incubated for 15 minutes with glucose and okadaic acid $(0.5 \mu \mathrm{M})$ or tungstate $(10 \mathrm{mM})$ or calyculin $\mathrm{A}(2 \mu \mathrm{M})$ as indicated. After isolation of total membranes, Pma1 specific activity was assayed as described in Materials and Methods. 


\section{Expression of a dominant-negative form of $G L C 7$ does not affect Pma1 activity}

Another strategy to inhibit Glc7 "in vivo" is to express a truncated gene, GLC7', encoding the first 208 amino acids of Glc7 (312 in total) and which has a dominantnegative effect by inhibiting wild type Glc7 (Wek et al., 1992; Rodriguez-Hernandez et al., 2012). We have utilized several constructions made by G. Hueso in our laboratory with another truncated form encoding the first 183 amino acids of Glc7 (YEp24-GLC7'; Hueso et al., 2012). In addition we have made a novel construction with the original deletion of Wek et al. (1992) encoding the first 208 amino acids (YEp352-GLC7' and pUN50$\left.G L C 7^{\prime}\right)$.

In the first place we tested $G L C 7$ ' expressed from its own promoter in single copy (centromeric) and in multicopy $(2 \mu)$ plasmids and there was no change in Pma1 activity in cells with glucose metabolism either in isolated membranes (ATP hydrolysis, Figure 25) or in whole cells (proton extrusion, Figure 26). Under these conditions it has been observed increased phosphorylation of a "bona-fide" substrate of Glc7, the translation initiation factor eIF $2 \alpha$ encoded by the SUI 2 gene in a partially defective mutant of GCN2, encoding the involved kinase (Wek et al., 1992; Rodriguez-Hernandez et al., 2012). 
$\mathbf{A}$

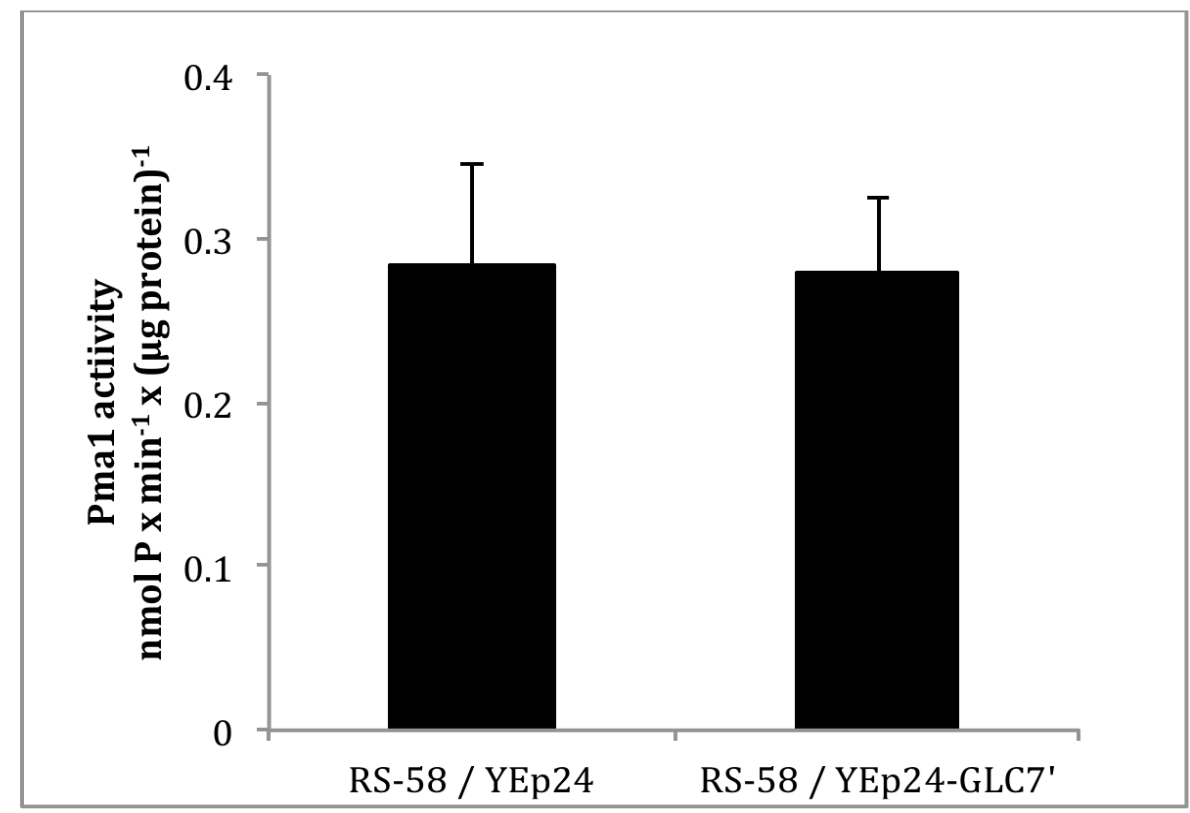

B

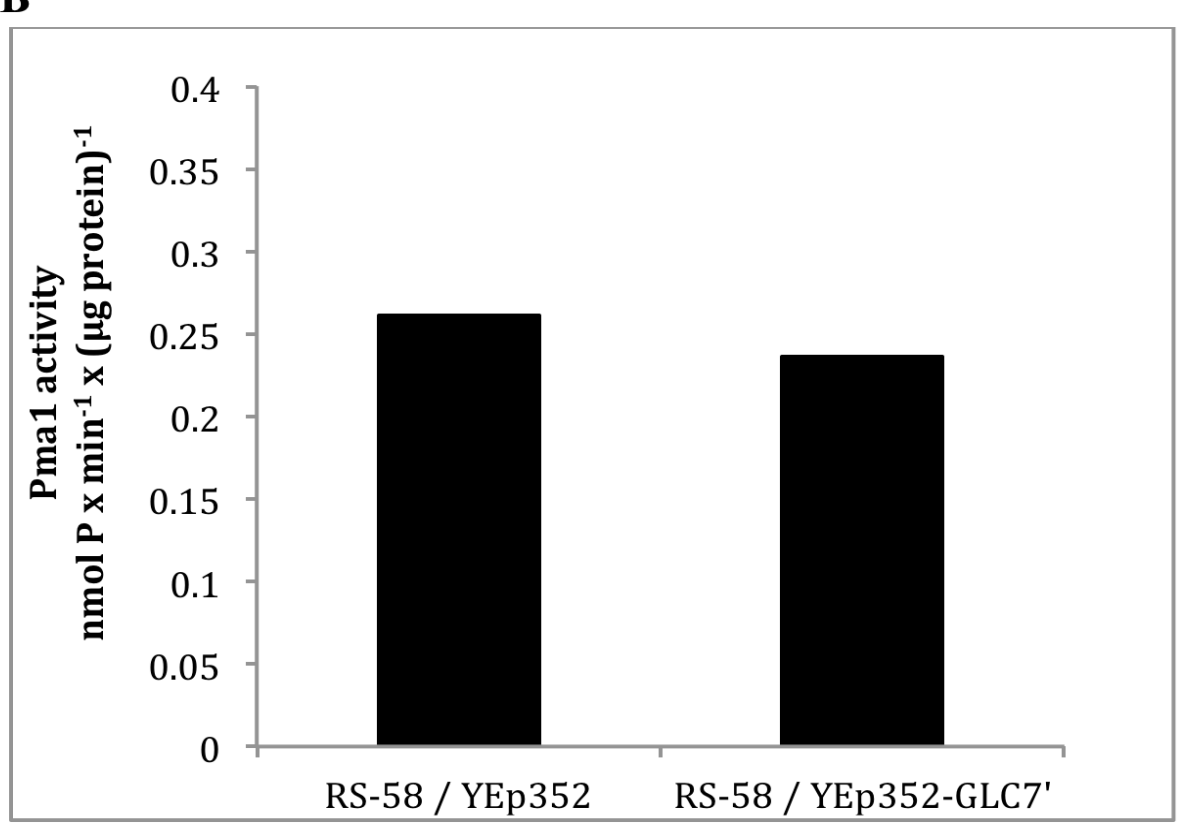

\section{Figure 25. "In vitro" Pma1 activity of yeast transformed with GLC7'}

S. cerevisiae (A) Strain RS-58 transformed with YEp24-GLC7' compared to its control RS-58 transformed with YEp24. (B) Strain RS-58 transformed with YEp352-GLC7' compared to its control RS-58 transformed with YEp352. Cultures were first grown in SD medium supplemented with leucine, histidine and adenine. Stationary phase cultures were used as inoculums in SD broth till reaching late exponential phase then cells were harvested and resuspended with $\mathrm{H}_{2} \mathrm{O}$ and processed as indicated in Materials and Methods to determine Pmal specific activity. The experiment (A) was repeated three times and error bars correspond to standard error. Experiment (B) was repeated twice with similar results and data presented are corresponding to a typical experiment. 


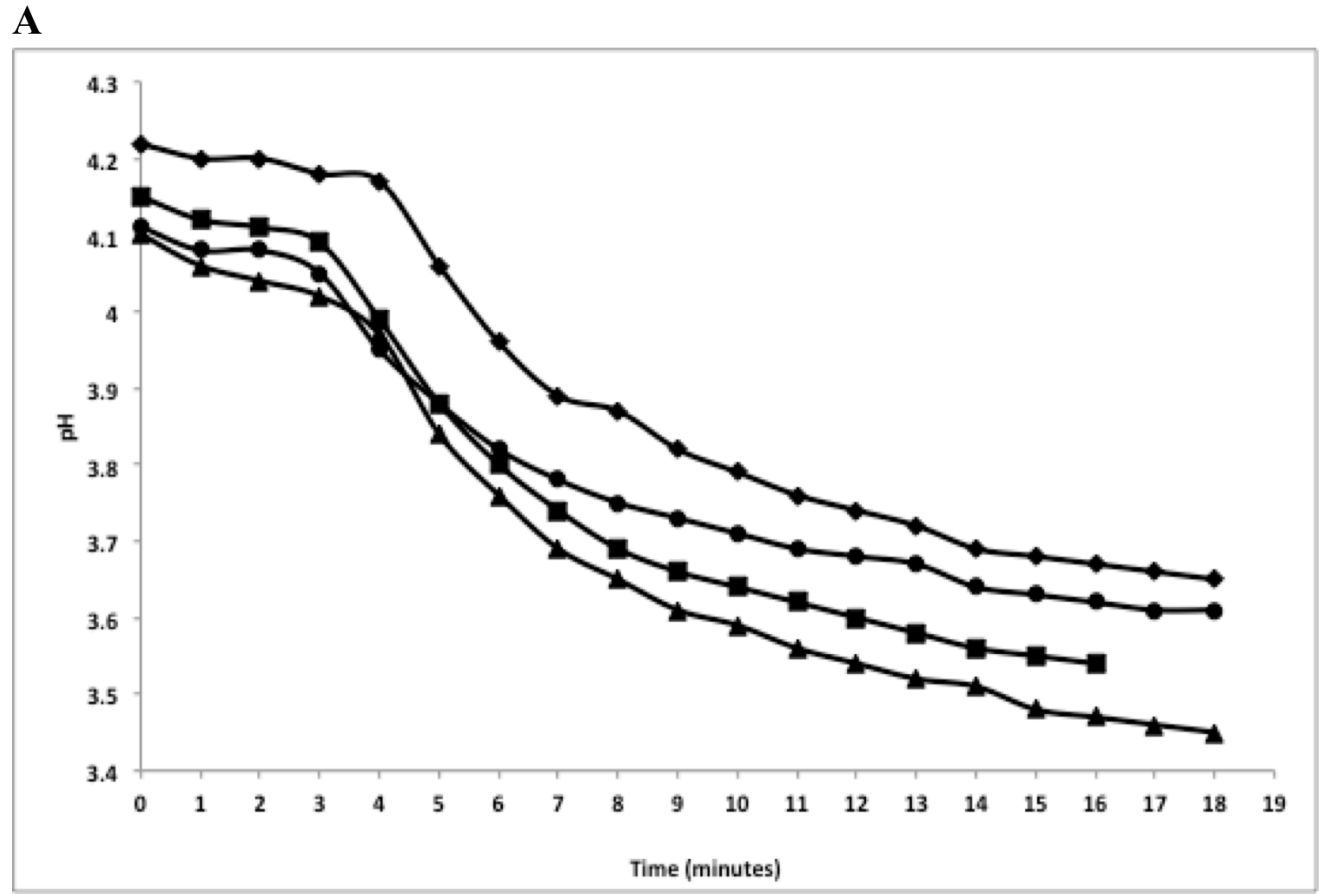

B

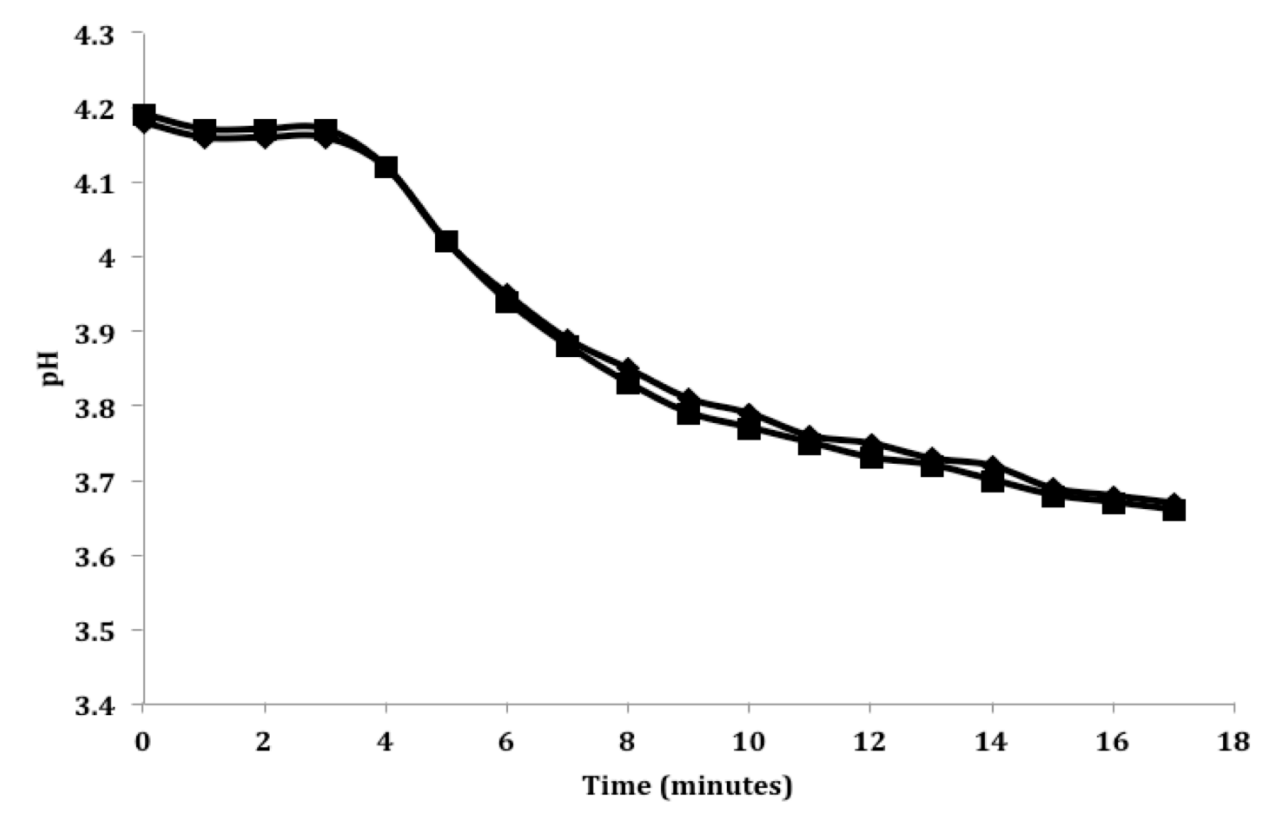

Figure 26. pH changes of yeast suspension induced by glucose

S. cerevisiae (A) Strain RS-58 / YEp24-GLC7’ (•) compared to its control RS-58 / YEp24 (•) and strain RS-58 / YEp352-GLC7' (অ) compared to its control RS-58 / YEp352 (-)). (B) Strain RS132 / pUN50-GLC7' (ם) in comparison to its control RS-132 / pUN50 ( ). Specific mg of each strain was suspended in $2 \mathrm{ml}$ of $(100 \mathrm{mM} \mathrm{KCl}$ and $10 \mathrm{mM}$ glycylglycine adjusted to $\mathrm{pH} 4$ with $\mathrm{HCl})$ and the $\mathrm{pH}$ was recorded as described in Materials and Methods. At the times indicated in materials and method glucose $(50 \mu \mathrm{mol})$ and calibration pulses of $100 \mathrm{nmol} \mathrm{HCl}$ were added. The maximal rate of proton pumping was (A) RS-58 / YEp24=24.5, RS-58 / YEp24-GLC7 $=23.8$, RS-58 / YEp352 = 23.8, RS-58 / YEp352-GLC7' $=22.7$ (B) RS-132 / pUN50= 8.1, RS-132 / pUN50-GLC7' $=8.07 \mathrm{nmol} \times \mathrm{min}^{-1} \times \mathrm{mg}$ yeast $^{-1}$. The experiments were made once. 


\section{Expression of $G L C 7$ ' under control of a doxycycline-regulated promoter}

It has been described in yeast that when genes expressed from multicopy plasmid are deleterious for yeast growth the copy number of the plasmid is greatly reduced (Eraso et al., 1987). As Glc7 activity is essential for yeast growth, too much inhibition by GLC7' in multicopy plasmid may have selected cells with low copy number and small inhibition. Accordingly we have utilized a system where the expression of $G L C 7$ ' is under control of a doxycycline-regulated promoter (Ariño and Herrero, 2003).

As indicated in Figures 27, 28 and 29, when the expression of $G L C 7^{\prime}$ is induced by removal of doxycycline the yeast growth is inhibited with two different constructs (with and without HA3-His6 at the C-terminus), suggesting that Glc7 is inhibited by the truncated protein acting as a dominant-negative of an essential enzyme. We used different concentrations of doxycycline as shown in the Figures (27 and 28) in order to determine the best concentration to be used to permit the cells to grow by inhibiting the gene expression and also avoiding toxic effects. The concentration selected was $2 \mu \mathrm{g} / \mathrm{ml}$ and it was used in the following experiments.

Then we checked if Pmal activity is affected by expression of GLC7' and, as indicated in Figure 30, no change in Pmal activity was observed with the two different constructs inhibiting yeast growth.

When the results showed such a lack of effect of Glc7' on Pmal activity, there was a slight doubt that maybe GLC7' was not expressed under the experimental conditions. So in order to confirm expression of Glc7' we carried out a semiquantitative RT-PCR from strain BY4741 transformed with PCM262-GLC7' before and after doxycycline removal. As indicated in the Figure 31 the gene did get expressed after 1.5 hours incubation of the cells in absence of doxycycline. These data are in agreement with our previous conclusion that Glc7 protein phosphatase is minorly involved or it is not the only phosphatase involved in regulation of Pmal activity. 
A

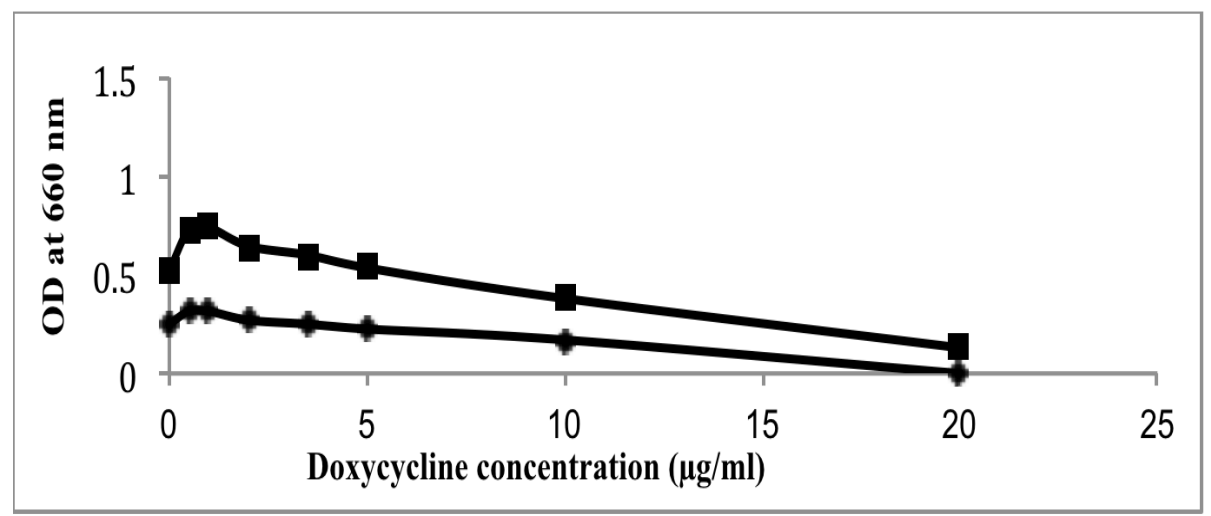

B

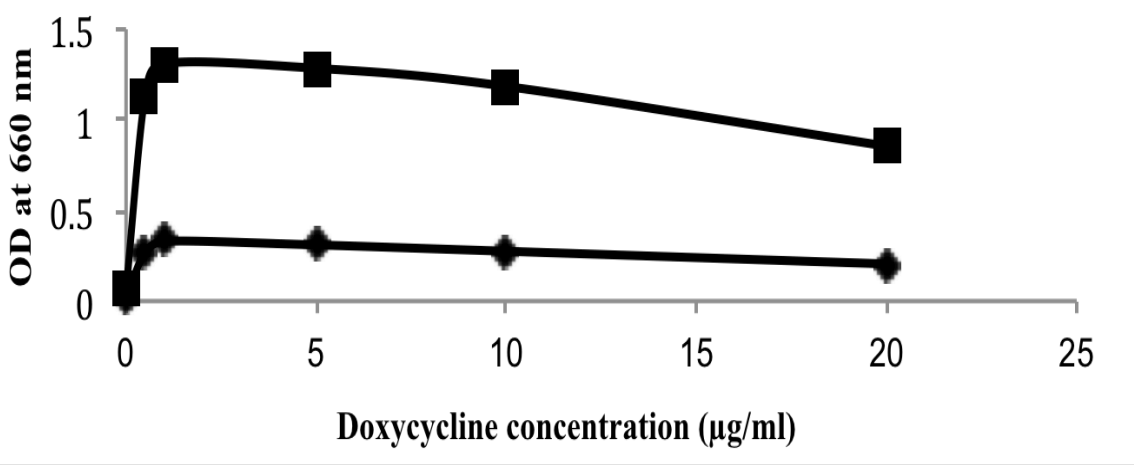

C

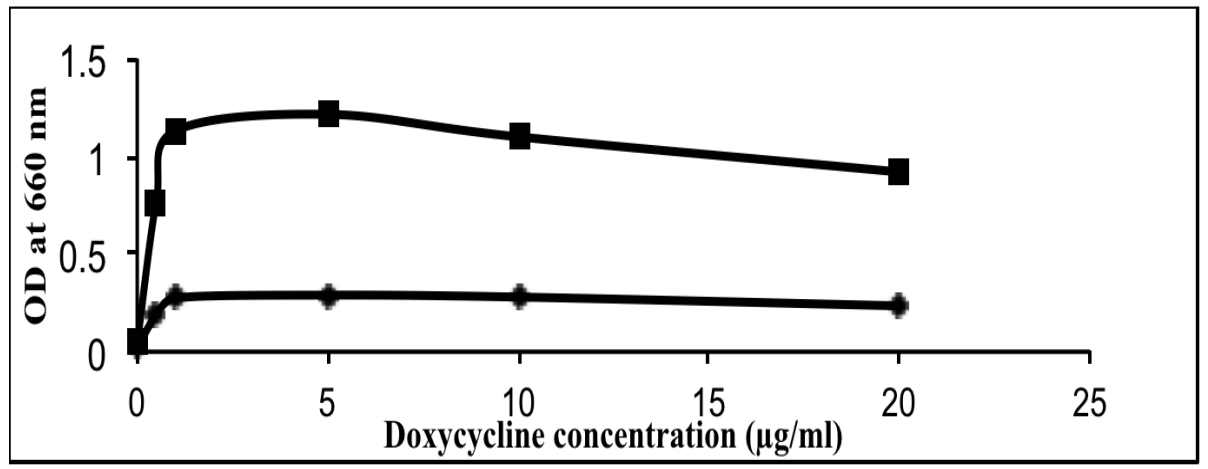

Figure 27. Effect of different doxycycline concentrations $(0-20 \mu \mathrm{g} / \mathrm{ml})$ on growth of $S$. cerevisiae strains derived from BY4741 by transformation with different plasmids. (A) strain RS-119 (transformed with PCM262) (B) strain RS-120 ( transformed with PCM262-GLC7'-HA3-His6) (C) strain RS-121(transformed with PCM262- GLC7').

S. cerevisiae cells were grown in SD medium supplemented with leucine, histidine, methionine and doxycycline $10 \mu \mathrm{g} / \mathrm{ml}$. Stationary phase cultures were washed twice and resuspended with sterile distilled water and used as inoculums in fresh medium of the same complosition with different doxycycline concentrations. Growth was then determined by measuring optical density (OD) after incubation at $30^{\circ} \mathrm{C}$ with shaking $200 \mathrm{rev} / \mathrm{min}$ for $18(\bullet)$ and $22(\bullet)$ hours. The experiment was repeated twice with similar results and data presented are corresponding to a typical experiment. 
A

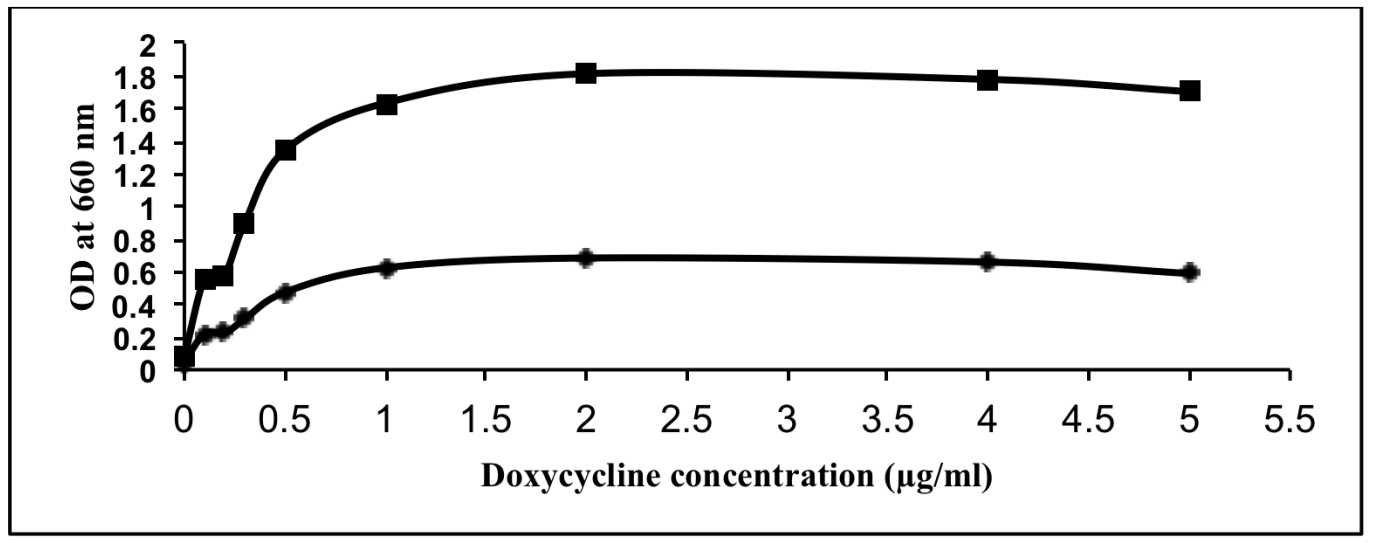

B

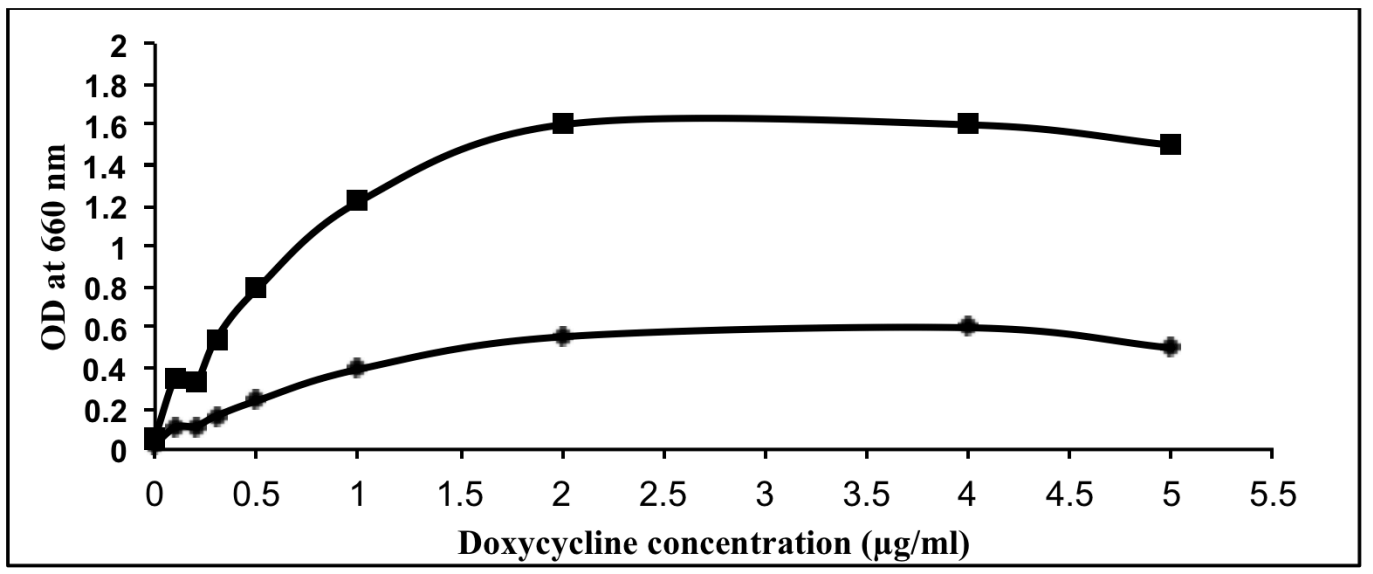

Figure 28. Effect of different doxycycline concentrations $(0-5 \mu \mathrm{g} / \mathrm{ml})$ on growth of $S$. cerevisiae strains derived from BY4741 by transformation with different plasmids. (A) strain RS-120 (transformed with PCM262-GLC7'-HA3-His6) (B) strain RS-121 (transformed with PCM262- GLC7').

Conditions and symbols as in Figure 27 but with lower range of doxycycline concentrations. The experiment was made once.

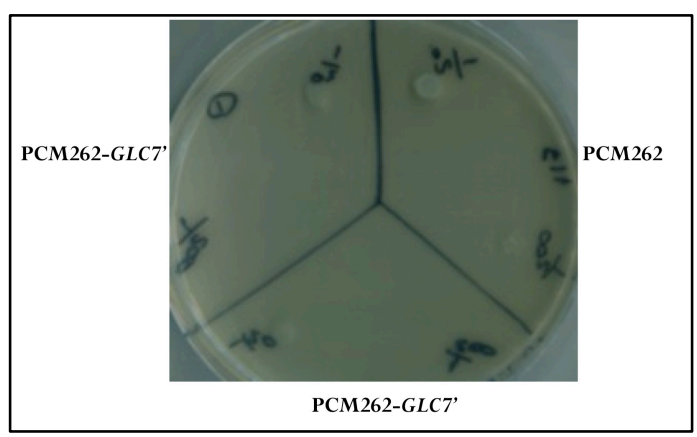

Figure 29. Inhibition of growth of cells expressing $G L C 7$ ' on solid medium in absence of doxycycline.

S. cerevisiae strain RS-119 (strain BY4741 transformed with PCM262) and strain RS-121 (strain BY4741 transformed with PCM262-GLC7') were grown in SD medium supplemented with leucine, histidine, methionine and doxycycline $(2 \mu \mathrm{g} / \mathrm{ml})$ till stationary phase, harvested, washed and resuspended with sterile distilled water same volume. Two dilutions $(1 / 20$ and $1 / 200)$ were made and $3 \mu \mathrm{L}$ of each dilution were spotted on a plate of the same medium. The experiment was repeated twice with similar results. 


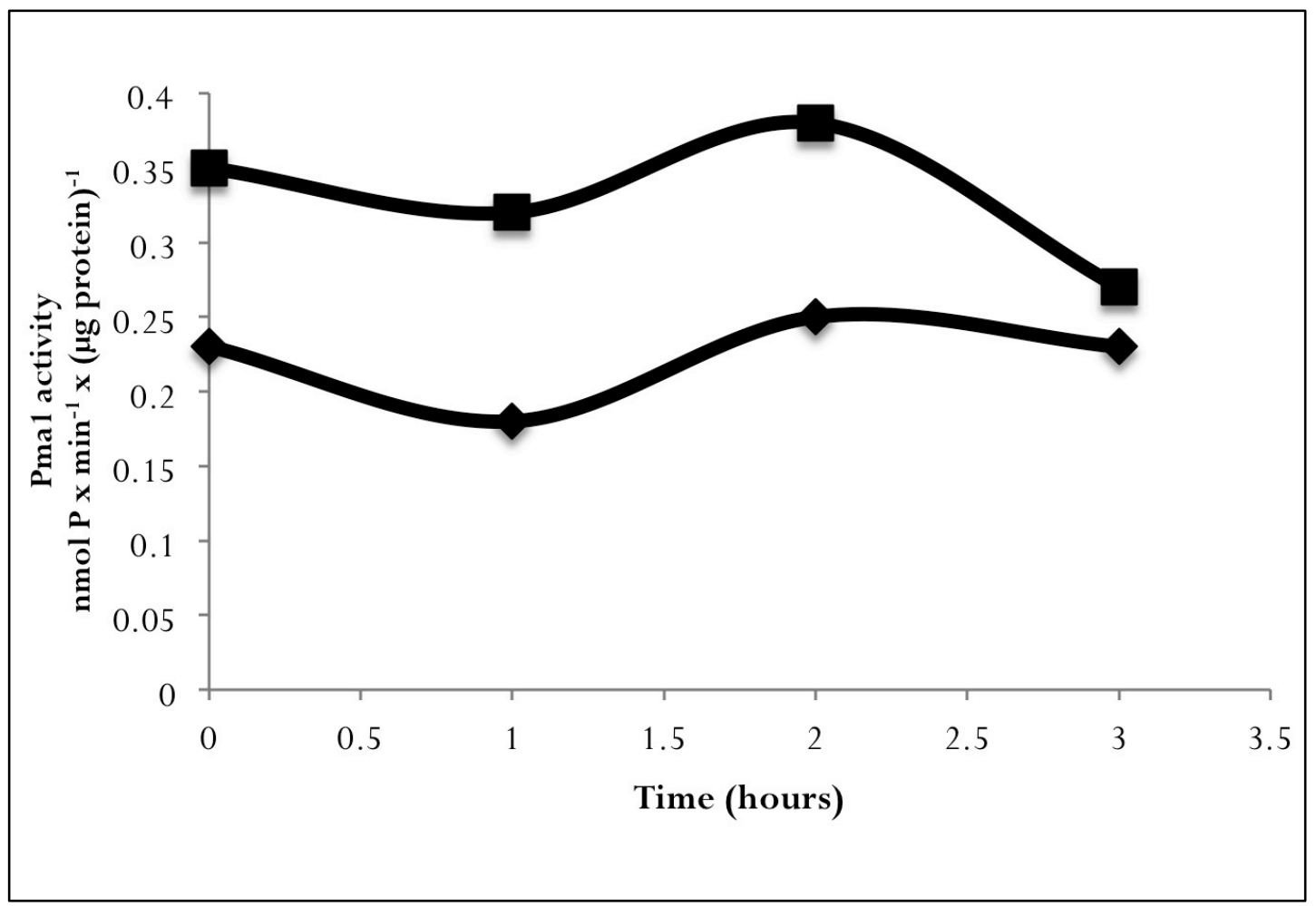

Figure 30. Lack of effect of doxycycline removal on Pma1 activity of strains RS-120 (strain BY4741 transformed with PCM262-GLC7'-HA3-His6) and RS-121 (strain BY4741 transformed with PCM262- GLC7').

S. cerevisiae cultures were first grown in SD medium supplemented with leucine, histidine, methionine and doxycycline $(2 \mu \mathrm{g} / \mathrm{ml})$. Stationary phase cultures of strains RS-120 (汭) and RS121(•) were used as inoculums in SD fresh broth with the same composition till reaching exponential phase then cells were harvested, washed and resuspended with the same medium without doxycycline. At indicated times, samples were processed as indicated in Materials and Methods to determine Pmal specific activity. The experiment with strain RS-120 was repeated twice, and with strain RS-121 for 5 times and measured once in galactose medium and the repetitions gave similar results and data presented are corresponding to a typical experiment. 
A

Doxycycline +

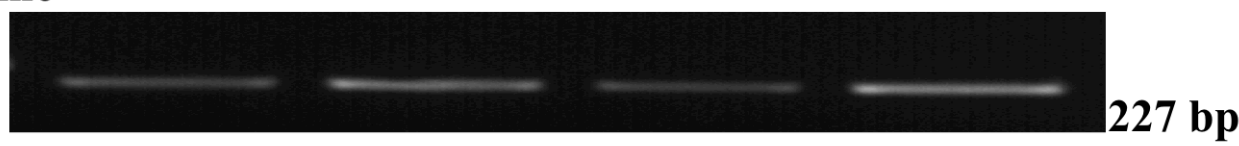

$\begin{array}{lllll}\text { Time (hour) } & 1.5 & 1.5 & 2 & 2\end{array}$

B
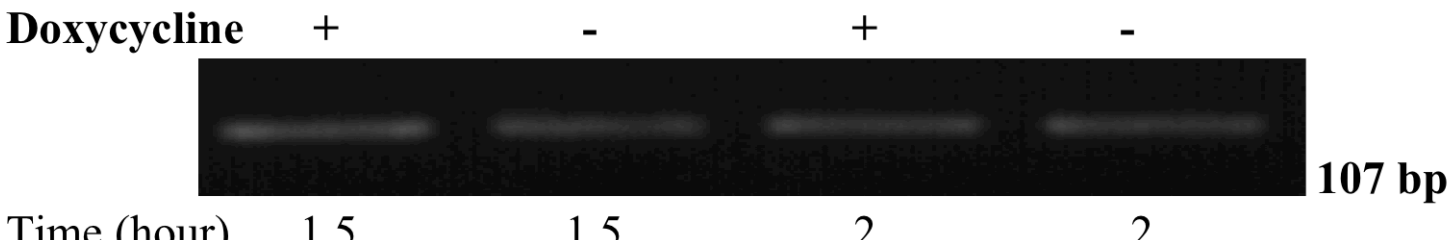

$\begin{array}{lllll}\text { Time (hour) } & 1.5 & 1.5 & 2 & 2\end{array}$

C

Yeast cDNA

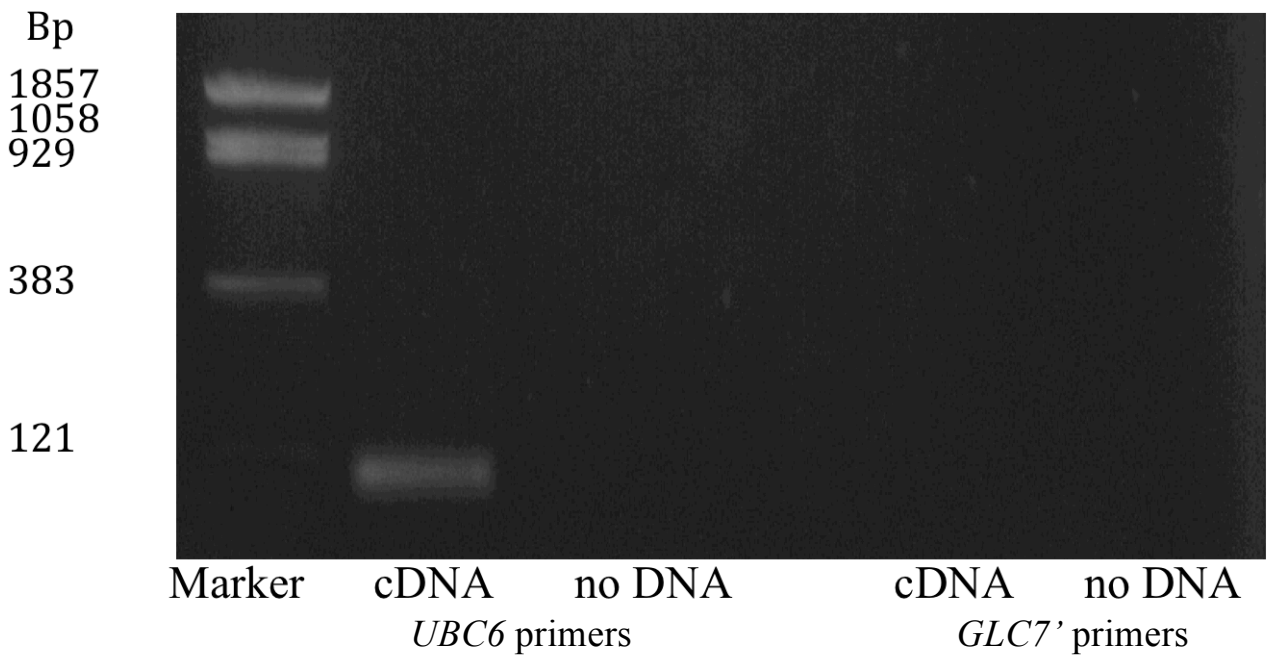

Figure 31. Semi quantitative RT-PCR analysis of expression of $G L C 7^{\prime}$ in RS-121 (strain BY4741 transformed with PCM262-GLC7') before and after removal of doxycycline.

(A) Semi quantitative RT-PCR with GLC7' primers of samples taken after 1.5 and 2 hours incubation of exponential phase cultures in presence $(+)$ or in absence $(-)$ of doxycycline $(2 \mu \mathrm{g} / \mathrm{ml})$. The amplified GLC7' fragment has 227 bp. (B) Control experiment using UBC6 primers on all the samples to check that the expression of genes other than $G L C 7$ ' is not affected. (C) Control experiment, GLC7' primers are specific because no product is amplified in a sample from yeast not transformed with a $G L C 7^{\prime}$ ' plasmid. One of the primers corresponds to a flanking sequence of the plasmid. On the other hand UBC6 primers result in amplification. The used marker is pBR322$B s t$ NI. The experiment was made once. 


\section{Expression of a dominant-negative form of $G L C 7$ does not affect dephosphorylation} of Pma1 after removal of glucose

One further strategy to investigate if protein phosphatase Glc7 participates in the regulation of Pmal has been to determine if inhibition of Glc 7 by expression of a truncated dominant-negative form of the enzyme affects the dephosphorylation of the regulatory domain of Pma1 after removal of glucose from the yeast medium. If Glc7 dephosphorylates this regulatory domain its inhibition should result in slower dephosphorylation after removal of glucose from the medium.

Recently, the group of Francisco Portillo at Madrid has developed specific antibodies against the two phosphorylated sites in the regulatory domain of Pmal modified by glucose metabolism (Mazón et al., 2015). Antibody $\alpha$-pS899 specifically recognizes phosphorylated Ser899, which slightly contributes to Pmal activation by increasing the affinity of the enzyme for ATP. Antibody $\alpha$-pST specifically recognizes the double phosphorylation on Ser911 and Thr912 that is the major regulatory event by increasing the maximal activity of the enzyme. By using these two antibodies we could show that expression of the dominant-negative form of Glc7 has no effect on the rate of dephosphorylation of Pmal after removal of glucose from the medium of the cells (Figure 32). In the same figure it is clear that the phosphorylation level of Pmal increases after glucose addition for 10 minutes and also shows the decreased phosphorylation on glucose removal. 


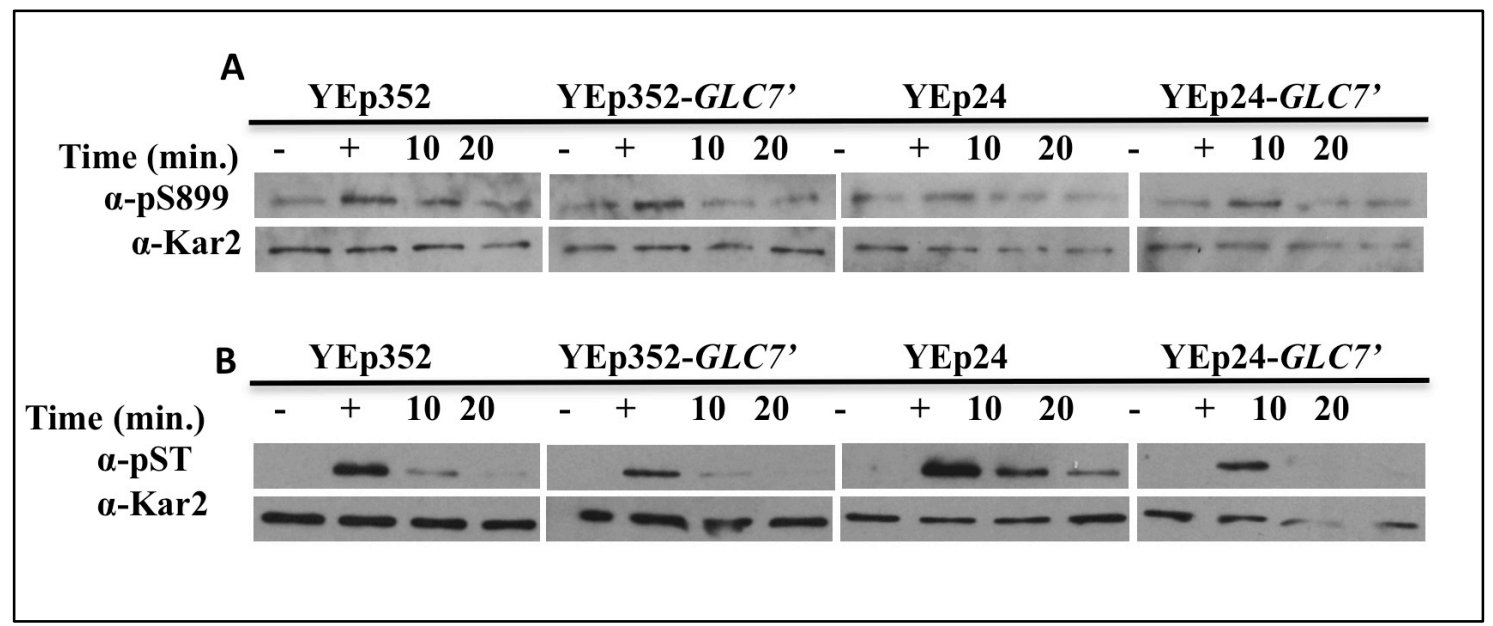

Figure 32. Effect of $G L C 7$ ' on the "in vivo" dephosphorylation rate of Pma1 phosphorylation site Ser899 (A) and Ser 911 Thr 912(B)

S. cerevisiae strain RS-132 transformed with YEp352-GLC7' compared to its control RS-132 transformed with YEp352, also RS-132 transformed with YEp24-GLC7' compared to its control (RS-132 transformed with YEp24). Late exponential phase cultures were harvested, washed and resuspended with sterile distilled water and incubated for 15 minutes (-), then incubated with glucose for 10 minutes $(+)$, glucose was removed by centrifugation then cells were incubated in water for 10 and 20 minutes as indicated. The levels of phosphorylated serine 899 (pS899) (A) and double phosphorylation at serine 911 and threonine 912 (pST) (B) were determined by western blotting as described in Materials and Methods. $\alpha$-Kar2 was used as control of loading. The bands recognized by the antibodies represent Pma1 of $100 \mathrm{KD}$ and Kar2 of $75 \mathrm{KD}$. The experiment was repeated twice with similar results.

\section{Phenotype of $G L C 7$ ' transformants with hygromycin B and acetic acid}

Any activation of Pmal by increased phosphorylation of the regulatory sites should manifest by increased tolerance to acetic acid and decreased tolerance to toxic cations such as hygromycin B (Hueso et al., 2012). Yeast cells with a more active Pmal should maintain a more neutral intracellular $\mathrm{pH}$ after treatment with acetic acid because of increased capability for proton extrusion. Also, these cells should have a hyperpolarized membrane potential and therefore a decreased tolerance to toxic cations such as hygromycin B whose uptake is driven by membrane potential (Perlin et al., 1989; Goossens et al., 2000). As indicated in Figure 33 GLC7' expressing cells have a slightly less tolerance to hygromycin but this phenotype is not very significant. On the other hand no phenotype of tolerance to acetic acid could be observed (Figure 34). Therefore again we conclude that Glc7 is minorly involved (or it is not the only phosphatase involved) in regulation of Pmal activity. 


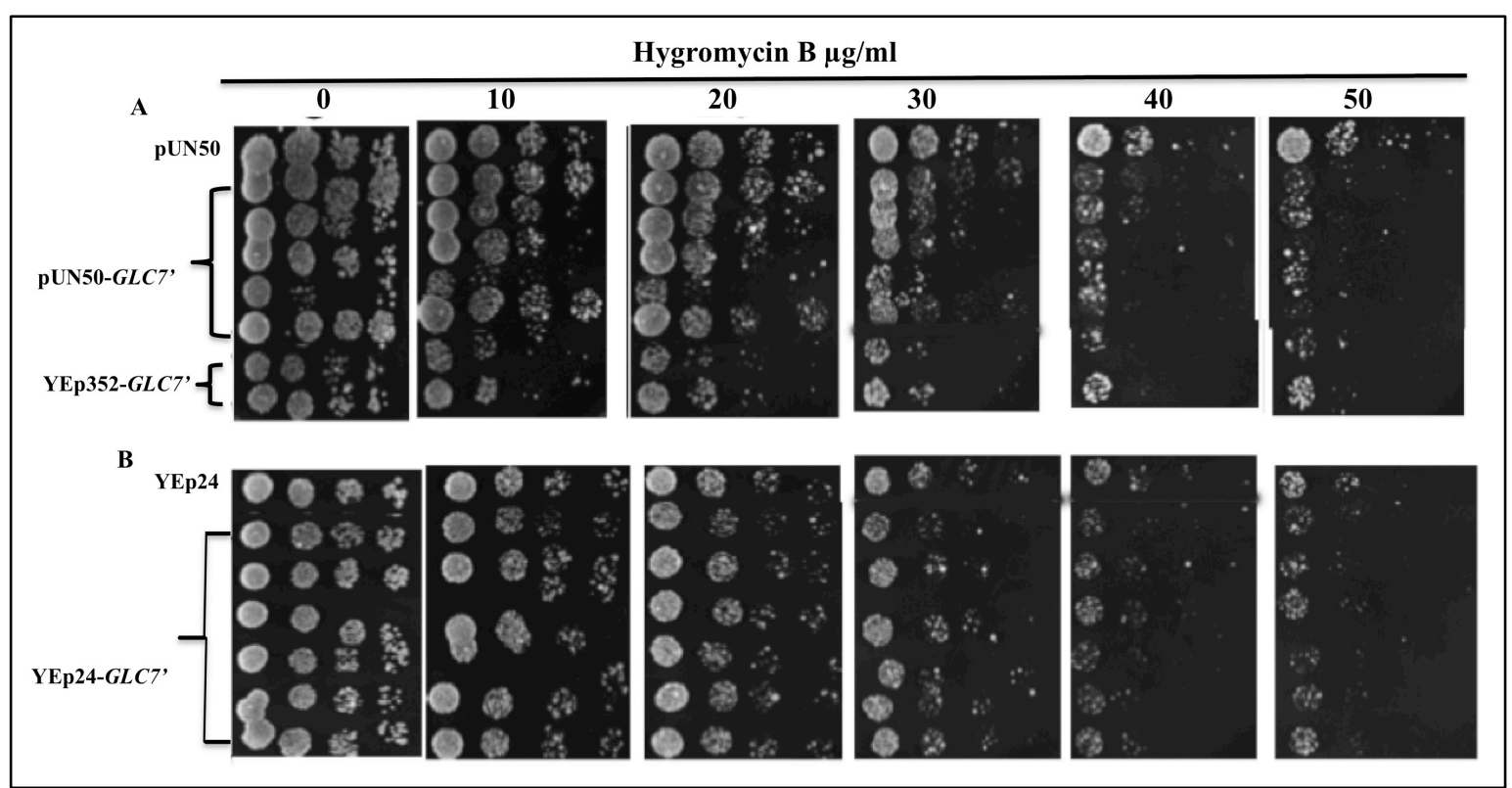

Figure 33. Effect of GLC7' on hygromycin B resistance.

S. cerevisiae (A) Strain RS-132 transformed with pUN50, pUN50-GLC7', YEp352-GLC7'. (B) Strain RS-132 transformed with YEp24, YEp24-GLC7'. Serial dilutions of stationary phase cultures of these strains prepared in SD, were incubated on YPD media for $2-3$ days at $30^{\circ} \mathrm{C}$. The experiment was made once with 5 different colonies of RS-132 / pUN50-GLC7' and 6 different colonies of RS-132 / YEp24-GLC7' and 2 colonies of RS-132 / YEp352-GLC7'.

\begin{tabular}{|c|c|c|c|c|c|c|c|c|c|c|}
\hline & & & Acetic acid (mM) & & & & & & & \\
\hline & 0 & 10 & 20 & & & & & & & \\
\hline pUN50 & $00 \div$ & $00 \% \because$ & 00 : & 0 & 0 & s & & & 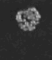 & 8 \\
\hline pUN50-GLC7' & $00 \div:$ & 00 年: & 00 : & 0 & 0 & $\Rightarrow$ & - & & 9 & 2 \\
\hline YEp352 & $00 \%$ & $00 *$ & 002 & 0 & 0 & 3 & st & c & 综 & $\therefore$ \\
\hline YEp352-GLC7' & 00 แั & $00 * 2$ & 00 눌 & & 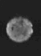 & 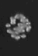 & & & b & $\therefore$ \\
\hline
\end{tabular}

Figure 34. Effect of $G L C 7^{\prime}$ on acetic acid resistance.

S. cerevisiae strain RS-132 transformed with pUN50, pUN50-GLC7', YEp352, YEp352-GLC7'. Serial dilutions of stationary phase cultures of these strains prepared in SD, were incubated on YPD media of $\mathrm{pH} 3.5$, for $2-3$ days at $30^{\circ} \mathrm{C}$. The experiment was repeated twice with similar results.

\section{Mutants in GLC7 exhibit altered ion homeostasis}

Another approach to investigate the role of Glc7 in Pmal activity has been to determine this activity in mutants of the GLC7 gene previously identified in the laboratory of Kelly Tatchell (Baker et al., 1997; Williams et al., 2002). Protein phosphatases exhibit little substrate specificity "in vitro" while the specificity "in vivo" is dictated by regulatory subunits that target the phosphatase catalytic subunit to its phosphorylated protein substrate 
(Cohen, 1989; Stark, 2004). One of the functions of Glc7 is to promote glycogen synthesis by dephosphorylating and activating glycogen synthase 2 (Gsy2) as cells approach stationary phase. The glc7-1 mutant is defective in interacting with the required regulatory subunit for this function, Gac1, and accumulates little glycogen (Stark, 2004). The glc7109 and glc7-132 mutants were isolated by directed mutagenesis of clusters of charged residues that could mediate interactions with regulatory subunits (Baker et al., 1997). The glc7-109 mutant exhibits increased glycogen accumulation while the glc7-132 mutant resembled the glc7-1 mutant in accumulating less glycogen. Interestingly, the glc7-109 mutant, but not the other two, is more sensitive to toxic cations such as $\mathrm{Na}^{+}, \mathrm{Li}^{+}$and hygromycin B and has a greater membrane potential (Williams-Hart et al., 2002). The activity of Pma1, however, was not affected.

We have reinvestigated the sensitivity of these mutants to acetic acid and toxic cations (Figure 35). The results indicate that $g l c 7-1$ and $g l c 7-132$ are more tolerant than wild type to acetic acid, glc7-109 is more sensitive than wild type to acetic acid and the three mutants are more sensitive than wild type to lithium and hygromycin $\mathrm{B}$. These phenotypes are difficult to explain in terms of changes of Pmal activity. Determinations "in vitro" and "in vivo" (Figure 36) indicate that the glc7-1 mutant exhibits a slight increase in Pmal activity with respect to wild type both "in vivo" and "in vitro" while the other two mutants had no change in the "in vitro" assay, while glc7-132 has increased rate of proton pumping from cells.

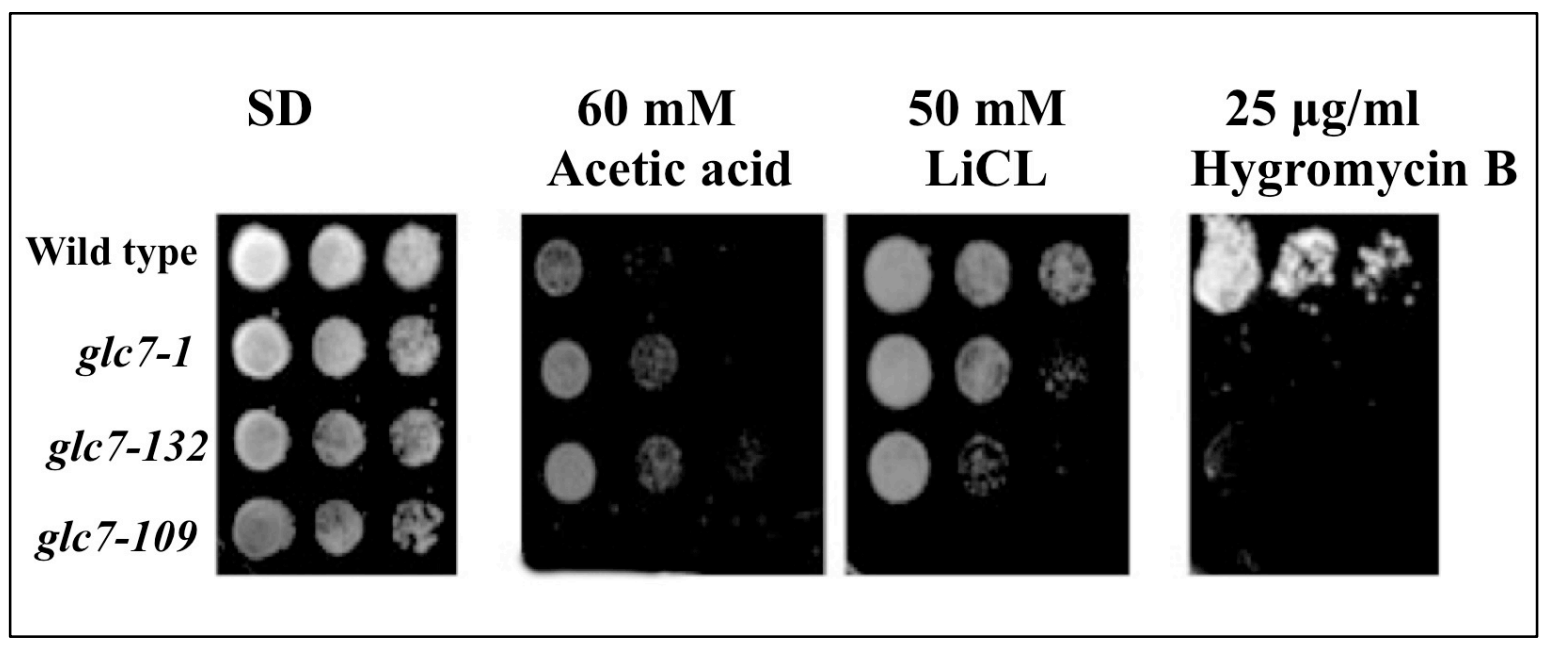

Figure 35. The growth phenotypes of 3 glc 7 mutants.

S. cerevisiae WT (strain KT1112) and mutants, glc7-1, glc7-132 and glc7-109 serial dilutions of stationary phase cultures were incubated on the indicated agar medium for $2-3$ days at $30^{\circ} \mathrm{C}$. The experiment was repeated twice with similar results. 
A

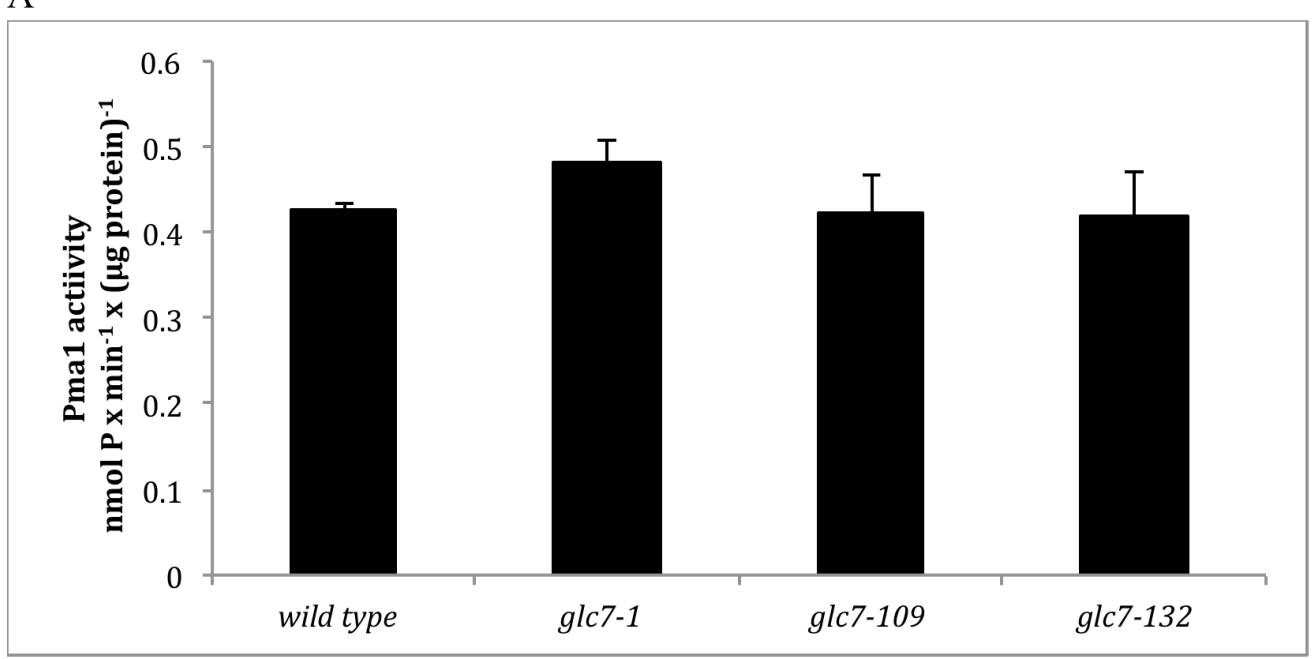

B

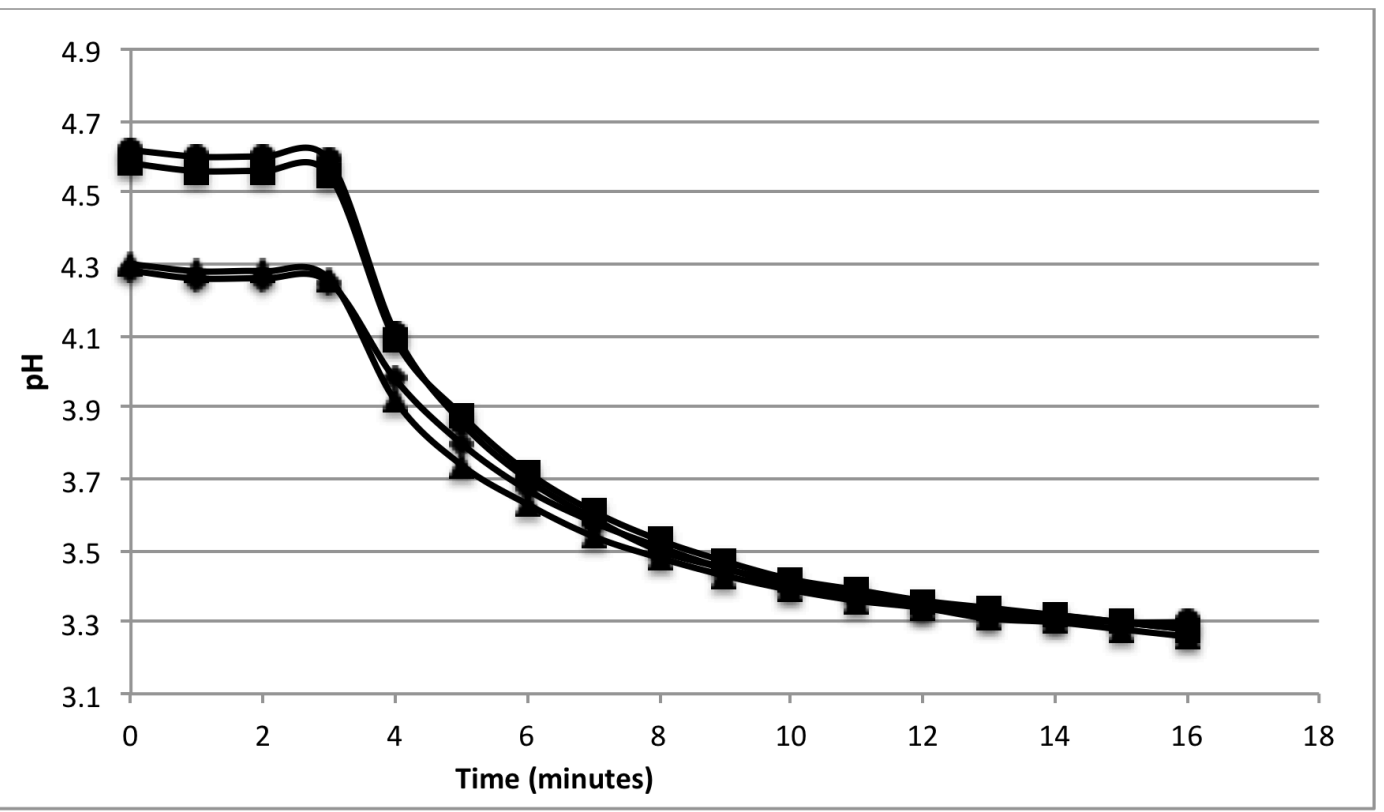

Figure 36. Pma1 specific activity of 3 GLC7 mutants. (A) "In vitro" activity (B) pH changes of yeast suspension induced by glucose.

(A) S. cerevisiae stationary phase cultures were used as inoculums in YPD broth till reaching stationary phase and then cells were harvested and resuspended with $\mathrm{H}_{2} \mathrm{O}$ then processed as indicated in Materials and Methods to determine Pmal specific activity. (B) Wild type (strain $\mathrm{KT1112})(\bullet), g l c 7-1(\boldsymbol{\square}), g l c 7-109(\boldsymbol{\Delta})$ and $g l c 7-132(\bullet)$ specific $\mathrm{mg}$ of each strain was resuspended in $2 \mathrm{ml}$ of $(100 \mathrm{mM} \mathrm{KCl}$ and $10 \mathrm{mM}$ glycylglycine adjusted to $\mathrm{pH} 4$ with $\mathrm{HCl})$ and the $\mathrm{pH}$ was recorded as described in Materials and Methods. At the times indicated in Materials and Methods, glucose $(50 \mu \mathrm{mol})$ and calibration pulses of $100 \mathrm{nmol} \mathrm{HCl}$ were added. The maximal rate of proton pumping was (A) wild type $=20.03, g l c 7-1=27.2, g l c 7-109=21.1, g l c 7-132=32.5 \mathrm{nmol}$ $\times \min ^{-1} \times \mathrm{mg}$ yeast ${ }^{-1}$. The experiment (A) was repeated three times and error bars correspond to standard error and experiment (B) was made once. 


\section{Effect of expression of a dominant-negative form of $G L C 7$ and of glucose metabolism on phosphorylation of eIF $2 \alpha$}

The translation factor eIF $2 \alpha$ is a known substrate of Glc7 and is phosphorylated by protein kinase Gen2 in response to amino acid starvation (Wek et al. 1992). We have tested the effect of glucose metabolism and of expression of the truncated dominantnegative form of Glc7 on the phosphorylation level of eIF2 $\alpha$. As indicated in Figures 37 and 38 , glucose metabolism greatly increases eIF $2 \alpha$ phosphorylation, as it also does in the case of Pmal phosphorylation at Ser911 Thr912 (Mazón et al., 2015). However, in a mutant with constitutive activity of Gen2 (Menacho-Marquez et al., 2007) eIF2 $\alpha$ phosphorylation was high in the absence and presence of glucose. GCN2 is not known to be activated by glucose metabolism and therefore it could be that glucose inhibits Glc 7 .

Figure 37 also shows the results of a comparison that we made between three different methods of protein extraction for SDS-PAGE. It was reported by Wright et al. (1989) that TCA method is the best and that it produces much higher protein amount. Our results indicated that the two other methods tested (Laemmli and alkaline lysis) produce almost equal amounts of protein like the tedious, more time consuming than TCA method that results in slightly more protein extraction. 


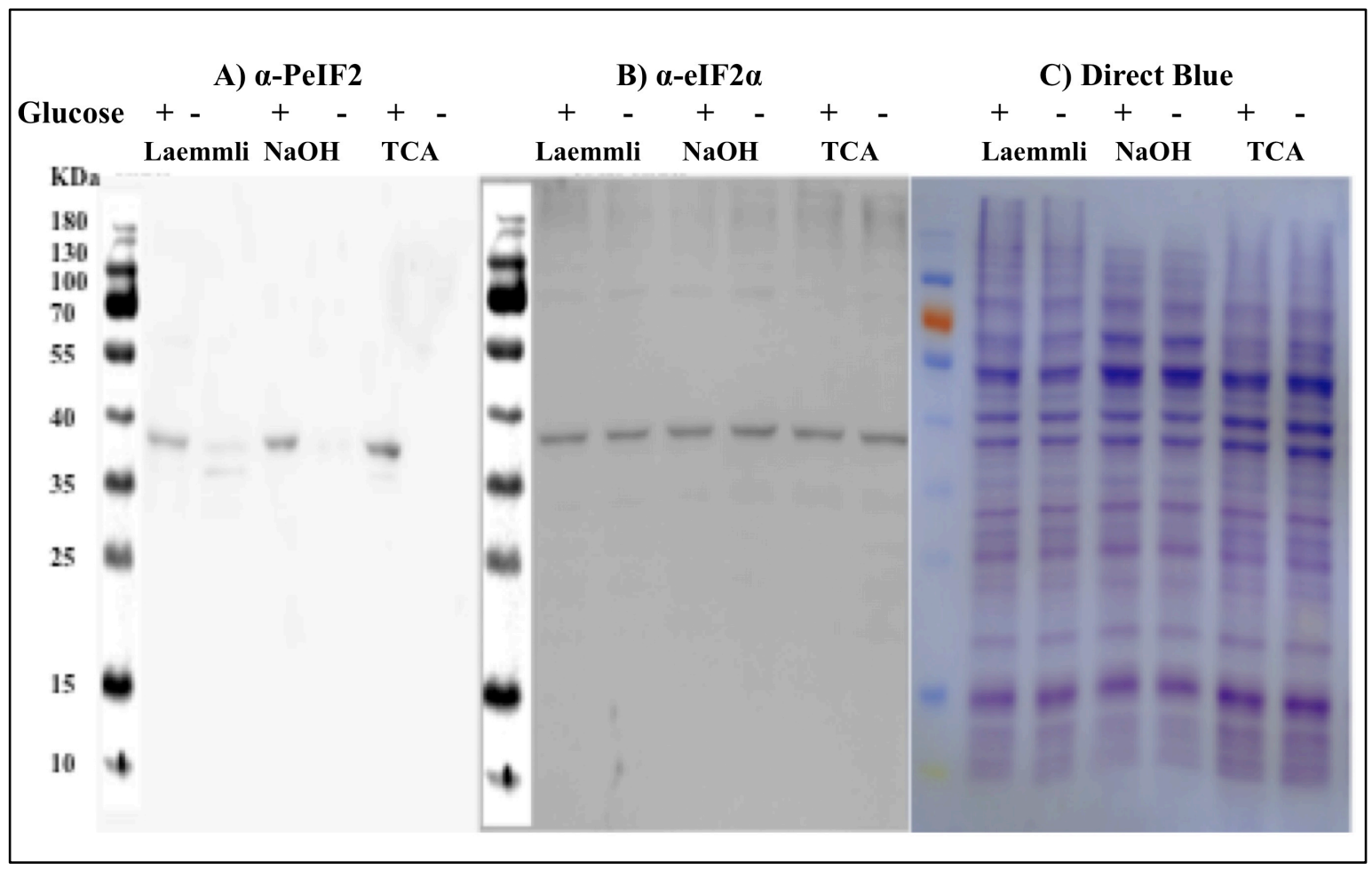

Figure 37. Comparison between three methods of protein extraction.

(A) Western blotting with antibodies against P-eIF2 $\alpha$ (B) Western blotting with antibodies against total eIF2 $\alpha(C)$ Direct blue stained membrane.

S. cerevisiae strain RS-259 stationary phase cultures were used as inoculums in YPD broth till reaching early exponential phase then cells were harvested, washed and resuspended with $\mathrm{H}_{2} \mathrm{O}$ then distributed into 6 samples, glucose was added to only 3 of them and incubated all for 10 minutes. Extraction was made by : harvesting the cells then boiling with hot Laemmli $1 \mathrm{X}$ for 10 minutes at $100^{\circ} \mathrm{C}$ or hot $\mathrm{NaOH}$ or precipitated by TCA as mentioned in details in Materials and Methods. Standard protein markers (PageRuler Prestained Protein Ladder, from Thermo Scientific), with masses indicated in $\mathrm{kDa}$. The experiment was repeated twice with similar results. 

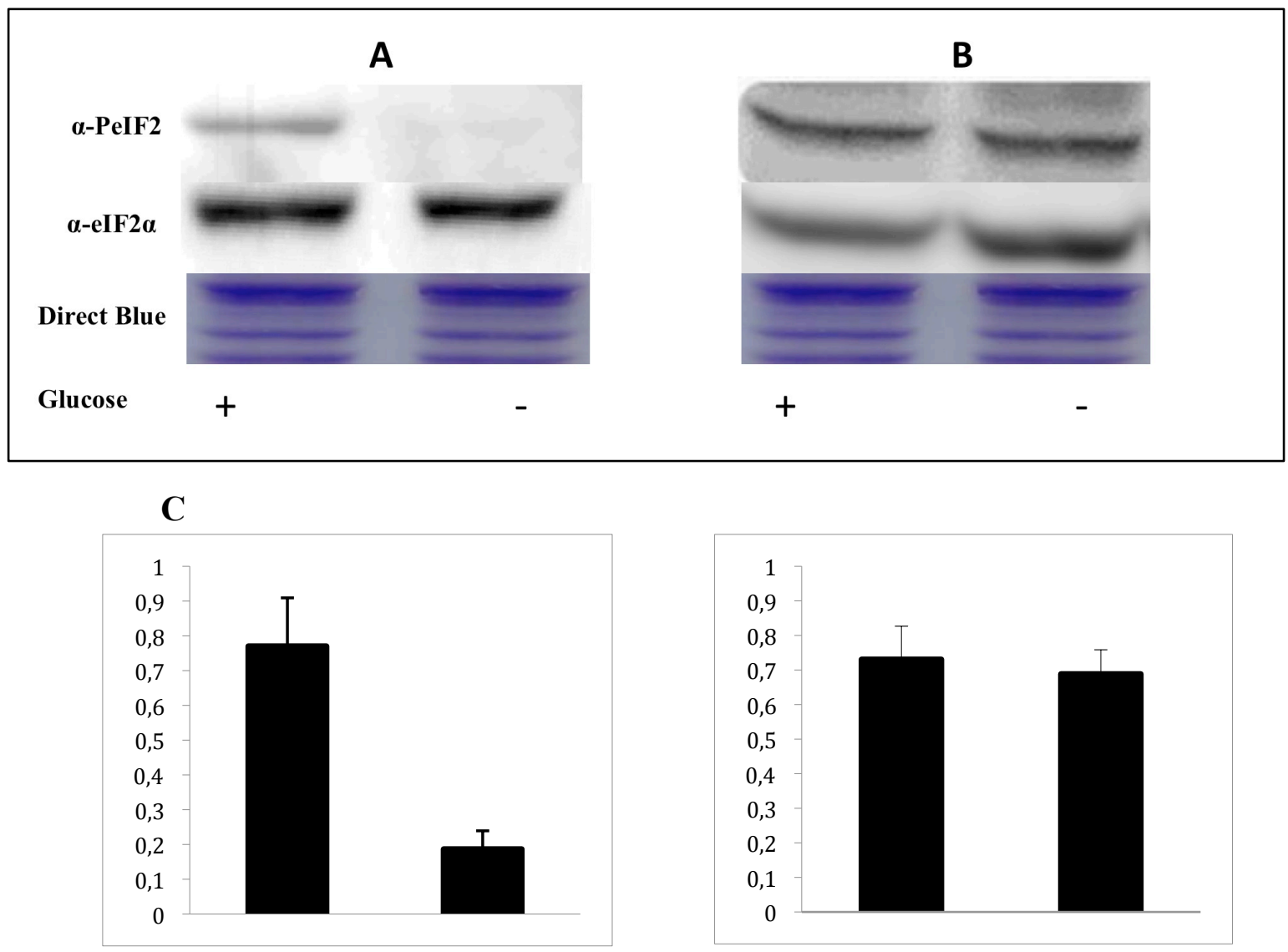

Figure 38. Glucose effect on phosphorylation level of eIF2 $\alpha$ in (A) wild type yeast (BY4741) and (B) $G C N 2^{\mathrm{c}}$ mutant

Western blotting with antibodies against PeIF2 $\alpha$ and, as control of loading: antibody against total eIF2 $\alpha$ and Direct blue stained membrane. S. cerevisiae strain RS-259 and $G C N 2^{c}$ mutant stationary phase cultures were used as inoculums in YPD broth till reaching early exponential phase then cells were harvested, washed and resuspended with $\mathrm{H}_{2} \mathrm{O}$ then distributed into $(5 \mathrm{ml})$ samples, $2 \%$ glucose was added or not and all were incubated for $10 \mathrm{~min}$. Extraction was made by Laemmli as described in materials and method. The experiment was repeated three times with similar results. The band intensity was quantified by Image Gauge software then relative band intensity (PeIF $2 \alpha /$ total eIF2 $\alpha$ ) was calculated and the average value was represented in (C) with arbitrary units of the $\mathrm{Y}$-axis and error bars correspond to standard error. 
In order to check if inhibition of Glc7 by Glc7' increases phosphorylation of eIF2 $\alpha$, we expressed Glc7' under control of doxycycline and, as indicated in Figure 39, inhibition of Glc7 by expression of the truncated Glc7' had no effect on eIF2 $\alpha$ phosphorylation. Therefore, even in a system where the Glc7 phosphatase is known to regulate the phosphorylation level of a protein substrate, inhibition of Glc7 by the truncated dominantnegative form does not increase phosphorylation.

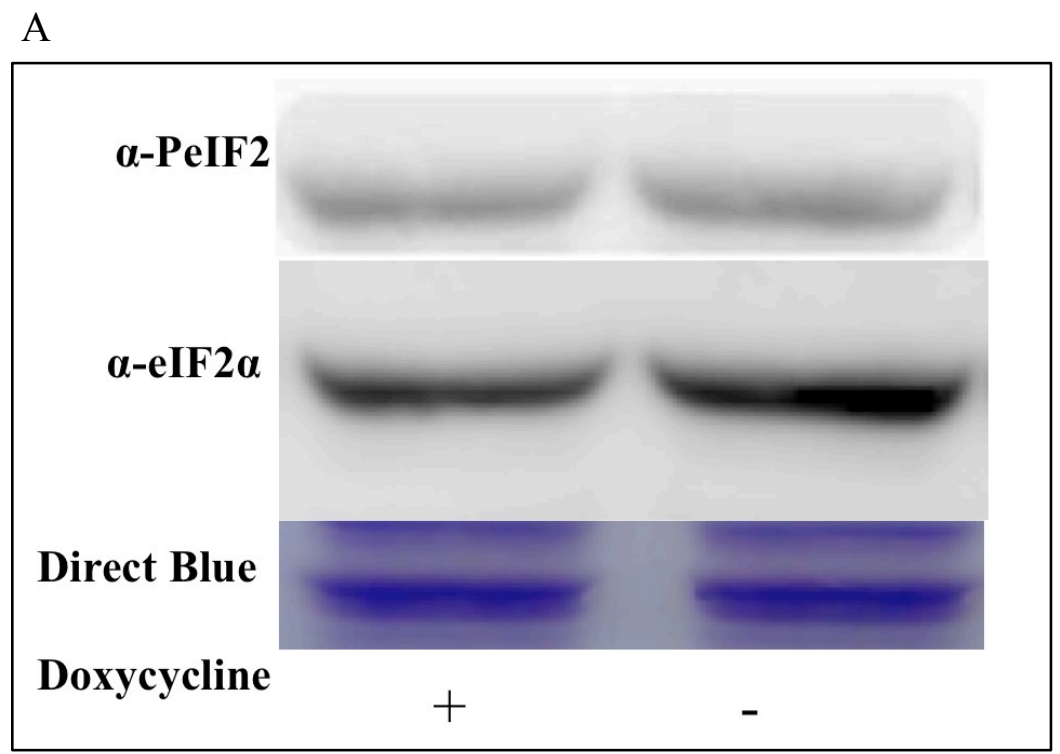

\section{B}

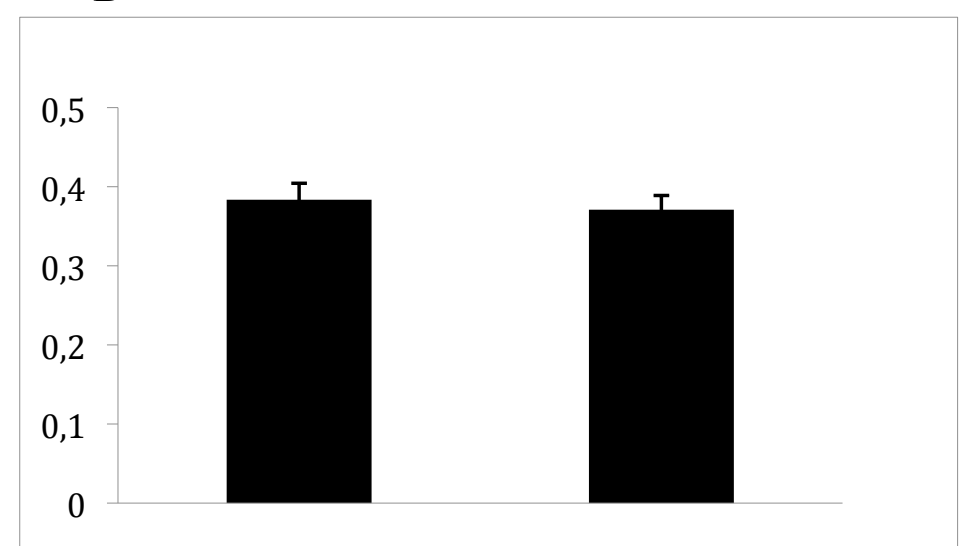

Figure 39. Inducing expression of $G L C 7$ ' has no effect on phosphorylation level of eIF2 $\alpha$.

(A)Western blotting with antibodies against PeIF2 $\alpha$ and as control of loading: antibody against total eIF2 $\alpha$ and Direct blue stained membrane. S. cerevisiae strain RS-121 was grown in SD medium supplemented with leucine, histidine and methionine and doxycycline $(2 \mu \mathrm{g} / \mathrm{ml})$ till reaching exponential phase then doxycycline was removed and samples incubated for one hour and a half with or without doxycycline. True zero control with doxycycline was made. The experiment was repeated three times with similar results. The band intensity was quantified by Image Gauge software then relative band intensity (P-eIF2 $\alpha /$ total eIF $2 \alpha$ ) was calculated and the average value was represented in (b) with arbitrary units of the $\mathrm{Y}$-axis and error bars correspond to standard error. 


\section{Effect of sit4 null mutation on the activity of Pma1}

sit4 null mutant is viable, so we used it in order to test the effect of Sit4, which is type 2A protein phosphatase, on Pmal activity. We tested the rate of dephosphorylation of activated Pmal of sit4 null mutant in comparison to the wild type. Results in Figure 40 showed that the dephosphorylation rate of the mutant was slower, yet the level of phosphorylation after glucose addition was less than in the wild type.

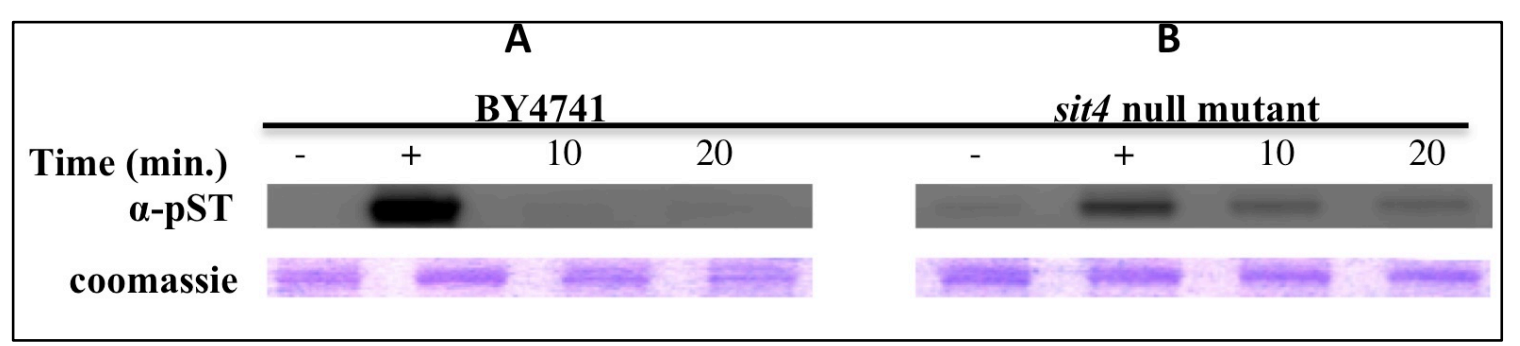

Figure 40. Dephosphorylation rate of Pma1 (A) wild type (strain BY4741) and (B) sit4 null mutant.

S. cerevisiae late exponential phase cultures were harvested, washed and resuspended with sterile distilled water then incubated for 15 minutes (-), then glucose was added and cells were incubated for 10 minutes $(+)$, glucose was removed by centrifugation then cells were incubated in water for 10 and 20 minutes as indicated. The levels of double phosphorylation at serine 911 and threonine 912 (pST) were determined as described in Materials and Methods. Coomassie stained gel is presented as control of loading. The bands recognized by the antibody and stained by Coomassie represent Pma1 of 100 KD. The experiment was repeated twice with similar results. 
In another approach to test the effect of Sit4 on Pmal activity we measured the "in vitro" activity of Pmal of the same samples used in dephosphorylation rate experiment, of both the sit 4 null mutant and the wild type. As indicated in Figure 41 the wild type showed higher Pmal activity after glucose activation than that of the null sit4 mutant.

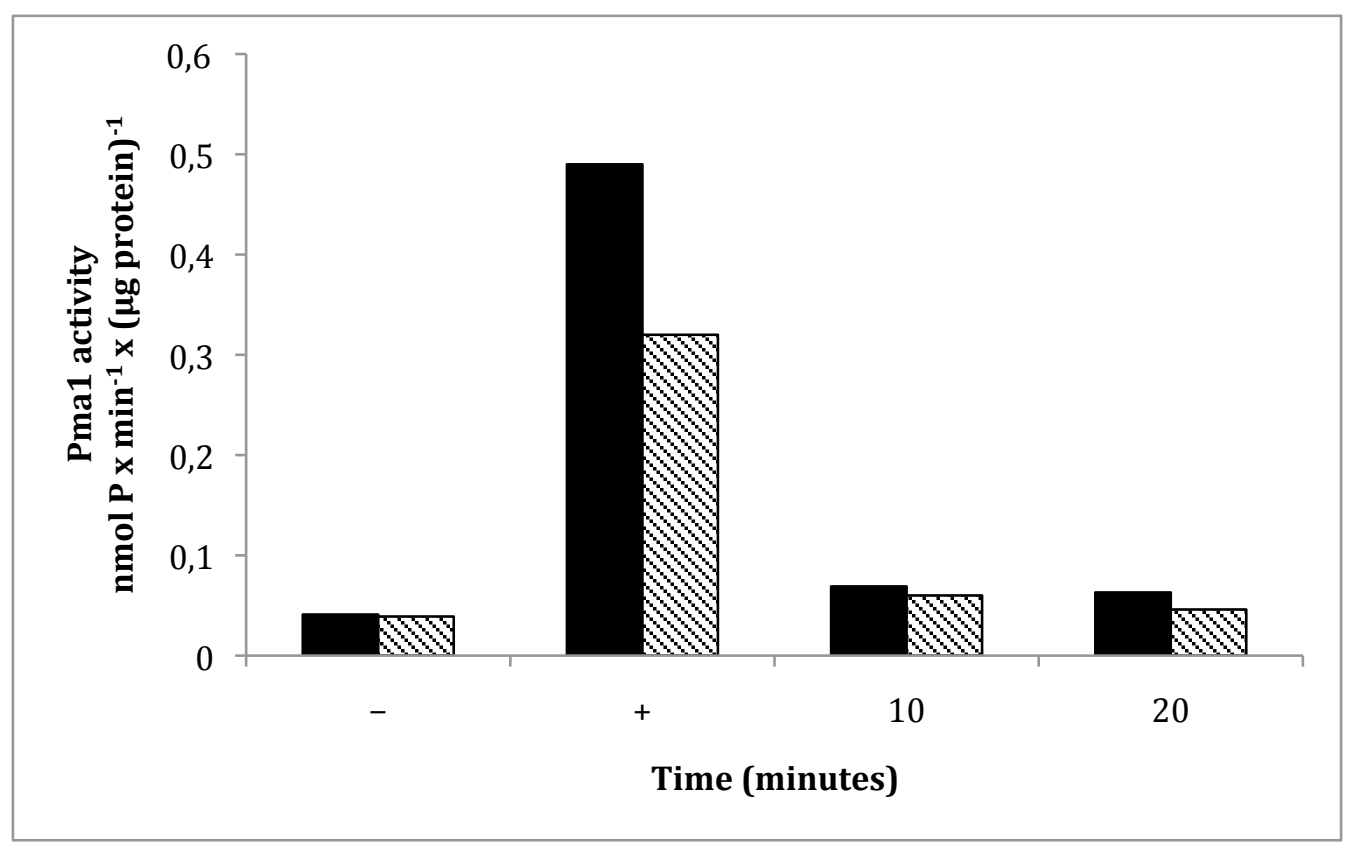

\section{Figure 41. Effect of sit4 null mutation on specific activity of Pma1.}

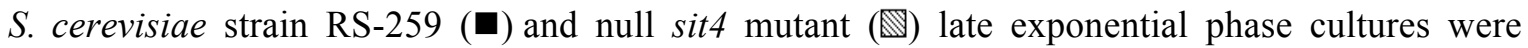
harvested, washed and resuspended with sterile distilled water then incubated for 15 minutes (-), then incubated with glucose for 10 minutes $(+)$, glucose was removed by centrifugation then cells were incubated in water for 10 and 20 minutes as indicated. The crude Pmal was extracted and its specific activity was determined as described in materials and method. The experiment was repeated twice with similar results and data presented are corresponding to a typical experiment. 
The sit4 null mutant also showed lower Pmal activity when the $\mathrm{pH}$ changes of yeast suspension induced by glucose were measured, the maximal rate of proton pumping of the wild type was almost twice that of the null mutant as shown in Figure 42. All these results together suggest that Sit4 is having a stimulatory effect on Pmal activity.

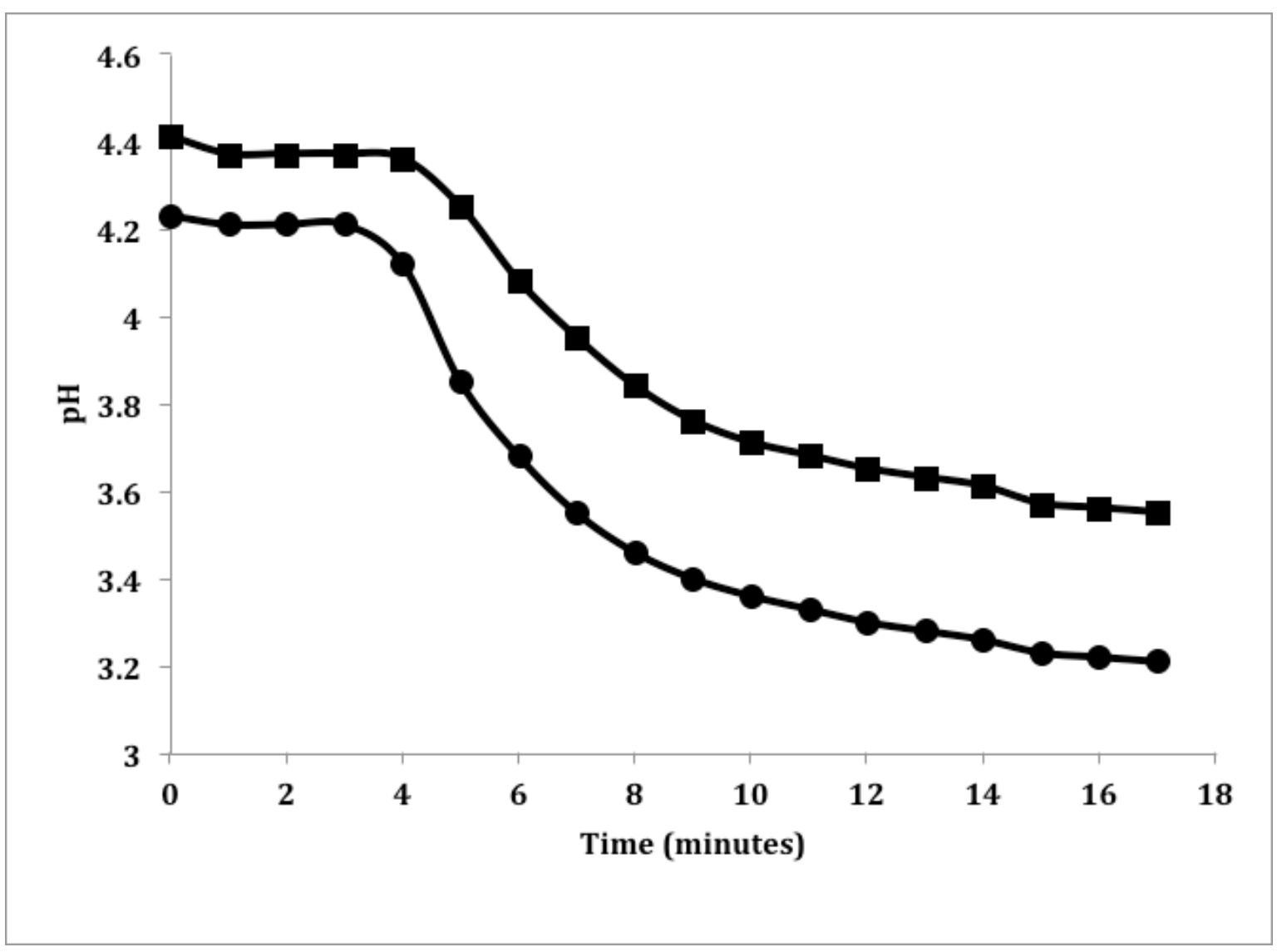

Figure 42. pH changes of yeast suspension induced by glucose.

S. cerevisiae strain RS-259 $(\bullet)$ and null sit4 mutant (ש). Specific $\mathrm{mg}$ of each strain was suspended in $2 \mathrm{ml}$ of $(100 \mathrm{mM} \mathrm{KCl}$ and10 $\mathrm{mM}$ glycylglycine adjusted to $\mathrm{pH} 4$ with $\mathrm{HCl})$ and the $\mathrm{pH}$ was recorded as described in Materials and Methods. At the times indicated in materials and method glucose $(50 \mu \mathrm{mol})$ and calibration pulses of $100 \mathrm{nmol} \mathrm{HCl}$ were added. The maximal rate of proton pumping was RS-259=13.7, null sit4 $=7.2 \mathrm{nmol} \times \min ^{-1} \times \mathrm{mg}_{\text {yeast }}{ }^{-1}$. The experiment was made once. 
We tested the effect of $\mathrm{LiCl}$ and hygromycin B on growth of sit4 null mutant. In Figure 43, we can see that null sit4 mutant is showing less growth in presence of LiCL and hygromycin than the wild type, yet the growth of the null mutant is already much lower in absence of any toxic cation, on YPD, as an effect of the null mutation on growth which makes it confusing to get a clear judgement on the mutant resistance.

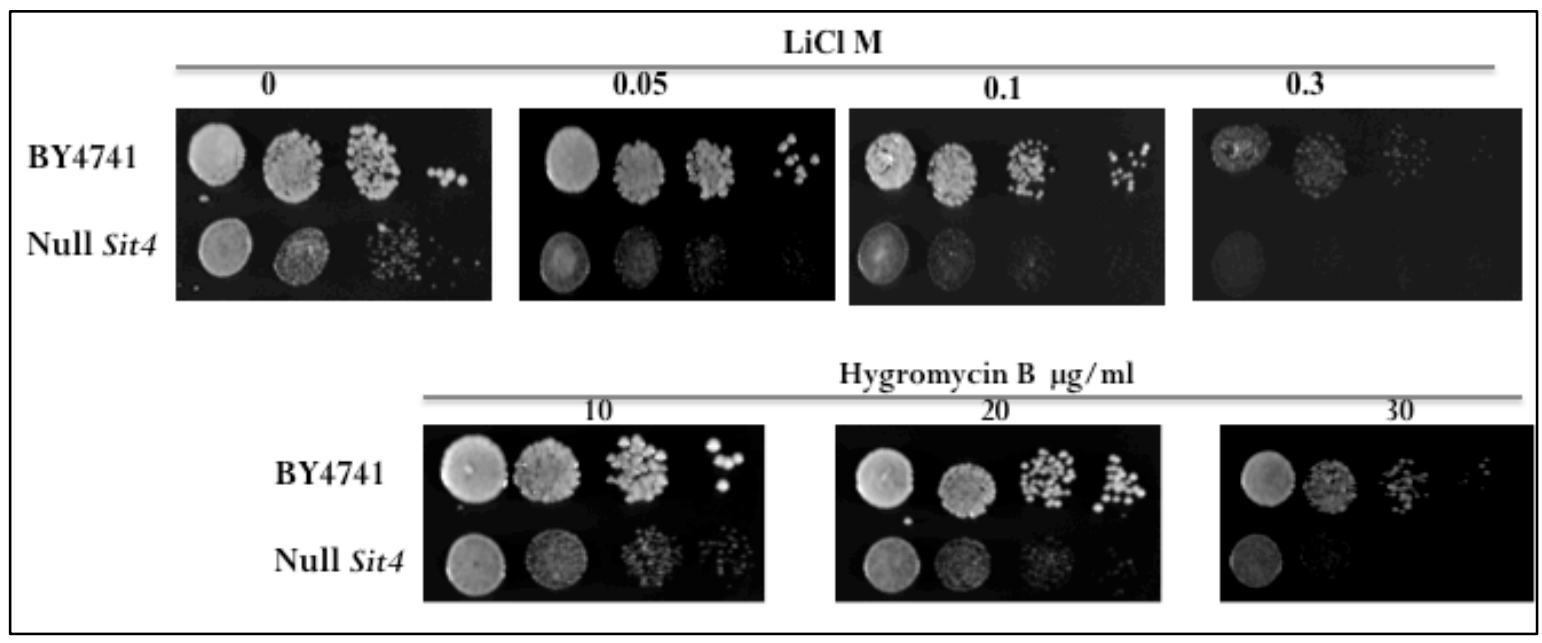

Figure 43. The growth phenotypes of sit4 null mutant in comparison to its wild type.

S. cerevisiae strains RS-259 (WT) and sit4 null mutant serial dilutions of stationary phase cultures were incubated on the indicated agar medium for $2-3$ days at $30^{\circ} \mathrm{C}$. The experiment was made once. 


\section{"In vitro" dephosphorylation of Pma1 by Glc7}

We have tested if the Glc7 phosphatase could dephosphorylate or not Pmal "in vitro". In order to do that we used a construction of Glc7 fused to GST (pGEX-3X-GLC7) to express the protein in E. coli then we purified it with glutathione beads. The presence of purified protein in the soluble fraction after inducing the expression with IPTG was confirmed by staining the membrane with Coomassie, Figure 44.

To test the "in vitro" interaction between Glc7 and Pma1, the purified Glc7 was incubated with activated Pmal for different time intervals. Figure 45A showed that the level of the double phosphorylation at serine 911 threonine 912 of Pmal decreased after being incubated with Glc7. A control experiment was conducted simultaneously (Pma1 incubated with purified GST extracted from cells harboring pGEX-3X induced with IPTG) and as shown in Figure 45B the phosphorylation level of Pma1 at ST911, 2 in this control experiment was constant at different time intervals of incubation, which confirms that Glc7 “in vitro" dephosphorylates Pma1.

\section{"In vitro" dephosphorylation of Pma1 by Sit4}

In order to test the ability of Sit4 to dephosphorylate Pmal "in vitro" we used a pYEX 4T-1-SIT4 construct, which can express the protein in the soluble fraction in yeast. The expression was confirmed with anti-GST antibody after expression induction with $\mathrm{CuSO}_{4}$, Figure 46. The purified Sit4 was incubated with activated Pmal for different time intervals. Figure 47A shows that Sit4 can dephosphorylate Pmal "in vitro" as the phosphorylation level at serine 911 threonine 912 decreased after incubation with Sit4, starting from 30 minutes incubation and decreasing more with increased incubation time. A control experiment was conducted simultaneously (Pmal incubated with purified GST extracted from cells harboring pYEX 4T-1 induced with $\mathrm{CuSO}_{4}$ ) and as shown in Figure 47B the phosphorylation level of Pmal at serine 911 threonine 912 in this control experiment was not affected. 


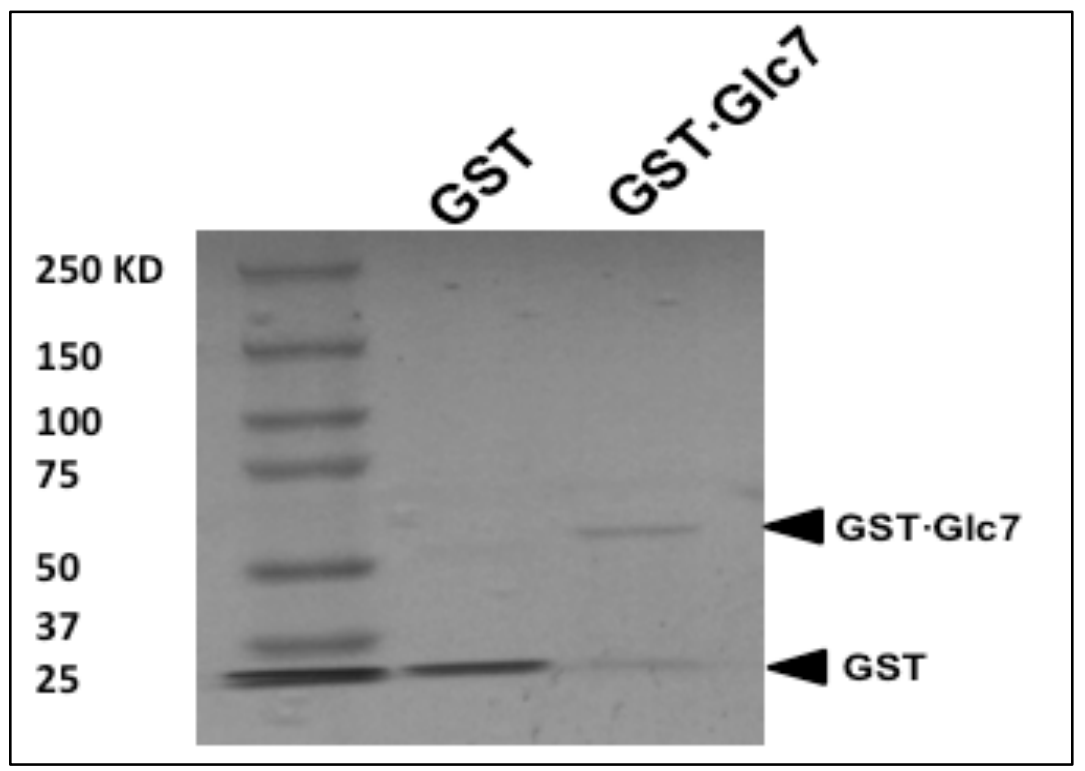

\section{Figure 44. Expression of recombinant Glc7 protein from pGEX-3X vector in Escherichia coli.}

RS-405 strain (E. coli transformed with pGEX-3X-GLC7) and a control strain (E. coli transformed with pGEX-3X). The cells were grown to exponential phase at $37^{\circ} \mathrm{C}$ and then induced with IPTG (see"Materials and Methods"). The cells were harvested, sonicated and the soluble materials were purified with Pierce ${ }^{\mathrm{TM}}$ Glutathione Magnetic Beads, then subjected to SDS-PAGE and stained for protein with Coomassie. Lane 1 marker (Precision Plus Protein Dual Color Standards) from BioRad; lane 2, a fraction from the control cells (harboring pGEX-3X) induced with 0.1- $0.2 \mathrm{mM}$ IPTG; Lane 3 a fraction from cells harboring pGEX-3X-GLC7 induced with 0.1- $0.2 \mathrm{mM}$ IPTG. The upper arrow refers to GST-Glc7 in correct position Glc7 (35.9) + GST (26) $=61 \mathrm{KD}$. The experiment was made once.

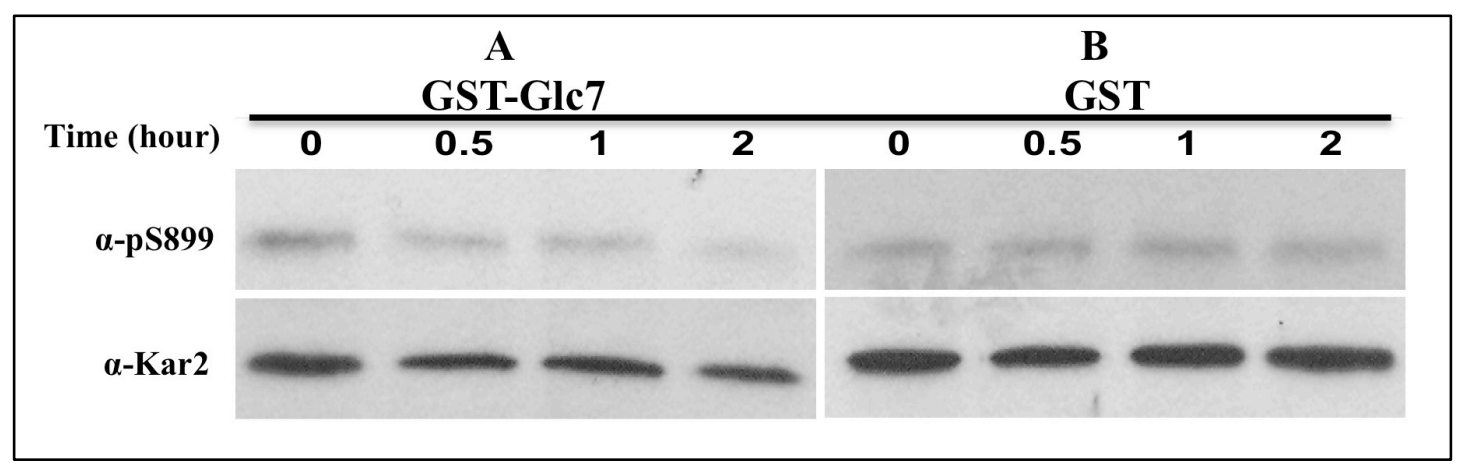

Figure 45. Purified Glc7 shows "in vitro" effect on activated Pma1.

E. coli (A) RS-405 strain (transformed with pGEX-3X-GLC7) and (B) a control, strain E. coli DH5 $\alpha$ transformed with pGEX-3X. The cells were grown to exponential phase at $37^{\circ} \mathrm{C}$ and then induced with IPTG (see "Materials and Methods"). The cells were harvested, sonicated and the soluble materials were purified with Pierce ${ }^{\mathrm{TM}}$ Glutathione Magnetic Beads. The purified soluble protein was incubated with activated Pma 1 at $30^{\circ} \mathrm{C}$ for the specified times then membrane proteins were analyzed by Western blotting with antibodies against phosphorylated Ser899 (pS899) and $\alpha$ Kar2 as control of loading, as described in materials and method. The bands recognized by the antibodies represent Pma1 of $100 \mathrm{KD}$ and Kar2 of $75 \mathrm{KD}$. The experiment was made once. 


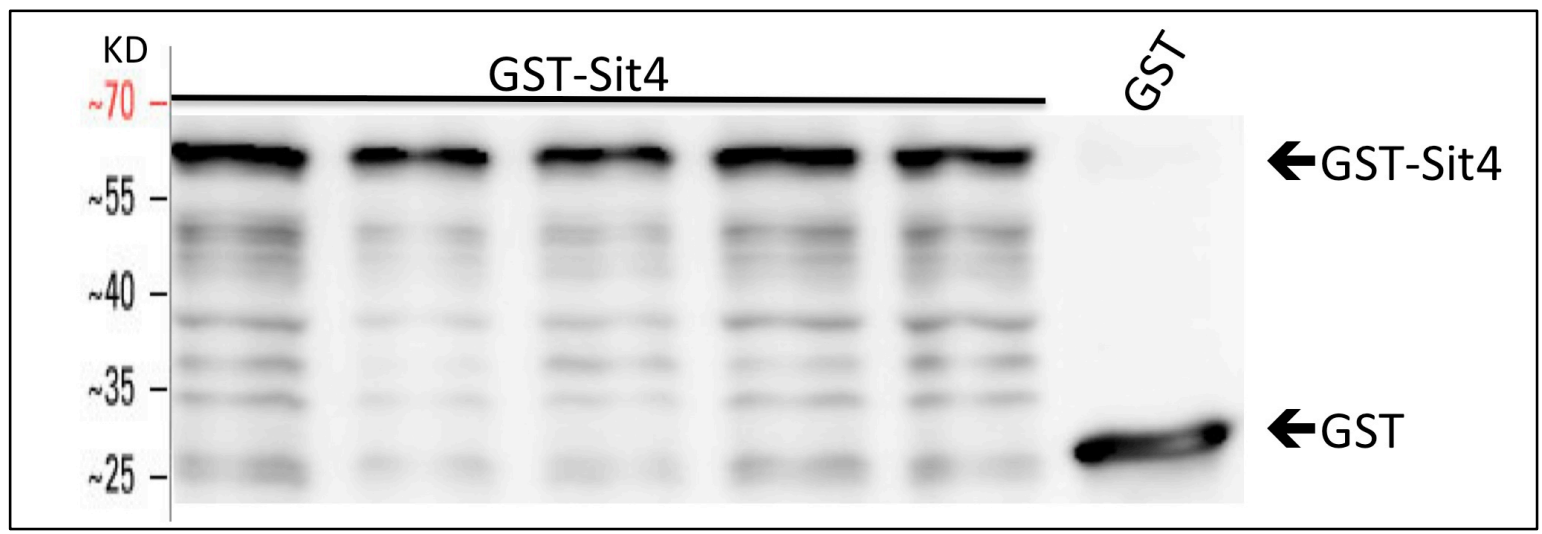

Figure 46. Expression of recombinant Sit4 protein from the pYEX 4T-1 vector in Saccharomyces cerevisiae.

S. cerevisiae strain (RS-259 transformed with pYEX 4T-1-SIT4) and a control strain (RS-259 transformed with pYEX 4T-1). The cells were grown to exponential phase at $28^{\circ} \mathrm{C}$ and then induced with $\mathrm{CuSO}_{4} 0.5 \mathrm{mM}$ (see "Materials and Methods"). The cells were harvested and broken with the aid of glass beads in specific lysis buffer then soluble material membrane proteins were analyzed by Western blotting with antibodies against GST. Lanes 1 to 5, fractions from cells harboring pYEX 4T-1-SIT4 after induction with $\mathrm{CuSO}_{4} 0.5 \mathrm{mM}$; lane 6 , a fraction from the control cells (harboring pYEX 4T-1) induced with $\mathrm{CuSO}_{4} 0.5 \mathrm{mM}$. The upper arrow refers to GSTSit4 in correct position Sit4 (35.9) + GST $(26)=61 \mathrm{KD}$. Standard protein markers (PageRuler Prestained Protein Ladder, from Thermo Scientific), with masses indicated in $\mathrm{kDa}$ was used. The experiment was made once.

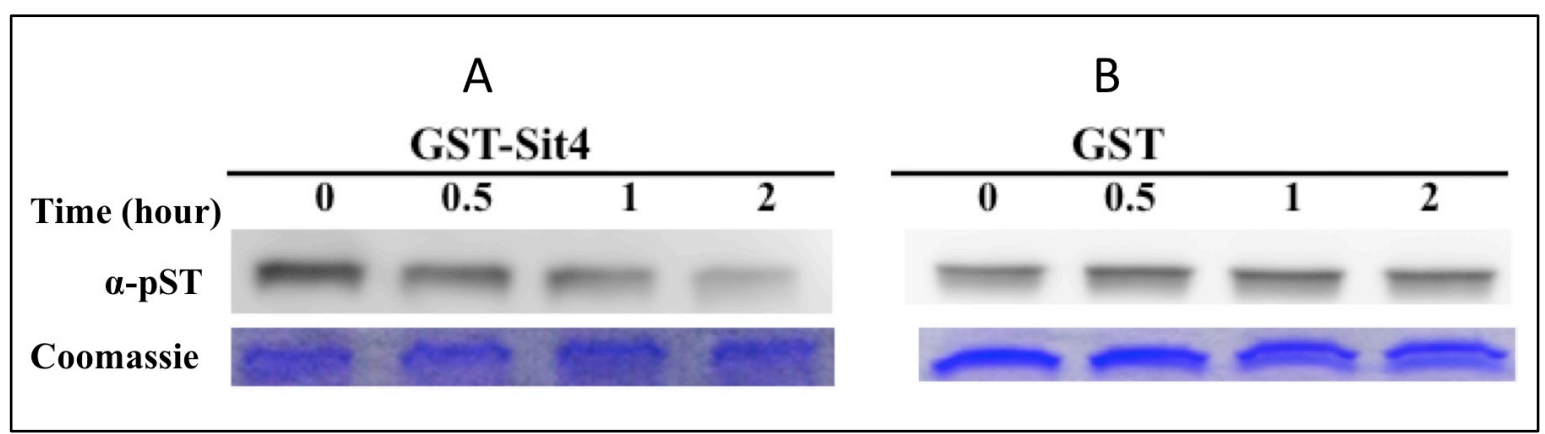

Figure 47. Purified Sit4 shows "in vitro" effect on activated Pma1.

S. cerevisiae strain (A) RS-259 transformed with pYEX 4T-1-SIT4 and (B) a control, strain RS-259 transformed with pYEX $4 \mathrm{~T}-1$. The cells were grown to exponential phase at $28^{\circ} \mathrm{C}$ and then induced with $\mathrm{CuSO}_{4} 0.5 \mathrm{mM}$ (see "Materials and Methods"). The cells were harvested and broken with the aid of glass beads in specific lysis buffer. The soluble materials were purified with (Glutathione sepharose ${ }^{\mathrm{TM}}$ 4B (GE Healthcare) Sweden). The purified soluble protein was incubated with activated Pma 1 at $30^{\circ} \mathrm{C}$ for the specified times then membrane proteins were analyzed by Western blotting with antibodies against the double phosphorylation at serine 911 and threonine 912 (pST). Coomassie stained membrane is presented as control of loading, procedures are described in materials and method. The bands recognized by the antibody and stained by Coomassie represent Pma1 of $100 \mathrm{KD}$. The experiment was repeated three times with similar results. 


\section{TOR kinase is a positive regulator of Pma1 activity}

The idea now was to take another direction and test the effect of one of the most important kinases of eukaryotic cells, TOR, on Pmal activity. Rapamycin is known to inhibit TORC1 so our first approach was to test the effect of rapamycin on Pma1 activity. In order to do that we first had to determine which concentration of rapamycin will give good inhibition of TORC1, and as the latter is necessary for growth, the effect of rapamycin was measured by OD of growing cultures. Figure 48 shows that higher concentrations of rapamycin are inhibiting TORC1, as represented by inhibition of growth.

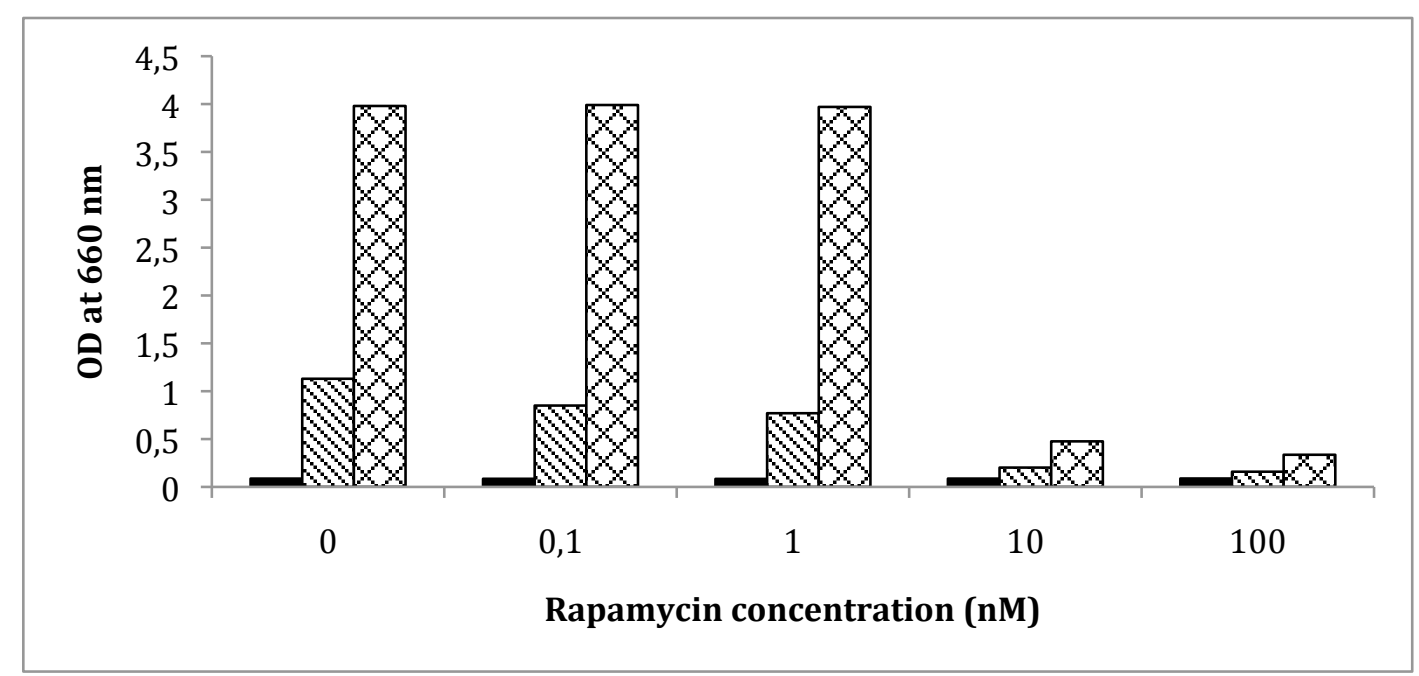

Figure 48. Effect of rapamycin different concentrations on TOR Kinase shown in terms of yeast growth inhibition

S. cerevisiae strain RS-132 was inoculated in YPD with initial OD at $660 \mathrm{~nm}=0.1$ with the specified rapamycin concentration $(0,0.1,1,10,100 \mathrm{nM})$ and incubated $\left(30^{\circ} \mathrm{C}, 200 \mathrm{rev} / \mathrm{min}\right)$. Growth was detected by measuring OD at $660 \mathrm{~nm}$ at zero time (ם), again after 8 hours $(\mathbb{Q})$ and finally after 24 hours (圈). The experiment was made once. 
The next step was to treat the cells with rapamycin and this was made at two stages: in the growth medium $(0.5 \mu \mathrm{M})$ and during treatment of cells with glucose $(10 \mu \mathrm{M})$. The concentration of this drug had to be increased in order to keep the ratio of rapamycin to cells in the procedures of the experiment. In the experiment of Figure 48 rapamycin was added to cells at an $\mathrm{OD}=0.1$, while for Pmal activity the culture was at about $\mathrm{OD}=2$ and after concentrating cells for incubation with glucose OD was about 40 .

When the activity of Pmal was measured "in vitro" after incubation with rapamycin for different time intervals, it showed a high decrease completed in two hours (Figure 49A). The same decrease was confirmed when the phosphorylation level of these samples was measured using $\alpha$-pST (Figure 49B). Total Pmal protein on the other hand did not show any change of amount when tested with the specific antibody, which means that the effect on activity is not explained by decreased amount of the enzyme.

Still in the same direction, testing the effect of TOR kinase on Pma1 activity, the second approach was to measure Pmal activity in a strain that is TORC1 and TORC2 thermosensitive, SH221 (tor1s tor $2^{\text {ts }}$ ) in comparison to its control strain (SH100) (Helliwell et al., 1998). First to confirm the phenotype, Figure 50A shows the different growth of the thermosensitive and control strain at non-permissive temperature $\left(37^{\circ} \mathrm{C}\right)$ on YPDA: while the control strain could grow normally, the tor $1 \Delta$ tor $2^{\text {ts }}$ mutant could not grow. The same difference is confirmed in terms of OD when the strains were grown in broth (Figure 50B). Both strains grew equally at room temperature (Figure 50C).

After finding good difference in growth between the two strains after 6 hours incubation at $37^{\circ} \mathrm{C}$, this time interval was used in the following experiment. Figure $51 \mathrm{~A}$ shows the decreases of Pma1 "in vitro" activity in SH221 strain in comparison to its control strain (SH100) at non-permissive temperature. Such a decrease was confirmed by measuring the phosphorylation level of the same samples using $\alpha$-pST (Figure 51B). These results confirm that TOR is a positive regulator of Pma1. 
A

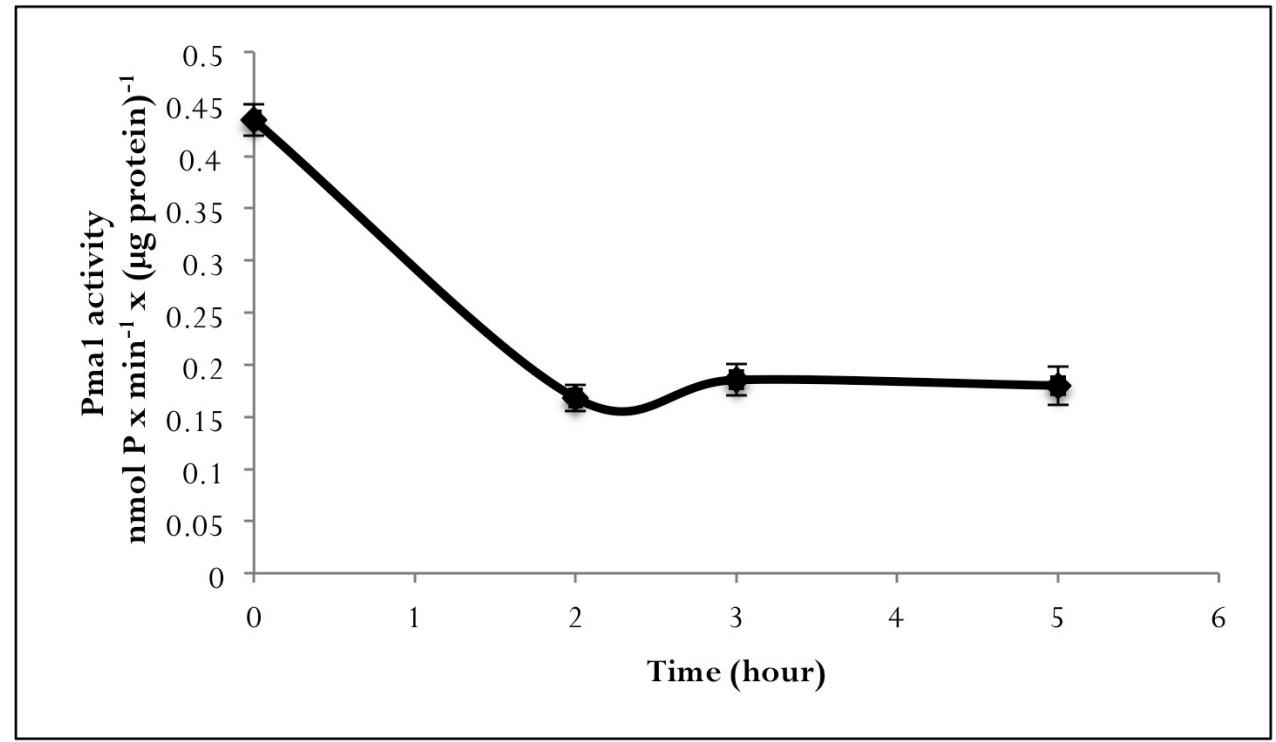

B

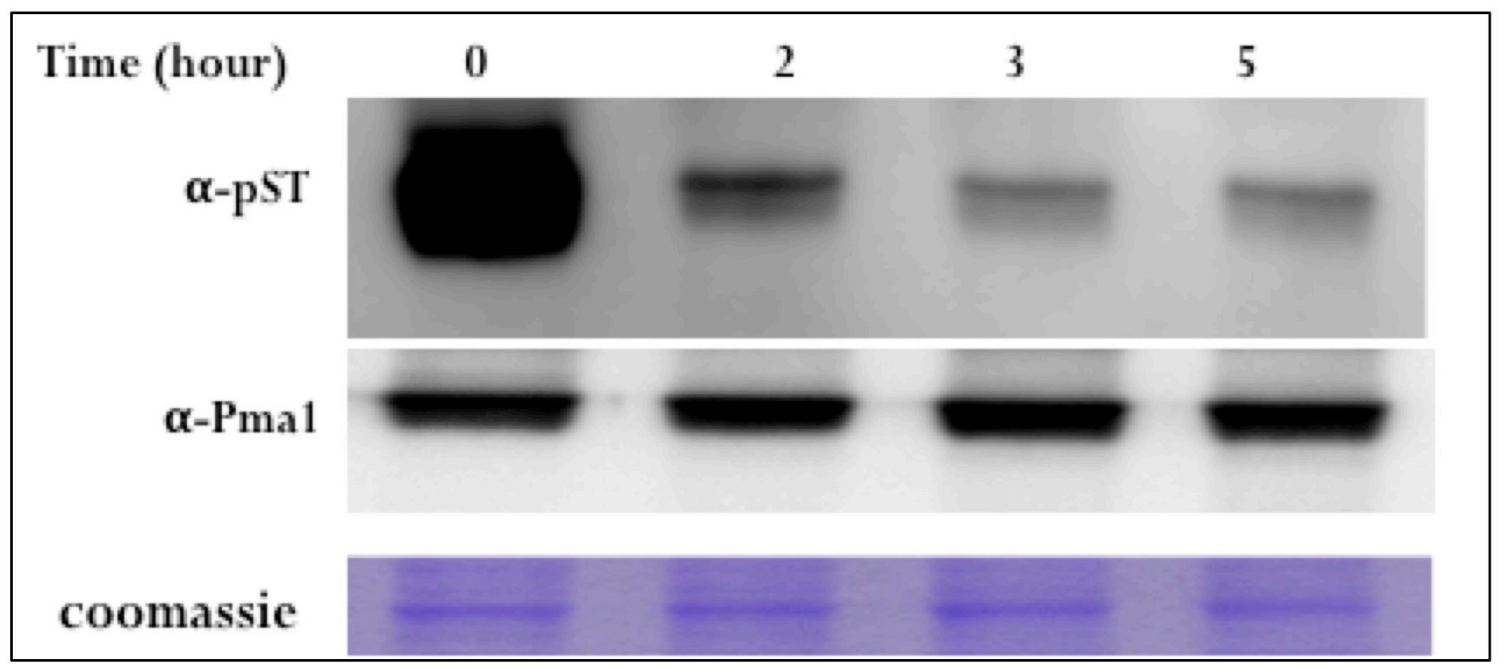

Figure 49. Rapamycin decreases Pma1 activity. (A) "in vitro" Pma1 specific activity of cells treated with rapamycin and (B) phosphorylation level of Pma1 of the same samples.

S. cerevisiae strain RS-132 exponential phase cultures were incubated with rapamycin $500 \mathrm{nM}$ at $30^{\circ} \mathrm{C}, 200 \mathrm{rev} / \mathrm{min}$ for the indicated time intervals. At each time interval cells were harvested, washed resuspended with $\mathrm{H}_{2} \mathrm{O}$ and rapamycin was added to final concentration of $10 \mu \mathrm{M}$ and mixed well by vortex. The suspension was proceeded to extract the Pma1. (A) Pma1 specific activity (•) was assayed "in vitro" as described in materials and method. (B) The same extracted membrane proteins were analyzed by western blotting with antibodies against the double phosphorylation at serine 911 and threonine 912 (pST) and against total Pma1. Coomassie stained membrane is presented as control, procedures are described in Materials and Methods. The bands recognized by the antibody and stained by Coomassie represent Pmal of $100 \mathrm{KD}$. The experiment (A) was repeated three times and and error bars correspond to standard error and experiment (B) was repeated twice with similar results. 
A

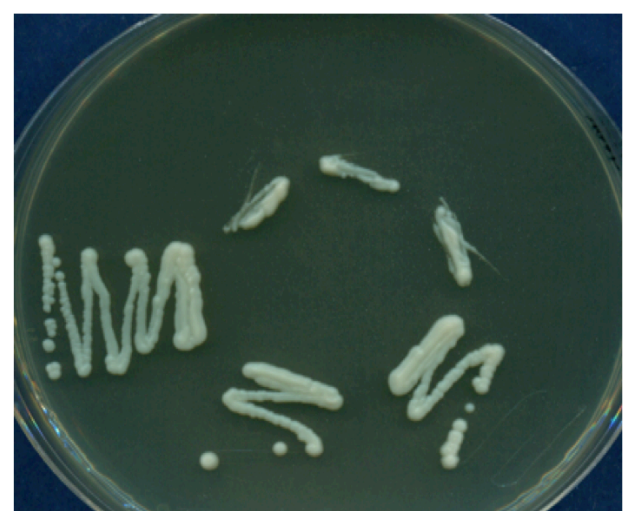

B

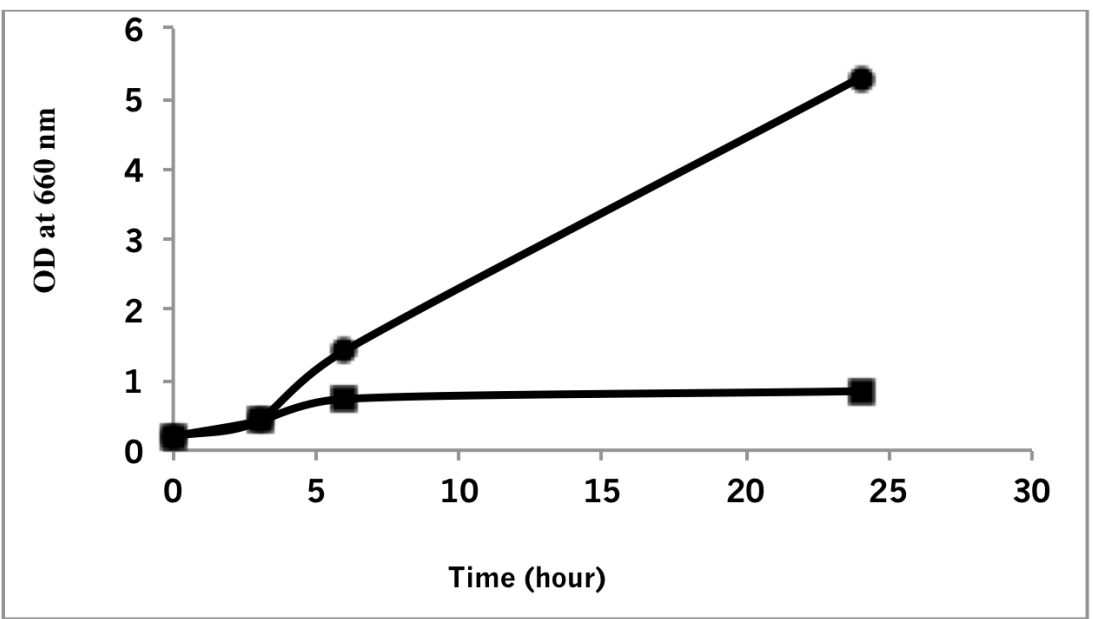

C

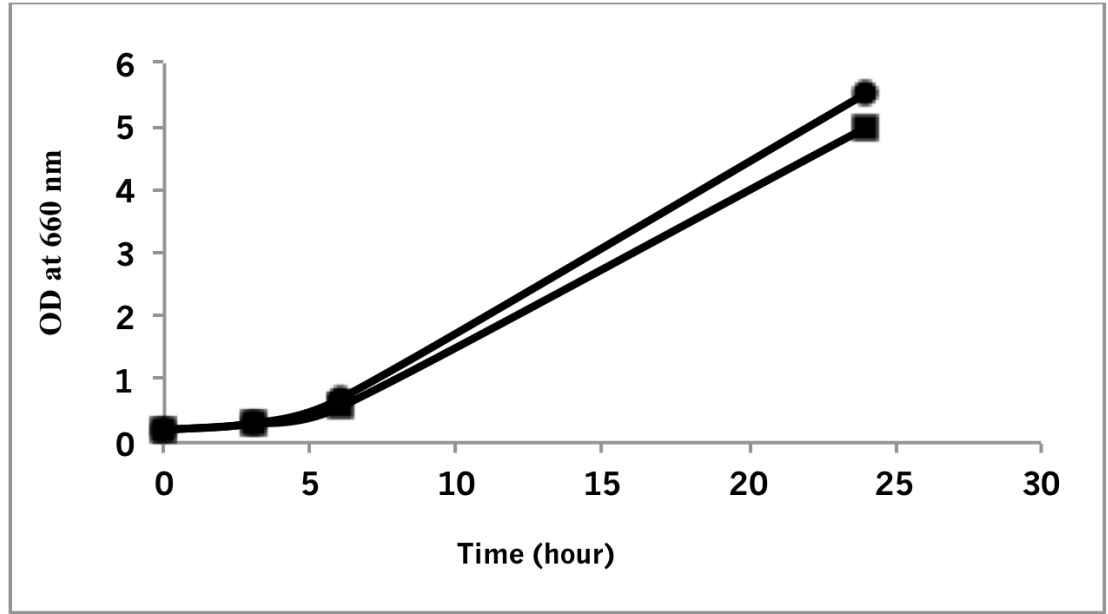

Figure 50. Growth difference between tor $1 \Delta$ tor $2^{t s}$ and its control strain at $37^{\circ} \mathrm{C}$ and at room temperature.

S. cerevisiae strain SH221 ( ) and its control strain SH100 $(\bullet)$ were cultured on YPDA plate (A), three different colonies of each strain and incubated at $37^{\circ} \mathrm{C}$ for two days. stationary phase culture of one transformant from each strain was inoculated in fresh YPD broth with starting OD of 0.2 then incubated at $37^{\circ} \mathrm{C}(\mathrm{B})$ or at room temperature (C) and growth was determined by measuring $\mathrm{OD}$ at different time intervals. The experiments were made once. 
A

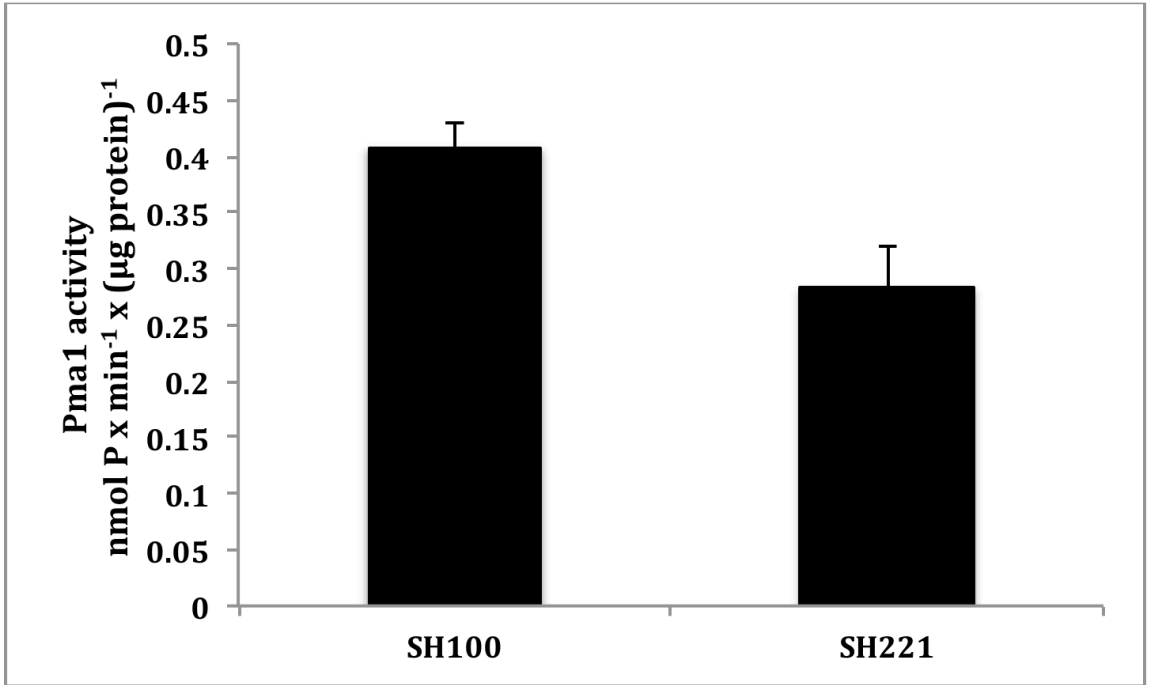

B

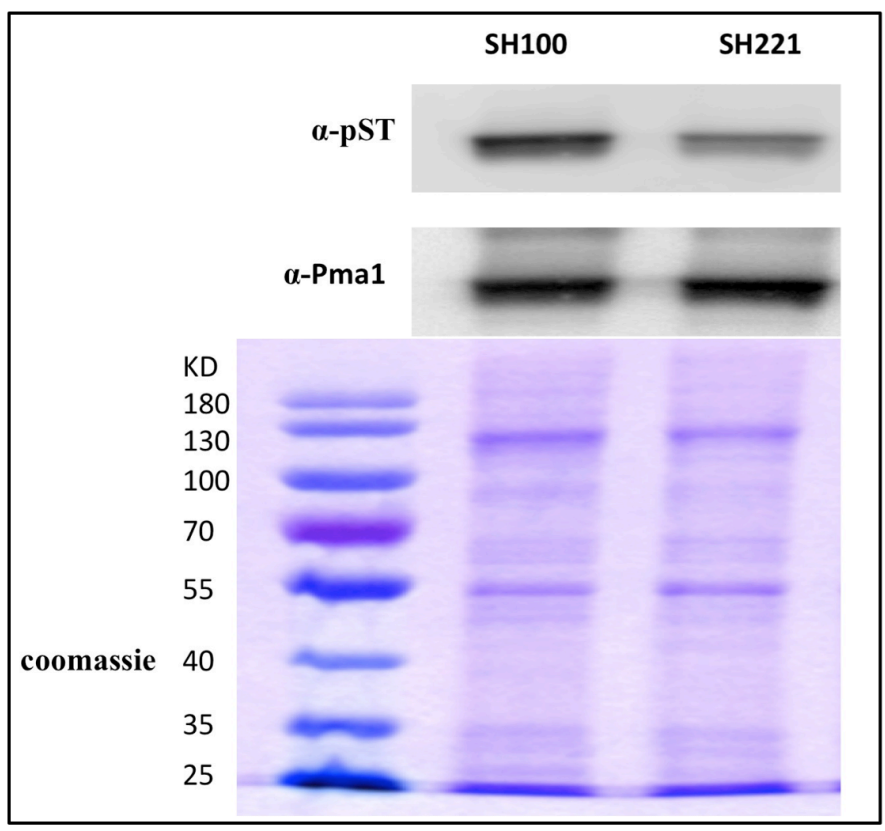

Figure 51. Decrease of Pma1 activity of tor1s $\operatorname{tor}^{t s}$ strain when grown at nonpermissive temperature.

S. cerevisiae strain SH221 and its control strain SH100, stationary phase cultures were inoculated in fresh YPD broth with starting OD of 0.2 and incubated at $37^{\circ} \mathrm{C}$ for 6 hours. cells were harvested and resuspended with $\mathrm{H}_{2} \mathrm{O}$ and processed to extract the Pma1. (A) specific activity of the extracted Pmal was assayed "in vitro". (B) The same extracted Pmal samples were analyzed by western blotting with antibodies against the double phosphorylation at serine 911 threonine 912 (pST) and also against total Pma1. Coomassie stained membrane is presented as control. Procedures are described in materials and method. Standard protein markers (PageRuler Prestained Protein Ladder, from Thermo Scientific), with masses indicated in $\mathrm{kDa}$ was used. Both experiments (A) and (B) were repeated three times with similar results and error bars in (A) correspond to standard error. 



\section{DISCUSSION}





\section{DISCUSSION}

Lack of effect of typical chemical inhibitors of protein phosphatases on Pma1 activity

Okadaic acid and calyculin A are potent inhibitors of type 1 protein phosphatases (PP1) in all mammalian cells because they are permeable. In yeast Glc7 is the most important PP1, it is essential for growth and it has been connected to ion homeostasis. However, when these inhibitors, and also tungstate, were added to a yeast culture there was no effect on Pmal activity (Figure 24). As no inhibition of growth was observed in case of treatment with okadaic acid and as Glc7 is an essential enzyme, it is likely that this inhibitor has poor uptake in yeast. In case of calyculin A there was a significant growth inhibition, shown in Figure 24D. Pmal activity of cells treated with calyculin A was slightly higher than in non-treated cells. Yet, we cannot conclude that Glc7 inhibition activates Pmal because the observed increase is very small (about 10\%) and the experiments were only done once as the results were disappointing. Both okadaic acid and calyculin A are hydrophobic compounds and their uptake by cells is affected by many things like the partitioning to cell membrane and also from the membrane to the cytoplasm and they might have needed much longer time in order to be well absorbed as stated by Swingle et al. (2007). Also the different compounds do not necessarily diffuse into cells at the same rate, especially if the compounds are added at different concentrations and finally, because organic anion efflux pumps may use these compounds as substrates (Swingle et al., 2009). On the other hand, tungstate is water-soluble and at the concentration we used in the experiment $(10 \mathrm{mM})$ it is reported to give a very high inhibition of Glc7 activity (Rodriguez-Hernandez et al., 2012). These considerations indicate that chemical inhibitors of Glc7 have no effect on Pma1 activity and that other methods should be used to reach definitive conclusions.

\section{Effect of expression of a dominant-negative form of $G L C 7$ on Pma1 activity}

As Glc7 is an essential enzyme, a null mutant could not be tested. Truncated Glc7 (Glc7') is reported to have a dominant negative effect, partially inhibiting wild type Glc7, (Wek et al., 1992). Constitutive expression of Glc7' driven by its genomic promoter had no effect on Pmal activity "in vitro" using a multicopy plasmid (Figure 25). The same lack of effect of expressing Glc7' on Pmal activity was noticed when the activity was measured "in vivo", when the $G L C 7$ ' gene was expressed from multicopy or centromeric plasmids (Figure 26). We also tried to measure the effect of GLC7' using 
a slightly different method because we thought the kinase effect on Pmal may be so high under glucose addition that it masks any possible effect of the phosphatase. We removed the glucose after 10 minutes activation to measure the dephosphorylation rate with antibody against phosphorylated Ser899 and also against the double phosphorylation at Ser911 and Thr912 (Mazón et al., 2015), and again even with this indirect approach there was no effect on Pmal: the dephosphorylation rate after removal of glucose in the cells transformed with $G L C 7^{\prime}$, was the same as in those transformed with empty plasmid (Figure 32).

When these transformants were tested for resistance to hygromycin B they showed a little more sensitivity than wild type (Figure 33). In the same experiment, we noticed that putting $G L C 7^{\prime}$ ' on high copy number plasmid does not produce higher effect than putting it on centromeric plasmid. On the other hand, when those transformants were tested for acetic acid resistance no change of tolerance was observed with respect to the control strain (the same strain transformed with empty plasmid) (Figure 34). An increase in Pmal activity should have resulted in improved tolerance to intracellular acidification induced by acetic acid. Because Pmal activity was not affected (measured either "in vivo" or "in vitro") the small effect on hygromycin tolerance could be due to an effect of Glc7' on potassium transporters (Trk1, Trk2) that are regulated by Hal4 and Hal5 kinases according to Mulet et al. (1999). When these genes are disrupted this leads to greater cation sensitivity and increase the membrane potential. Another explanation could be that Glc7 directly affects the channels involved in hygromycin transport.

\section{Expression of $G L C 7^{\prime}$ under control of a doxycycline-regulated promoter}

As the continuous expression of Glc7' may be deleterious to cells and selections of non-expressing mutants could have occurred, a truncated form of Glc7 under control of a doxycycline-regulated promoter was used. When Glc7' was conditionally expressed growth was inhibited (Figure 27, 28, 29) because Glc7 is a vital protein for cell growth and with such high expression of a dominant negative gene cells cannot grow. Cells were allowed to grow in the presence of a selected concentration of doxycycline until exponential phase and then were incubated in a medium free from doxycycline to induce Glc7' expression. The activity of Pma1 was assayed "in vitro" after different time intervals and there was no effect on Pmal activity in the two constructs used (with and without HA3-His6 at the C-terminus; Figure 30). The 
expression of the GLC7' gene, suggested by the observed growth inhibition, was confirmed by semi quantitative RT-PCR and as shown in Figure 31. These results confirm the previous results with constitutive expression of GLC7' and suggest that inhibition of Glc7 has a minor effect on Pmal activity probably because it is involved in the dephosphorylation of S899 which is related to Pma1 Km (Mazón et al., 2015).

\section{Mutants in $G L C 7$ exhibit altered ion homeostasis}

Some Glc7 mutants were tested for Pmal activity and the results showed that glc7-1 and glc7-132, reported to have decreased glycogen accumulation and less Glc7 activity, both had a higher rate of proton extrusion from cells (higher "in vivo" Pmal activity) (Figure 36B), higher tolerance to acetic acid and lower tolerance to hygromycin $\mathrm{B}$ and $\mathrm{LiCl}$ (Figure 35). This may suggest that these glc7 mutations increase Pmal activity but when the activity was assayed "in vitro" in isolated membranes only glc7-1 exhibited slightly higher Pmal activity while glc7-132 did not show any increase (Figure 36A). On the other hand a third mutant, glc7-109, reported to have a dominant, hyperglycogen defect and that was expected to have a lower Pmal activity and consequently higher sensitivity to acetic acid, it did show the latter effect but when the activity of Pmal was assayed it was almost equal to the wild type, both "in vitro" and "in vivo". Also, glc7-109 was expected to have lower sensitivity to hygromycin and $\mathrm{LiCl}$, yet it acted in an opposite direction showing higher sensitivity to both of them. Some of these phenotypes of glc7-109 were already tested by WilliamsHart T et al. (2002) and are in agreement with our results. So if we tried to make some conclusions about such results with phenotypes of tolerance to toxic cations and acetic acid going in unexpected directions, it seems that the mechanism is not clear and it could be that $g l c 7$ mutations affected the transport system of these cations and acetic acid. When the Pmal activity was assayed "in vitro", it was equal to wild type ( $g l c 7$ 132 and $g l c 7-109$ ) yet there were effects on acetic acid and toxic cation tolerance. It could be that the effect of these Glc7 mutations is not on Pmal but for example on potassium transporters (see above). Williams-Hart et al. (2002) state that Glc7 itself might be regulating ion homeostasis through directly controlling ion transport and/or plasma membrane potential. However, in the same publication, when the ability of the glc7-109 mutant to grow on low K concentration conditions was tested, it grew equally to the wild type, suggesting that the increased sensitivity to $\mathrm{LiCl}$ and Hygromycin B is not due to a defect in $\mathrm{K}^{+}$transporter. As this mutant is clearly hyperpolarized, a more 
direct determination of $\mathrm{K}^{+}$transport should be made. In any case, these authors also stated that they could not find a direct involvement of Glc7 in Pmal regulation. So we believe our results are in the same direction, where Glc7 does not affect Pma1 activity yet it affects ion sensitivity, which could be explained by the hypothesis that Glc7 activates either $\mathrm{K}^{+}$transport or an unknown mechanism of transport that affects ion homeostasis. Another explanation could be that because Glc7 is involved in dephosphorylation of S899 on glucose starvation (Mazón et al., 2015) which only affects the Pmal Km, so the final effect on Pmal activity is minor and is more apparent in terms of ion tolerance than "in vitro" assay with high ATP concentration. To further complicate this issue, the "in vivo" assay of Pmal activity by proton extrusion from cells is not only dependent on Pmal activity but also influenced by $\mathrm{K}^{+}$transport for electrical balance (Serrano, 1980; Bissoli et al., 2012).

Because the regulatory subunits are responsible for Glc7 specificity (Luan 2003), it may be that a mutation of GLC7 affects its binding to certain regulatory subunits responsible for the enzyme binding to glycogen synthase but that such a mutation will have no effect on the enzyme activity on other substrates. Therefore it is very complicated to explain the glycogen defect and the different acetic acid and toxic cation sensitivity in the mutants.

\section{A plausible role for protein phosphatases in the activation of Pma1 by glucose metabolism}

As discussed at the Introduction, protein phosphatases may be more than mere reset buttons of important phosphorylated proteins. The steady-state level of phosphorylation of important regulated proteins such as Pmal could depend not only on the activity of the protein kinases but also on the relative activities of the kinases and phosphatases acting on the regulatory domain of the enzyme. The fact that these enzymes have not been identified by loss of function approaches suggests that they may be redundant or encode essential functions. As we have discarded the essential GLC7 gene, a plausible mechanism for glucose activation could be that, in addition to activation of some protein kinases, phosphorylated metabolites derived from glucose cause a general inhibition of protein phosphatases. Although protein phosphatases have little specificity "in vitro" and are inhibited by many phosphorylated compounds, the situation "in vivo" is uncertain because the accessory subunits of the phosphatases put them in close proximity to their protein substrates. In any case, glucose induces in yeast 
cells a dramatic increase in phosphorylated metabolites, reaching total values around 10 $\mathrm{mM}$ (Gancedo and Gancedo, 1973) and therefore it is not unlikely that many protein phosphatases could be inhibited "in vivo" and contribute to activation of Pma1. This could explain the mysterious regulatory pathway of glucose requiring metabolism of the sugar (Belinchón and Gancedo, 2007).

\section{Effect of expression of a dominant-negative form of $G L C 7$ and of glucose metabolism on phosphorylation of eIF $2 \alpha$}

The effect of the possible inhibition of Glc7 by glucose metabolites was investigated "in vivo" by measuring the phosphorylation level of eIF $2 \alpha$ with specific antibody in wild type and in the $G C N 2^{c}$ mutant, before and after addition of glucose. Figures 37 and 38 showed that glucose starvation led to decreased phosphorylation of eIF2 $\alpha$ in the wild type. These results differ from those of Castelli et al. (2011), who found that glucose starvation does not affect the levels of phosphorylated eIF2 $\alpha$. The experimental conditions, however, were different from ours because they worked with cells in rich YPD medium and then removed the glucose but kept all the other components of media while we resuspended cells in water with or without glucose. It would be interesting to determine what component of medium explains the differences in the results.

The decrease of eIF2 $\alpha$ phosphorylation level in the wild type means that glucose starvation leads to either an increase of phosphatase activity or a decrease of the kinase's one. Then checking the effect on a $G C N 2^{c}$ mutant that has a constitutive hyperactivity of the kinase, we found out that there was no change of the phosphorylation level of eIF2 $\alpha$ upon glucose starvation (Figure 38). This may suggest that the effect of glucose on eIF2 $\alpha$ phosphorylation is mainly due to activation of Gen2 because when it was kept constant as in the $G C N 2^{c}$ mutant there was no change of the phosphorylation level upon removal of glucose. However, the $G C N 2^{c}$ mutant has a constitutive hyperactivity and this high effect might have masked the increase of Glc7 activity under glucose starvation conditions. Therefore we believe that the hypothesis that glucose metabolism inhibits "in vivo" the activity of protein phosphatases such as Glc7 deserves further investigation.

In the strain expressing Glc7' under doxycycline promoter there was no difference of the phosphorylation level of eIF2 $\alpha$ before and after inducing the expression (Figure 39). The GLC7' expression was confirmed by semiquantitative RT- 
PCR under the same conditions as mentioned before (Figure 31). However, in this experiment glucose was present and this may have already inhibited Glc7, making further inhibition by Glc7' undetectable. Also, the experiment was done in minimal medium where Gen2 is hyperactivated by the lack of amino acids. According to Wek et al. (1992) Glc7' produces increased level of eIF2 $\alpha$ phosphorylation in the gcn2-507 mutant, with reduced activity of Gen2. It maybe that an effect of Glc7'on eIF $2 \alpha$ phosphorylation could only be seen in a defective mutant with decreased activity of Gen2.

Also in the same Figure 37 we have tested the different protein extraction methods in order to choose the best one for all the following experiments of western blotting and the results showed that the amount of protein produced by three different types of protein extraction (Laemmli, alkaline lysis and TCA) was so close unlike what was mentioned by (Wright et al., 1989). So we settled to the most convenient one, which is Laemmli method.

\section{Effect of sit4 null mutation on the activity of Pma1}

Another important yeast phosphatase is Sit4, a major PP2A phosphatase. The sit4 null mutant is viable so we used it to investigate the effect of Sit4 on Pma1. The phosphorylation level of Pmal by using specific antibody against the double phosphorylation of SerT911 Thr912 (that is the major regulatory event by increasing the maximal activity of the enzyme, see Mazón et al., 2015) was less than that of the control strain after glucose activation (Figure 40). On the other hand, the mutant showed a decreased Pmal activity "in vitro" and "in vivo" (Figures 41 and 42, respectively). These results together indicate that Sit4 is a positive regulator of Pma1 phosphorylation and activity.

The effect of $\mathrm{LiCl}$ and hygromycin on the sit4 mutant was not clear (Figure 43). The growth of this mutant is much slower than that of control strain in normal conditions and therefore the effect of sit4 null mutation on tolerance to toxic cations was difficult to ascertain.

\section{"In vitro" and "in vivo" effects of Glc7 and Sit4 on Pma1}

It was possible to express active GST-Glc7 in the soluble fraction from E. coli (Figure 44). On the other hand, we made many trials to express GST-Sit4 in E. coli using several plasmids and growth conditions but we could never recover it in the 
soluble fraction. Finally we could produce soluble and active GST-Sit4 by expression in yeast (Figure 46). GST-Glc7 and GST-Sit4 were purified, incubated with glucoseactivated Pmal and finally the level of phosphorylation of Pmal was checked with specific antibodies. Recombinant Glc7 dephosphorylated phospho-Ser899 (Figure 45) as suggested by Mazón et al. (2015). On the other hand, recombinant Sit4 dephosphorylated the major activation site of Pma1 (double phosphorylation at Ser911 Thr912; Figure 47).

The "in vitro" activity of protein phosphatases is not very specific because they depend "in vivo" on regulatory subunits to target them to the different specific substrates (Luan, 2003). Therefore these experiments do not demonstrate that Glc7 and Sit4 act on Pma1 "in vivo". Actually, our experiments on inhibition of Glc7 "in vivo" failed to demonstrate a participation of this phosphatase on the regulation of Pma1. It cannot be discarded, however, that the activating site of Pmal was dephosphorylated by several redundant phosphatases and that Glc7 could be one of them.

On the other hand, the effect of the null mutation of Sit4 on Pmal activity ("in vitro", "in vivo" and phosphorylation level at the regulatory site, Ser911 Thr912) suggests that Sit4 promotes "in vivo" the phosphorylation of the activating site of Pma1 instead of decreasing it as expected from a phosphatase. Therefore, instead of having a direct effect on Pmal by dephosphorylation, Sit4 must act "in vivo" by an indirect mechanism to activate Pmal by promoting the phosphorylation of its activating site. The nature of this mechanism is presently unknown but it could be related to the growth-promoting effect of Sit4. It can be speculated that Sit4 could dephosphorylate and activate a protein kinase acting on Pmal or dephosphorylate and inactivate protein phosphatases acting on Pma1.

\section{TORC1 kinase is a positive regulator of Pma1 activity}

The participation of TORC1 protein kinase in the regulation of Pma1 was investigated by two different mechanisms: using the specific TORC1 inhibitor (rapamycin) and increasing the temperature in a thermosensitive mutant of the TOR system.

Rapamycin treatment inhibited growth of yeast cells (Figure 48) because TORC1 is necessary for cell growth (Loewith and Hall, 2011). Pma1 activity showed a high decrease upon incubation with rapamycin, (Figure 49A) and there was a decrease on the phosphorylation level of the activation domain of Pma1 (Ser911 Thr912; Figure 
49B). This indicates that the TOR kinase is necessary for maximal activation of Pma1 by glucose. Such an effect could either be direct, TORC1 phosphorylating Pma1, or indirect by activating another kinase or inhibiting a phosphatase with negative effect on Pma1. The effect could also be a consequence of the inhibition of growth by rapamycin. Rapamycin treatment leads to inhibition of TORC1 and as a result to a G0 growth arrest within one generation (Barbet et al., 1996). However, growth arrest by glucose deprivation does not affect the activation of Pmal upon glucose addition (Serrano, 1983). Another possibility could be a decrease in Pmal amount. Rapamycin treatment causes high drop in protein synthesis by blocking translation initiation (Barbet et al., 1996). Such an explanation could not be used to justify the decrease in Pma1 activity in terms of decreased protein synthesis because according to Benito et al., (1990) the half life of Pma1 under our experimental conditions (presence of glucose and exponential phase culture) is more than 20 hours while the decrease in activity in our experiment was detected after just 2 hours, so clearly this is not the explanation. Accordingly, we did not observe a decrease in Pma1 protein levels measured with antibodies against the whole enzyme during the rapamycin treatment (Figure 49B).

Another way to inhibit TORC1 is by using a non-permissive temperature with a thermosensitive mutant of this essential protein kinase. Mutant SH221 (tor 1 tor $2-21^{\text {ts }}$ ) is temperature sensitive for both TOR complexes and functions (activation of translation initiation of TORC1 and the organization of the actin cytoskeleton of TORC2), although only TORC1 is sensitive to rapamycin (Helliwell et al., 1998). Its growth was normal at room temperature but defective at $37^{\circ} \mathrm{C}$ as expected from inhibition of TOR (Figure 50). Accordingly, incubation at the non-permissive temperature reduced the activity of Pmal and the phosphorylation of Ser911 Thr912 in this mutant with no effect on the control strain (Figure 51).

According to Helliwell et al. (1998) loss of TOR1 and TOR2 functions causes arrest in the early G1 phase of the cell cycle, like rapamycin treatment does (Barbet et al., 1996) and the arrested cells show characteristics of starved cells in stationary phase (G0), glycogen accumulation and a decrease in protein synthesis. The block in protein synthesis happens at the level of initiation and is the cause of the cell cycle arrest. TOR2 overlaps with TOR1 and mediates protein synthesis and cell cycle progression through the G1 phase of the cell cycle in response to nutrients (Barbet et al., 1996).

We have observed that in order to detect the effect of TOR on Pmal activity cells must be in exponential phase, because at the beginning we tried treatment of 
rapamycin on cells in stationary phase and this did not lead to change of Pmal activity, probably because TORC1 activity is already decreased in this phase due to lack of nutrients (Galdieri et al., 2010).

Another practical point refers to the fact that although 10-100 $\mathrm{nM}$ rapamycin was enough to inhibit growth of inoculated cultures, in grown cultures with much higher cell density, these concentrations of rapamycin had no effect on Pmal activity (Figure 48). We then considered that when working with hydrophobic inhibitors such as rapamycin there should be an increase in inhibitor concentration when the cell concentration is increased. With cells in late exponential phase and during the glucose activation step before cell homogenization the concentration of yeast is much higher than in inoculated cultures at the beginning of growth. When rapamycin was added to the cells at higher concentration $(10 \mu \mathrm{M})$ keeping the rapamycin to cells ratio, the effect on Pma1 activity was noticed.

The decrease of Pmal activity after rapamycin treatment was higher than that obtained when TOR was inhibited in the thermosensitive mutant SH221 by incubation at the non-permissive temperature (activity decreased to $45 \%$ and $65 \%$ of control, respectively). This could mean that the effect on Pmal of the high concentrations of rapamycin employed may have additional targets other than TORC1 or that the nonpermissive temperature does not fully inhibits TORC1.

Because Sit4 increased Pma1 activity and rapamycin decreased it, and knowing that TORC1 inactivation results in Tap42 weakened association with phosphatases (Yan et al., 2006), so probably Sit4 needs the binding with Tap42 in its pathway to activate Pma1.

Our finding that both TORC1 and Sit4 are required for full activation of Pma1 is in agreement with the finding that Sit4 acts downstream of TORC1 for many important physiological functions, including nutrient sensing for growth control (Rhode et al., 2004; Loewith and Hall, 2011), a function also contributed by Pma1, activated by glucose and determining growth rate (Serrano, 1983: Portillo and Serrano 1989).

Recently it has been reported that Pmal activation increases intracellular $\mathrm{pH}$ and this activates TORC1 (Dechant et al., 2014). Together with our results this suggest that there is cross activation between TORC1 and Pma1, the two cellular systems responding to nutrients. TORC1 is mostly activated by amino acids while Pmal is mostly activated by sugar metabolism and therefore it makes sense that there is cross activation to integrate both kinds of nutrient signals. 



\section{CONCLUSIONS}





\section{CONCLUSIONS}

The objectives of the present thesis were:

1- Determine if Glc7, the major PP1 protein phosphatase of yeast and also implicated in ion homeostasis, has a role in the activation of yeast plasma membrane $\mathrm{H}^{+}$ATPase (Pma1) by glucose

2- Determine if Sit4, a PP2A protein phosphatase implicated in yeast growth, has a role in the activation of Pmal by glucose

3- Investigate the participation of the growth-promoting protein kinase TORC1 in the activation of Pmal by glucose

And the conclusions are:

1- Inhibition "in vivo" of Glc7 results in neither increased activity of Pma1 nor increased phosphorylation of the major regulatory site (Ser911 Thr912) in the presence of glucose metabolism. However, in the glc7-1 and glc7-132 mutants acetic acid tolerance and Pmal activity are increased. Glc7 may be involved in regulation of Pmal but with only a minor effect and other protein phosphatases are redundant with it.

2- Glc7 itself might be regulating ion homeostasis through directly controlling ion transport and/or plasma membrane potential or an unknown mechanism of transport that affects ion homeostasis.

3- Protein phosphatase Sit4 can dephosphorylate "in vitro" the regulatory site of the glucose-activated form of Pma1. However, deletion of the SIT4 gene results in decreased phosphorylation of the regulatory site and decreased activity of Pma1 in the presence of glucose metabolism. Therefore Sit4 activates "in vivo" Pma1 by an indirect mechanism instead of inactivating it by direct dephosphorylation. This activation may contribute to the activation of growth and proliferation by this phosphatase

4- Inhibition of protein kinase TORC1 results in decreased phosphorylation of the regulatory site and decreased activity of Pmal in the presence of glucose metabolism. Activation of Pmal by TORC1 maybe direct or through contribution to the activation of growth and proliferation by this kinase 



\section{REFERENCES}



Ariño J, Herrero E (2003) Use of tetracycline-regulatable promoters for functional analysis of protein pohosphatases in yeast. Methods Enzymol 366: 347-358

Ashe MP, De Long SK, Sachs AB (2000) Glucose depletion rapidly inhibits translation initiation in yeast. Mol Biol cell 11: 833-848

Axelsen KB, Palmgren MG (1998) Evolution of substrate specificities in the P-type ATPase superfamily. J Mol Evol 46: 84-101

Baker SH, Frederick DL, Bloecher A, Tatchell K (1997) Alanine-scanning mutagenesis of protein phosphatase type 1 in the yeast Saccharomyces cerevisiae. Genetics 145: 615-626.

Barbet NC, Schneider U, Helliwell SB, Stansfield I, Tuite MF, Hall MN (1996) TOR controls translation initiation and early G1 progression in yeast. Mol Biol Cell 7: $25-42$

Belinchón MM, Gancedo JM (2007) Glucose controls multiple processes in Saccharomyces cerevisiae through diverse combinations of signaling pathways. FEMS Yeast Res 7: 808-818

Benito B, Moreno E, Lagunas R (1991) Half-life of the plasma membrane ATPase and its activating system in resting yeast cells. Biochem Biophys Acta 1063: 265268

Benito B, Portillo F, Lagunas R (1992) In vivo activation of the plasma membrane ATPase during nitrogen starvation. Identification of the regulatory domain that controls activation. FEBS Lett 300: 271-274

Binda M, Peli-Gulli MP, Bonfils G, Panchaud N, Urban J, Sturgill TW, Loewith R, de Virgilio C (2009) The Vam6 GEF controls TORC1 by activating the EGO complex. Mol Cell 35: 563-573

Birnboim HC (1983) A rapid alkaline extraction method for the isolation of plasmid DNA. Methods Enzymol 100: 243-255

Bissoli G, Niñoles R, Fresquet S, Palombieri S, Bueso E, Rubio L, García-Sánchez MJ, Fernández JA, Mulet JM, Serrano R (2012) Peptidyl-prolyl cis-trans isomerase ROF2 modulates intracellular pH homeostasis in Arabidopsis. Plant J 70 :704716

Blagosklonny MV, Hall MN (2009) Growth and aging: a common molecular mechanism. Aging 1: 357- 362 
Bloecher A, Tatchell K (2000) Dynamic localization of protein phosphatase type 1 in the mitotic cell cycle of Saccharomyces cerevisiae. J Cell Biol 149:125-140

Botstein D, Falco SC, Stewart SE, Brennan M, Scherer S, Stinchcomb DT, Struhl K, Davis RW (1979) Sterile host yeasts (SHY): a eukaryotic system of biological containment for recombinant DNA experiments. Gene 8: 17-24

Bradford MM (1976) A rapid and sensitive method for the quantitation of microgram quantities of protein utilizing the principle of protein-dye binding. Anal Biochem 72: 248-254

Brandão RL, de Magalhães-Rocha NM, Alijo R, Ramos J, Thevelein JM (1994) Possible involvement of a phosphatidylinositol-type signaling pathway in glucose-induced activation of plasma membrane $\mathrm{H}(+)$-ATPase and cellular proton extrusion in the yeast Saccharomyces cerevisiae. Biochim Biophys Acta 11223: $117-124$

Breitkreutz A, Choi H, Sharom JR, Boucher L, Neduva V, Larsen B, Lin ZY, Breitkreutz BJ, Stark C, Liu G, Ahn J, Dewar-Darch D, Reguly T, Tang X, Almeida R, Qin ZS, Pawson T, Gingras AC, Nesvizhskii AI, Tyers M (2010) A global protein kinase and phosphatase interaction network in yeast. Science 328: 1043-1046

Bublitz M, Poulsen H, Morth JP, Nissen P (2010) In and out of the cation pumps: Ptype ATPase structure revisited. Curr Opin Struct Biol 20: 1-10

Campetelli AN, Previtali G, Arce CA, Barra HS, Casale CH (2005) Activation of the plasma membrane $\mathrm{H}+$-ATPase of Saccharomyces cerevisiae by glucose is mediated by dissociation of the $\mathrm{H}(+)$-ATPase-acetylated tubulin complex. The FEBS journal 272: 5742-5752

Capieaux E, Vignais ML, Sentenac A, Goffeau A (1989) The yeast $\mathrm{H}^{+}$-ATPase gene is controlled by the promoter binding factor TUF. J Biol Chem 264: 7437-7446

Castelli LM, Lui J, Campbell SG, Rowe W, Zeef LA, Holmes LE, Hoyle NP, Bone J, Selley JN, Sims PF, Ashe MP (2011) Glucose depletion inhibits translation initiation via eIF4A loss and subsequent 48S preinitiation complex accumulation, while the pentose phosphate pathway is coordinately up-regulated. Mol Biol Cell 22: 3379-93

Castermans D, Somers I, Kriel J, Louwet W, Wera S, Versele M, Janssens V, Thevelein JM (2012) Glucose-induced posttranslational activation of protein phosphatases PP2A and PP1 in yeast. Cell Res 22: 1058-77 
Ceulemans H, Stalmans W, Bollen M (2002) Regulator-driven functional diversification of protein phosphatase-1 in eukaryotic evolution. Bioessays 24: $371-381$

Ceulemans H, Bolen M (2004) Functional diversity of protein phosphatase-1, a cellular economizer and reset button. Physiol Rev 84: 1-39

Cherkasova VA, Hinnebusch AG (2003) Translational control by TOR and TAP42 through dephosphorylation of eIF2alpha kinase GCN2. Genes Dev 17: 859-872

Cid A, Perona R, Serrano R (1987) Replacement of the promoter of the yeast plasma membrane ATPase gene by a galactose-dependent promoter and its physiological consequences. Curr Genet. 12:105-110

Cohen P (1989) The structure and regulation of protein phosphatases. Annu Rev Biochem 58: 453-508

Cook M, Tyers M (2007) Size control goes global. Curr Opin Biotechnol 18: 341-350

Cybulski N, Hall MN (2009) TOR complex 2: a signaling pathway of its own. Trends Biochem Sci 34: 620-627

De Virgilio C, Loewith R (2006a) Signalling networks in focus: The TOR signalling network from yeast to man. Int J Biochem Cell Biol 38: 1476-1481

De Virgilio C, Loewith R (2006b) Cell growth control: little eukaryotes make big contributions. Oncogene 25: 6392-6415

Dechant R, Saad S, Ibáñez AJ, Peter M (2014) Cytosolic pH regulates cell growth through distinct GTPases, Arf1 and Gtr1, to promote Ras/PKA and TORC1 activity. Mol Cell 55: 409-421

Di Como CJ, Arndt KT (1996) Nutrients, via the Tor proteins, stimulate the association of Tap42 with type 2A phosphatases. Genes Dev 10: $1904-1916$

Dos Passos JB, Vanhalewyn M, Brandão RL, Castro IM, Nicoli JR, Thevelein JM (1992) Glucose-induced activation of plasma membrane $\mathrm{H}(+)$-ATPase in mutants of the yeast Saccharomyces cerevisiae affected in cAMP metabolism, cAMP-dependent protein phosphorylation and the initiation of glycolysis. Biochim Biophys Acta 1136: 57-67

Egloff MP, Cohen PTW, Reinemer P, Barford D (1995) Crystal structure of the catalytic subunit of human protein phosphatase 1 and its complex with tungstate. J Mol Biol 254: 942-59 
Egloff MP, Johnson DF, Moorhead G, Cohen PT, Cohen P, Barford D (1997) Structural basis for the recognition of regulatory subunits by the catalytic subunit of protein phosphatase 1. EMBO J 16: 1876-1887

Elledge SJ, Davis RW (1988) A family of versatile centromeric vectors designed for use in the sectoring-shuffle mutagenesis assay in Saccharomyces cerevisiae. Gene 70: 303-312.

Eraso P, Gancedo C (1987) Activation of yeast plasma membrane ATPase by acid pH during growth. FEBS Lett 224: 187-192

Eraso P, Cid A, Serrano R (1987) Tight control of the amount of yeast plasma membrane ATPase during changes in growth conditions and gene dosage. FEBS Lett 224: 193-197

Eraso P, Portillo F (1994) Molecular mechanism of regulation of yeast plasma membrane $\mathrm{H}^{+}$-ATPase by glucose. Interaction between domains and identification of new regulatory sites. J Biol Chem 269: 10393-10-399

Eraso P, Mazón MJ, Portillo F (2006) Yeast protein kinase Ptk2 localizes at the plasma membrane and phosphorylates in vitro the C-terminal peptide of the $\mathrm{H}^{+}$-ATPase. Biochim Biophys Acta 1758: 164-170

Estrada E, Agostinis P, Vandenheede JR, Goris J, Merlevede W, Francois J, Goffeau A, Ghislain M (1996) Phosphorylation of yeast plasma mebrane $\mathrm{H}^{+}$-ATPase by casein kinase I. J Biol Chem 271: 32064-32072

Feng Z, Wilsonll SE, Pengs Z, Schlender KK, Reimann EM, Trumbly RJ (1991) The Yeast GLC7 gene required for glycogen accumulation encodes a type 1 protein phosphatase. 214: 23796-23801

Galdieri L, Mehrotra S, Yu S, Vancura A (2010) Transcriptional regulation in yeast during diauxic shift and stationary phase. J Integ Bio 14: 629-638

Gancedo JM, Gancedo C (1973) Concentrations of intermediary metabolites in yeast. Biochimie 55: 205-211

Gancedo C, Serrano R (1988) Energy yielding metabolism. In: The Yeasts: Metabolism and Physiology of Yeasts, Rose AH and Harrison JS (eds), Academic Press, London, pp 205-259

Garcia-Gimeno MA, Munoz I, Arino J, Sanz P (2003) Molecular characterization of Ypil, a novel Saccharomyces cerevisiae type 1 protein phosphatase inhibitor. J Biol Chem 278: 47744-47752 
Gasch AP, Werner-Washburne M (2002) The genomics of yeast responses to environmental stress and starvation. Funct Integr Genomics 2: 181-192

Gietz RD (2014) Yeast transformation by the LiAc/SS carrier DNA/PEG method. Methods Mol Biol 1205: 1-12

Goossens A, de la Fuente N, Forment J, Serrano R, Portillo F (2000) Regulation of yeast $\mathrm{H}^{+}$-ATPase by a family of protein kinases belonging to a family dedicated to activation of plasma membrane transporters. Mol Cell Biol 20: 7654-7661

Grassl J, Westbrook JA, Robinson A, Borén M, Dunn MJ, Clyne RK (2009) Preserving the yeast proteome from sample degradation. Proteomics 9: 4616-4626

Green NM (1992) Evolutionary relationships within the family of P-type cation pumps. Ann N Y Acad Sci 671: 104-112

Guarente L, Yocum RR, Gifford P (1982) A Gal10-CYC1 hybrid yeast promoter identifies the GAL4 regulatory region as an upstream site. Proc Natl Acad Sci USA 79: 7410-7414

Hanks SK, Hunter T (1995) The eukaryotic protein kinase superfamily: kinase (catalytic) domain structure and classification. FASEB J 9: 576-596

Haystead TA, Sim AT, Carling D, Honnor RC, Tsukitani Y, Cohen P, Hardie DG (1989) Effects of the tumour promoter okadaic acid on intracellular protein phosphorylation and metabolism. Nature 337: 78-81

Helliwell SB, Wagner P, Kunz J, Deuter-Reinhard M, Henriquez R, Hall MN (1994) TOR1and TOR2 are structurally and functionally similar but not identical phosphatidylinositol kinase homologues in yeast. Mol Biol Cell 5: 105-118

Helliwell SB, Howald I, Barbet N, Hall MN (1998) TOR2 is part of two related signaling pathways coordinating cell growth in Saccharomyces cerevisiae. Genetics 148: 99-112

Hill JE, Myers AM, Koerner TJ, Tzagoloff A (1986) Yeast/E. coli shuttle vectors with multiple unique restriction sites. Yeast 2: 163-167

Hinnebusch AG (2005) Translational regulation of GCN4 and the general amino acid control of yeast. Annu Rev Microbiol 59: 407-450

Holyoak CD, Stratford M, McMullin Z, Cole MB, Crimmins K, Brown AJP, Coote PJ (1996) Activity of the plasma Membrane $\mathrm{H}^{+}$-ATPase and optimal glycolytic flux are required for rapid adaptation and growth of Saccharomyces cerevisiae in the presence of the weak-acid preservative sorbic acid. Appl Environ Microbiol 62: $3158-3164$ 
Huber A, Bodenmiller B, Uotila A, Stahl M, Wanka S, Gerrits B, Aebersold R, Loewith $\mathrm{R}$ (2009) Characterization of the rapamycin-sensitive phosphoproteome reveals that Sch9 is a central coordinator of protein synthesis. Genes Dev 23: 19291943

Hunter T, Plowman GD (1997) The protein kinases of budding yeast: six scores and more. Trends Biochem Sci 22: 14-22

Hueso G, Aparicio-Sanchis R, Montesinos C, Lorenz S, Murguía JR, Serrano R (2012) A novel role for protein kinase $\mathrm{Gcn} 2$ in yeast tolerance to intracellular acid stress. Biochem J 441: 255-264

Inoue H, Nojima H, Okayama H (1990) High efficiency transformation of Escherichia coli with plasmids. Gene 96: 23-28

Jencks WP (1989) How does a calcium pump pump calcium?. J Biol Chem 264: 1888518858

Johnson LN, O’Reilly M (1996) Control by phosphorylation. Curr Opin Struct Biol 6: $762-69$

Johnson A, Skotheim JM (2013) Start and the restriction point. Curr Opin Cell Biol 25: 717-723.

Kaeberlein M, Kennedy BK (2011) Hot topics in aging research: protein translation and TOR signaling. Aging Cell 10: 185-190

Kamada Y, Yoshino K, Kondo C, Kawamata T, Oshiro N, Yonezawa K, Ohsumi Y (2010) Tor directly controls the Atg1 kinase complex to regulate autophagy. Mol Cell Biol 30: 1049-1058

Keith CT, Schreiber SL (1995) PIK-related kinases: DNA repair, recombination, and cell cycle checkpoints. Science 270: 50-51

Kühlbrandt W (2004) Biology, structure and mechanism of P-type ATPases. Nat Rev Mol Cell Biol 5: 282-295

Kunz J, Henriquez R, Schneider U, Deuter-Reinhard M, Movva NR, Hall MN (1993) Target of rapamycin in yeast, TOR2, is an essential phosphatidylinositol kinase homolog required for G1 progression. Cell 73: 585-596

Lecchi S, Nelson CJ, Allen KE, Swaney DL, Thompson KL, Coon JJ, Sussman MR, Slayman CW (2007) Tandem phosphorylation of Ser-911 and Thr-912 at the C terminus of yeast plasma membrane $\mathrm{H}^{+}$-ATPase leads to glucose-dependent activation. J Biol Chem 282: 35471-35481 
Li J, Liu J, Wang X, Zhao L, Chen Q, Zhao W (2009) A waterbath method for preparation of RNA from Saccharomyces cerevisiae. Anal. Biochem. 384: 189190

Loewith R (2010) TORC1 signaling in budding yeast. In: The Enzymes, Hall MN and Tamanoi F (eds), Academic Press/Elsevier, New York, pp 147- 176

Loewith R, Hall MN (2011) Target of rapamycin (TOR) in nutrient signaling and growth control. Genetics 189: 1177-1201

Luan S (2003) Protein phosphatases in plants. Annu Rev Plant Biol 54: 63-92

Luke MM, Della Seta F, Di Como CJ, Sugimoto H, Kobayashi R, Arndt KT (1996) The SAP, a new family of proteins, associate and function positively with the SIT4 phosphatase. Mol Cell Biol 16: 2744-2755

Lutsenko S, Kaplan JH (1995) Organization of P-type ATPases: significance of structural diversity. Biochem 34: 15607-15613

Madeo F, Eisenberg T, Buttner S, Ruckenstuhl C, Kroemer G (2010) Spermidine: a novel autophagy inducer and longevity elixir. Autophagy 6: 160-162

Maloney PC, Wilson TH (1985) The evolution of ion pumps. BioScience 35: 43-48

Mazón MJ, Behrens MM, Portillo F, Piñón R (1989) cAMP- and RAS-independent nutritional regulation of $\mathrm{H}^{+}$-ATPase activity in Saccharomyces cerevisiae. J Gen Microbiol 135: 1453-1460

Mazón MJ, Eraso P, Portillo F (2015) Specific phopho-antibodies reveal two phosphorylation sites in yeast Pmal in response to glucose. FEMS Yeast Res, in press

Menacho-Marquez M, Perez-Valle J, Ariño J, Gadea J, Murguía JR (2007) Gcn2p regulates a G1/S cell cycle checkpoint in response to DNA damage. Cell Cycle 6: $2302-2305$

Muench SP, Trinick J, Harrison MA (2011) Structural divergence of rotary ATPases. Quat Rev Biophys 44: 311-356

Mulet JM, Leube MP, Kron SJ, Rios G, Fink GR, Serrano R (1999) A novel mechanism of ion homeostasis and salt tolerance in yeast: the Hal4 and Hal5 protein kinases modulate the Trk1-Trk2 potassium transporter. Mol Cell Biol 19: 3328-37

Mulet JM, Martin DE, Loewith R, Hall MN (2006) Mutual antagonism of target of rapamycin and calcineurin signaling. J Biol Chem 281: 33000-33007

Mumby MC, Walter G (1993) Protein serine/threonine phosphatases: structure, regulation, and functions in cell growth. Physiol Rev 73: 673-699 
Nuccitelli R, Deamer DW, eds. (1982) Intracellular pH: its measurement, regulation and utilization in cellular functions. Alan R. Liss, New York

Pawson T (1995) Protein modules and signalling networks. Nature 373: 573-80

Pedersen BP, Buch-Pedersen MJ, Morth JP, Palmgren MG, Nissen P (2007) Crystal structure of the plasma membrane proton pump. Nature 450: 1111-1115

Perlin DS, Brown CL, Haber JE (1988) Membrane potential defect in hygromycin Bresistant pmal mutants of Saccharomyces cerevisiae. J Biol Chem 263: 1811818122

Permyakov S, Suzina N, Valiakhmetov A (2012) Activation of H+-ATPase of the plasma membrane of Saccharomyces cerevisiae by glucose: the role of sphingolipid and lateral enzyme mobility. PLoS One 7, e30966

Plowman GD, Sudarsanam S, Bingham J, Whyte D, Hunter T (1999) The protein kinases of Caenorhabditis elegans: a model for signal transduction in multicellular organisms. Proc Natl Acad Sci USA 96: 13603-13610

Portillo F (2000) Regulation of plasma membrane H+-ATPase in fungi and plants. Biochim Biophys Acta 1469: 31-42

Portillo F, Serrano R (1989) Growth control strength and active sites of yeast plasma membrane ATPase studies by site-directed mutagenesis. Eur J Biochem 186: $501-507$

Portillo F, de Larrinoa IF, Serrano R (1989) Deletion analysis of yeast plasma membrane $\mathrm{H}^{+}$-ATPase and identification of a regulatory domain at the carboxyl terminus. FEBS Lett 247: 381-385

Portillo F, Eraso P, Serrano R (1991) Analysis of the regulatory domain of yeast plasma membrane $\mathrm{H}^{+}$-ATPase by directed mutagenesis and intragenic suppression. FEBS Lett 287: 71-74

Powers T (2007) TOR signaling and S6 kinase 1: yeast catches up. Cell Metab 6: 1-2

Powers T, Aranova S, Niles B (2010) TORC2 and spingolipid biosynthesis and signaling: lessons from budding yeast. In: The Enzymes: Structure, Function and Regulation of TOR Complexes from Yeast to Mammals, Hall MN and Tamanoi F (eds), Academic Press, San Diego, pp 177-197

Rohde JR1, Campbell S, Zurita-Martinez SA, Cutler NS, Ashe M, Cardenas ME (2004) TOR controls transcriptional and translational programs via Sap-Sit4 protein phosphatase signaling effectors. Mol Cell Biol 24:8332-8341 
Rodriguez-Hernandez CJ, Guinovart JJ, Murguia JR (2012) Anti-diabetic and antiobesity agent sodium tungstate enhances GCN pathway activation through Glc7p inhibition. FEBS Lett. 586: 270-276

Rothman-Denes LB, Cabib E (1971) Glucose 6-phosphate dependent and independent forms of yeast glycogen synthetase. Their properties and interconversions. Biochem 10: 1236-1242

Sambrook J, Russell DW (2001) Molecular Cloning. A Laboratory Manual, vol. 1-3, Cold Spring Harbor Laboratory Press, Cold Spring Harbor, New York

Santangelo GM (2006) Glucose signaling in Saccharomyces cerevisiae. Microbiol Mol Biol Rev 70: 253-282

Santiago J, Dupeux F, Betz K, Antoni R, Gonzalez-Guzman M, Rodriguez L, Márquez JA, Rodriguez PL (2012) Structural insights into PYR/PYL/RCAR ABA receptors and PP2Cs. Plant Sci 182: 3-11

Schlesser A, Ulaszewski S, Ghislain M, Goffeau A (1988) A second transport ATPase gene in Saccharomyces cerevisiae. J Biol Chem 263: 19480-19487

Spartz AK, Ren H, Park MY, Grandt KN, Lee SH, Murphy AS, Sussman MR, Overvoorde PJ, Gray WM (2014) SAUR inhibition of PP2C-D phosphatases activates plasma membrane $\mathrm{H}^{+}$-ATPases to promote cell expansion in Arabidopsis. Plant Cell 26: 2129-2142

Schmidt A, Kunz J, Hall MN (1996) TOR2 is required for organization of the actin cytoskeleton in yeast. Proc Natl Acad Sci USA 93: 13780-13785

Serrano R (1980) Effect of ATPase inhibitors on the proton pump of respiratorydeficient yeast. Eur J Biochem 105: 419-424

Serrano R (1983) In vivo glucose activation of the yeast plasma membrane ATPase. FEBS Lett 156: 11-14

Serrano R (1985) Plasma membrane ATPase of plants and fungi. CRC Press, Boca Raton, Florida, USA

Serrano R, Kielland-Brandt M, Fink GR (1986) The yeast plasma membrane ATPase is essential for growth and has homology with $(\mathrm{Na}, \mathrm{K}),(\mathrm{K})$ and $(\mathrm{Ca})$ ATPases. Nature 319: 689-693

Serrano R (1988) $\mathrm{H}^{+}$-ATPase from plasma membranes of Saccharomyces cerevisiae and Avena sativa roots: purification and reconstitution. Methods Enzymol 157: $533-544$ 
Serrano R, Portillo F (1990) Catalytic and regulatory sites of yeast plasma membrane $\mathrm{H}^{+}$-ATPase studied by directed mutagenesis. Biochim Biophys Acta 1018: 19599

Serrano R (1991) Transport across yeast vacuolar and plasma membranes. In: The Molecular and Cellular Biology of The Yeast Saccharomyces: Genome Dynamics, Protein Synthesis and Energetics, Broach JR, Pringle JR, Jones EW (eds), Cold Spring Harbor Laboratory Press, New York, pp 523-585

Shamji AF, Kuruvilla FG, Schreiber SL (2000) Partitioning the transcriptional program induced by rapamycin among the effectors of the Tor proteins. Curr Biol 10: $1574-1581$

Shenolikar S (1994) Protein serine/threonine phosphatases-New avenues for cell regulation. Annu Rev Cell Biol 10: 55-86

Sherman F (1991) Getting started with yeast. Methods Enzymol 194: 3-21

Silberman SR, Speth M, Nemani R, Ganapathi, MK, Dombradi V, Paris H, Lee EY (1984) Isolation and characterization of rabbit skeletal muscle protein phosphatases C-I and C-II. J Biol Chem 259: 2913-2922

Smith DB, Johnson KS (1988) Single-step purification of polypeptides expressed in Escherichia coli as fusions with glutathione S-transferase. Gene 67: 31-40

Spartz AK, Ren H, Park MY, Grandt KN, Lee SH, Murphy AS, Sussman MR, Overvoorde PJ, Gray WM (2014) SAUR Inhibition of PP2C-D phosphatases activates plasma membrane $\mathrm{H}^{+}$-ATPases to promote cell expansion in Arabidopsis. Plant Cell 26: 2129-2142

Stark MJR (1996) Yeast protein serine/threonine phosphatases: multiple roles and diverse regulation. Yeast 12: 1647-1675

Stark MJR (2004) Protein phosphorylation and dephosphorylation. In: The Metabolism and Molecular Physiology of Saccharomyces cerevisiae, Dickinson JR and Schweizer (eds), CRC Press, Boca Raton, Florida, USA, pp 284-375

Stuart JS, Frederick DL, Varner CM, Tatchell K (1994) The mutant type 1 protein phosphatase encoded by glc7-1 from Saccharomyces cerevisiae fails to interact productively with the GAC1-encoded regulatory subunit. Mol Cell Biol 14: 896905

Sturgill TW, Cohen A, Diefenbacher M, Trautwein M, Martin DE, Hall MN (2008) TOR1 and TOR2 have distinct locations in live cells. Eukaryot Cell 7: 18191830 
Sutton A, Immanuel D, Arndt KT (1991) The SIT4 protein phosphatase functions in late G1 for progression into S phase. Mol Cell Biol 11: 2133-2148

Swingle M, Ni L, Honkanen RE (2007) Small Molecule Inhibitors of Ser/thr Protein Phosphatases: Specificity, Use and Common Forms of Abuse Methods. Mol Biol 365: 23-38

Urban J, Soulard A, Huber A, Lippman S, Mukhopadhyay D, Deloche O, Wanke V, Anrather D, Ammerer G, Riezman H, Broach JR, De Virgilio C, Hall MN, Loewith R (2007) Sch9 is a major target of TORC1 in Saccharomyces cerevisiae. Mol Cell 26: 663-674

Vallejo CG, Serrano R (1989) Physiology of mutants with reduced expression of plasma membrane $\mathrm{H}^{+}$-ATPase. Yeast 5: 307-319

Vellai T, Takacs-Vellai K, Zhang Y, Kovacs AL, Orosz L, Müller F (2003) Genetics: influence of TOR kinase on life span in C. elegans. Nature 426: 620-621

Venema K, Palmgren MG (1995) Metabolic modulation of transport coupling ratio in yeast plasma membrane $\mathrm{H}^{+}$-ATPase. J Biol Chem 270: 19659-19667

Viegas CA, Sebastião PB, Nunes AG, Sá-Correia I (1995) Activation of plasma membrane $\mathrm{H}(+)$-ATPase and expression of PMA1 and PMA2 genes in Saccharomyces cerevisiae cells grown at supraoptimal temperatures. Appl Environ Microbiol 61:1904-1909

Von der Haar T (2007) Optimized protein extraction for quantitative proteomics of yeasts. PLoS One 2: e1078

Wang H, Wang X, Jiang Y (2003) Interaction with Tap42 is required for the essential function of Sit4 and type 2A phosphatases. Mol Biol Cell 14: 4342-4351

Ward AC, Castelli LA, Macreadie IG, Azad AA (1994) Vectors for $\mathrm{Cu}^{2+}$-inducible production of gluthathione S-transferase-fusion proteins for single step purification in yeast. Yeast 10: 441-449

Wek RC, Cannon JF, Dever TE, Hinnebusch AG (1992) Truncated protein phosphatase GLC7 restores translational activation of GCN4 expression in yeast mutants defective for the eIF-2 alpha kinase GCN2. Mol Cell Biol 12: 57005710

Williams-Hart T, Wu X, Tatchell K (2002) Protein phosphatase type 1 regulates ion homeostasis in Saccharomyces cerevisiae. Genetics160: 1423-1437

Winston F, Chumley F, Fink GR (1983) Eviction and transplacement of mutant genes in yeast. Methods Enzymol 101: 211-228 
Wright APH, Brons M, Hartley BS (1989) Extraction and rapid inactivation of proteins from Saccharomyces cerevisiae by trichloroacetic acid precipitation. Yeast 5: $51-53$

$\mathrm{Wu}$ X, Tatchell K (2001) Mutations in yeast protein phosphatase type 1 that affect targeting subunit binding. Biochem 40: 7410-7420

Wullschleger S, Loewith R, Hall MN (2006) TOR signaling in growth and metabolism. Cell 124: 471-484

Yan G, Shen X, Jiang Y (2006) Rapamycin activates Tap42-associated phosphatases by abrogating their association with Tor complex 1. EMBO J 25: 3546-3555 
